University of Rhode Island

DigitalCommons@URI

Open Access Dissertations

2017

\title{
Investigation of Health Risk Patterns Across Sexual and Gender Minority Identities
}

Loren Andrew Bauerband

University of Rhode Island, lorenbauerband@gmail.com

Follow this and additional works at: https://digitalcommons.uri.edu/oa_diss

\section{Recommended Citation}

Bauerband, Loren Andrew, "Investigation of Health Risk Patterns Across Sexual and Gender Minority Identities" (2017). Open Access Dissertations. Paper 600.

https://digitalcommons.uri.edu/oa_diss/600

This Dissertation is brought to you for free and open access by DigitalCommons@URI. It has been accepted for inclusion in Open Access Dissertations by an authorized administrator of DigitalCommons@URI. For more information, please contact digitalcommons-group@uri.edu. 
INVESTIGATION OF HEALTH RISK PATTERNS ACROSS

SEXUAL AND GENDER MINORITY IDENTITIES

BY

LOREN ANDREW BAUERBAND

A DISSERTATION SUBMITTED IN PARTIAL FULFILLMENT OF THE

REQUIREMENTS FOR THE DEGREE OF

DOCTOR OF PHILOSOPHY

IN

PSYCHOLOGY

UNIVERSITY OF RHODE ISLAND

2017 
DOCTOR OF PHILOSOPHY DISSERTATION

OF

LOREN ANDREW BAUERBAND

APPROVED:

Dissertation Committee:

Major Professor Wayne Velicer

Joseph Rossi

Colleen Redding

Bryan Blissmer

Nasser H. Zawia

DEAN OF THE GRADUATE SCHOOL

UNIVERSITY OF RHODE ISLAND

2017 


\begin{abstract}
The Minority Stress Model posits gender and sexual minorities experience stigma-related stressors, that increase their risk for poor mental and physical health. Historically, these groups have been considered one "community" (lesbian, gay, bisexual, transgender, queer: LGBTQ), with similar experiences including: shared social groups and deviation from gender norms (e.g. gender roles and expression, and relationships). As research into the experiences of LGBTQ individuals increases, evidence supports people with different sexual orientations (e.g. lesbian/gay vs. bisexual) and gender experiences (e.g. cisgender vs. transgender) within the community are diverse, and should not be researched as one population. By researching each gender and sexual orientation individually, we can capture the diversity of experiences and uncover specific public health needs for each subgroup. As this perspective expands, our understanding of health needs for lesbian and gay individuals continues to develop. However, less represented LGBTQ subgroups (e.g. bisexual and transgender) remain understudied. This dissertation consisted of three manuscripts investigating minority stress and health behaviors across trans and nontrans genders among LGBTQ identified individuals.

Transgender $(N=460)$ and cisgender (nontransgender) LGBQ $(N=523)$ individuals were recruited from trans and LGBT-related social networks. All three manuscripts utilized the same data. The first manuscript examined the measurement invariance of the Everyday Discrimination Scale (EDS) and the Discrimination-Related Vigilance Scale (DRVS) across transgender and cisgender gender identities. Partial metric invariance was found across trans and cis, and across gender within trans respondents for the EDS. Full scalar invariance was found across trans and cis for the
\end{abstract}


DRVS, but partial metric invariance across gender within trans individuals. In general, transgender individuals reported more perceived discrimination and vigilance.

The second manuscript compared the rates of health behaviors across LGBTQ genders to investigate the distinct health risks for each group. After accounting for age, most differences across gender identity and trans status were small. The largest differences were found in vegetable consumption and psychological distress. Cisgender women reported more vegetable consumption than all other groups. On average, transgender men, women, and nonbinary-identified individuals reported more depression and anxiety than cisgender men and women.

The third manuscript examined subtypes of physical activity across transgender and cisgender groups with replicated cluster analyses. The same five cluster subtypes were found across 2 subsamples of transgender and 2 subsamples of cisgender respondents: (1) Overall Active, (2) Vigorous Active, (3) Moderate Active, (4) Walkers, and (5) Inactive. On average, individuals in the overall active and vigorous active subtypes rated their overall health higher than people in the other subtypes. 


\section{ACKNOWLEDGEMENTS}

I would like to acknowledge my advisor Wayne Velicer, for his commitment to my success during my graduate studies at the University of Rhode Island. His patience and gentle reality checks are the reason I was able to complete this research. I would also like to thank Robert Laforge, Diane Goldsmith, and Joe Rossi for their thoughtful advice and continuous support during my time at URI. Two previous mentors provided me with the foundation and opportunities that led me here: Paz Galupo and Ainsley Mitchum. Most notably, my parents and sisters who have remained a constant support for me, and my nieces who motivate and inspire me to continue.

I would also like to recognize the 1,087 LGBTQ individuals who gave their time to complete the survey included in this dissertation. The large number of responses testifies to the community investment in being understood, and improving health for future LGBTQ individuals. 


\section{PREFACE}

This dissertation was prepared in manuscript format. The three manuscripts contained therein have been prepared in anticipation for submission to the following journals: Psychology of Sexual Orientation and Gender Diversity (Manuscript 1), LGBT Health (Manuscript 2), and Journal of Community Health (Manuscript 3). 


\section{TABLE OF CONTENTS}

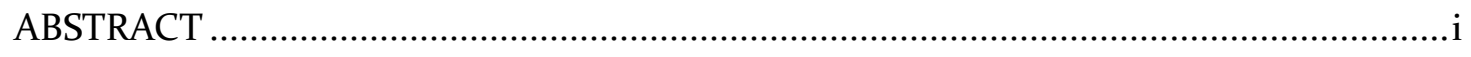

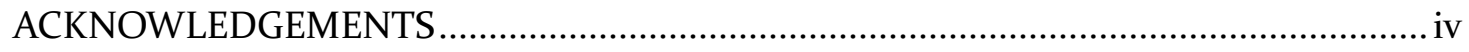

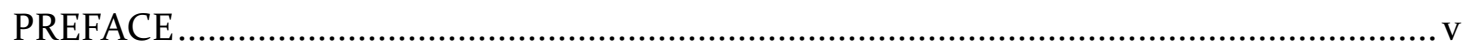

TABLE OF CONTENTS ........................................................................................... vi

LIST OF TABLES ….......................................................................................... vii

LIST OF FIGURES ............................................................................................ vii

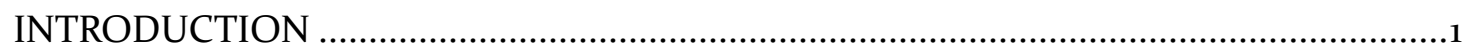

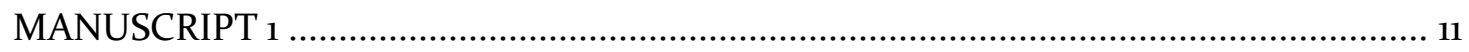

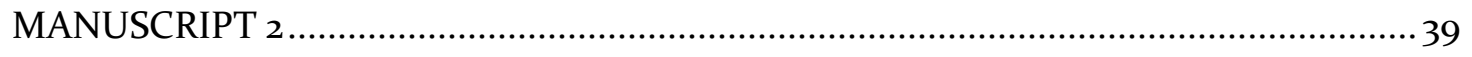

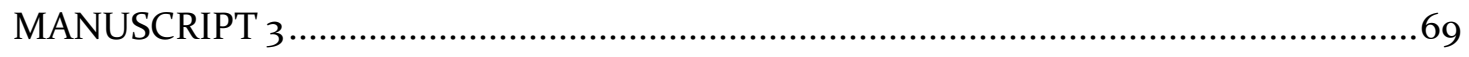

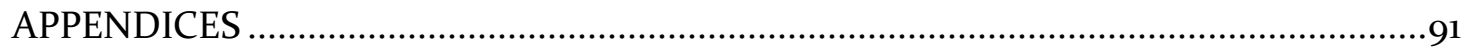

APPENDIX A: RECRUITMENT LETTER ....................................................... 92

APPENDIX B: ANONYMOUS CONSENT FORM ................................................. 93

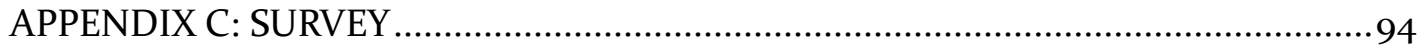

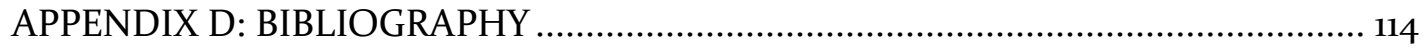




\section{LIST OF TABLES}

\section{MANUSCRIPT 1}

Table 1.1: Demographics Of Analytic Sample …....................................................... 31

Table 1.2: Fit Indices For Cfa Models Of Discrimination And Vigilance Scales ............... 32

Table 1.3: Invariance Models For Discrimination And Vigilance Scales ......................... 33

Table 1.4: Means And Standard Deviations Of The Eds And Drvs ................................. 34

\section{MANUSCRIPT 2}

Table 2.1: Sample Demographics By Trans Status And Gender ....................................61

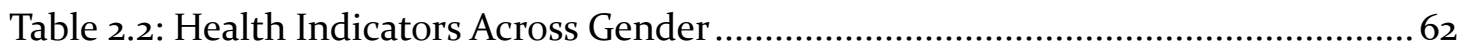

Table 2.3: Standard Score Means And Effect Sizes For Health Indicators ....................... 63

\section{MANUSCRIPT 3}

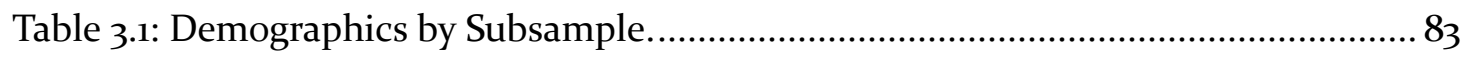

Table 3.2: Standard Score Means And Standard Deviations For The Five Clusters..........84

Table 3.3: Health Validity Analyses For Clusters. ..................................................... 85

Table 3.4: Cluster Membership Proportions For Ascribed Gender Groups ......................86 


\section{LIST OF FIGURES}

\section{MANUSCRIPT 1}

Figure 1.1: Everyday Discrimination CFA For Transgender ….................................... 35

Figure 1.2: Everyday Discrimination CFA For Cisgender Lgbq.................................. 36

Figure 1.3: Discrimination-Related Vigilance CFA For Transgender.............................. 37

Figure 1.4: Discrimimination-Related Vigilance CFA For Cisgender LGBQ .................... 38

\section{MANUSCRIPT 2}

Figure 2.1: Low Impact Activity By Gender For Trans And LGBQ ................................64

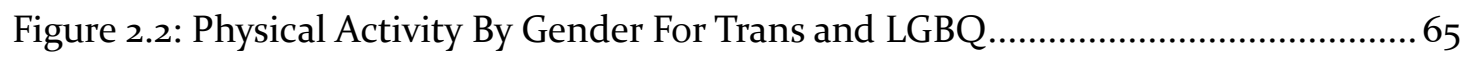

Figure 2.3: Vegetable Consumption By Gender For Trans And LGBQ...........................66

Figure 2.4: Depression, Anxiety, And Stress For Gender Groups..................................6 67

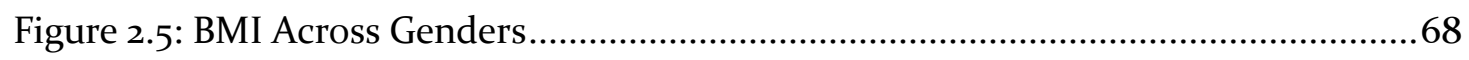

\section{MANUSCRIPT3}

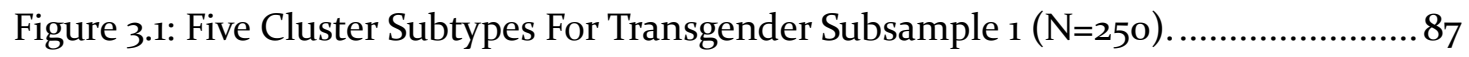

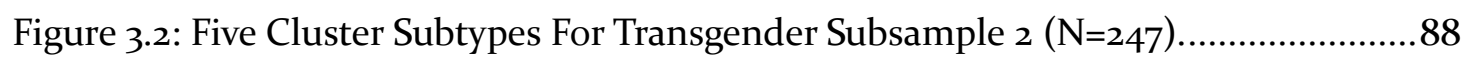

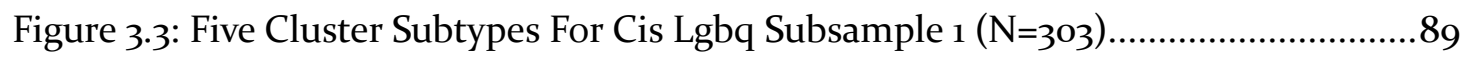

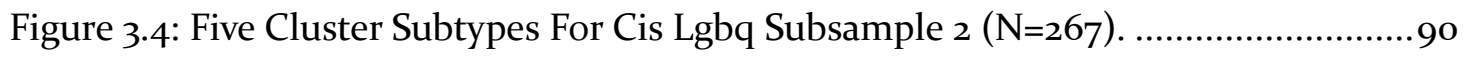




\section{INTRODUCTION}

For more than a decade, gender and sexual minority (GSM) researchers have utilized the Minority Stress Model (Meyer, 2003) to investigate the relationship between GSM-related stress and mental health outcomes. The evidence supporting the relationship between distal stressors (i.e. experiences of discrimination, victimization, and violence) and proximal stressors (i.e. vigilance, internalized negativity, and identity concealment) with depression, anxiety, and substance use are extensive for both sexual minorities and gender minorities. GSM researchers have utilized a variety of self-report measures to capture minority stressors, both developed by community researchers and translated from research with different minority statuses (e.g. racial minorities).

The conceptualization of the Minority Stress Model was specifically for lesbian, gay, and bisexual (LGB) individuals. Historically, transgender persons have been considered part of this community (LGBT: IOM, 2011), and share common experiences with LGB persons, including minority stress. Therefore, the Minority Stress Model was theoretically appropriate to apply to the understanding of transgender mental health. Transgender individuals experience unique minority stressors not experienced by sexual minorities (e.g. Testa, Habarth, Peta, Balsam \& Bockting, 2015), including identity nonaffirmation and nondisclosure (as opposed to concealment). Additionally, although LGBT individuals are often grouped into one community, the subgroups within this community encounter different levels and types of discrimination (e.g. Bostwick \& Hequembourg, 2014; James, Herman, Rankin, Keisling, Mottet \& Anafi, 2016) and identity-related experiences (Fassinger \& Arseneau, 2007). Best practices among LGBT researchers is to recognize the distinct subgroups within the “community" and investigate transgender and LGB individuals separately. 
Since the Institute of Medicine Report (2011), research into the health of LGBT individuals has expanded at a rapid rate. The addition of sexual orientation questions on national surveys, and improved NIH funding on non-HIV-related LGBT research significantly contributed to this progress. Moreover, researchers are more accurately representing their studies to specifically target subgroups of the LGBT population (e.g. LGB, bisexual, sexual minority women, transgender). These changes have both improved methodology employed by LGBT researchers and extended our understanding of the unique health concerns across LGBT individuals. Although transgender persons are no longer being misrepresented in LGBT research, transgender health research is not growing at the same rate as LGB research.

\section{Transgender Research}

Transgender persons are at increased risk for depression, anxiety, and consistently report high rates of suicidality ( $41 \%$ of transgender individuals have attempted suicide: Grant, Mottet, Tanis, Herman, Harrison \& Keisling, 2010; James, Herman, Rankin, Keisling, Mottet \& Anafi, 2016) compared to both the overall population and other LGB individuals. They face significant barriers to healthcare services, including being turned away simply for being transgender, or settling for physicians who are unsure of how to treat them. However, there is currently no population-level data on rates of health issues or health behaviors. Estimated rates of health concerns are based on known LGB rates or nonprobability samples. For example, current smoking rates among LGB individuals is 1 in 5 (CDC), but a comparison of a nonprobability internet sample found a similar rate for LGB (19\%) and slightly higher rate (23-25\%) among transgender individuals (Smalley, Warren \& Barefoot, 2016), but this was assessed with a single item question on frequency of 
smoking (rates were the proportion of people indicating a frequency of "most of the time" or "all the time"). Smoking rates may be higher among transgender individuals, but there is currently no way to assess this at the population level.

Much of transgender research relies on assumptions that transgender experience is similar to LGB experience and the pathways to health outcomes are similar. In many cases, we find the same mechanisms of resiliency or positive outcomes in this population such as social support (Budge, Adelson \& Howard, 2013), identity pride (Bockting, Miner, Swinburne Romine, Hamilton \& Coleman, 2013) and community (Riggle, Rostosky, McCants \& Pascale-Hague, 2011). However, dissimilar experiences are less understood, and tend to be mentioned, but not researched. For example, identity concealment (actively hiding or avoiding the discussion of one's sexual orientation or gender identity) is a significantly different concept for a transgender person. Specifically, sharing one's identity means different things given the "stage" in coming out a transgender person is currently in and whether their gender identity is binary (male or female) or nonbinary (does not identify with binary genders). In general, a transgender person must share their gender identity when undergoing a "transition" in which they will be identifying with a gender different from the gender the current people in the person's life know. This identity disclosure is necessary for a transgender person to live authentically as the gender they identify with. However, once a transgender person has socially transitioned to their current gender identity, there may be no reason to continue disclosing one's transgender status. In fact, for some transgender people, once they have transitioned, they do not identify with their transgender status, and disclosing would be comparable to sharing a medical condition (not an identity). Although identity concealment is considered a 
proximal stressor for LGB individuals (e.g. Meyer, 2003), identity nondisclosure can be both a stressor or a protective factor depending on the transgender individual. More research needs to investigate the complexity of this issue to understand how it relates to gender minority stress.

\section{Measuring Gender Minority Stress}

A person's perspective on their identity plays a significant role in their experiences of minority stress. The extent to which an identity is salient, and relevant to a person's self-concept drastically affects how they experience identity-related discrimination (e.g. Bauerband \& Galupo, 2014; Galupo \& Bauerband, 2016). However, the complexity of a transgender person's identity is rarely considered when designing measures of minority stress, especially when they are translated from current measures utilized with LGB populations. When choosing the language included in identityrelated measures, researchers tend to use either "gender identity", "transgender identity/status/history", or "LGBT identity", but each of these options has different meanings and needs to be carefully examined before using in research. Scholars have known for over a decade that the relationship between transgender persons and the LGBT community is complex, and many trans individuals do not identify or consider themselves "LGBT" (e.g. Fassinger \& Arseneau 2007; Stone, 2009). Despite this, "LGBT" is still being used to design measures of positive transgender identity, community connection (Riggle \& Mohr, 2015) and inclusive minority stress measures (Outland, 2016).

When a researcher translates an identity-related measure from LGB research to transgender research by only changing sexual orientation to gender language there is an assumption that the measure is capturing the same construct, and the structure of 
the measure is the same. This is especially true when researchers do not report any preliminary factor analysis, confirmatory factor analysis, or tests of validity before utilizing the measure. However, even when confirmatory analyses are conducted, measures created for another population are limited by the conceptualization of the construct for the original population. Developing identity-related measures for LGB and transgender persons separately is the only way to determine if a construct manifests the same way for the two LGBT subgroups. In fact, Bauerband and Galupo (2014) designed a measure of identity reflection for transgender individuals and simultaneously assessed a similar measure for sexual minorities (Galupo \& Bauerband, 2016) and found different structures. Although both populations had distinctive thoughts about positive, negative, and other's perceptions of their identity, ruminative thoughts were only split into two types for sexual minorities. If these measures had not been designed exclusively within the subpopulations, the distinct factors would not have been captured, and the construct of identity reflection would be assumed to be the same across groups.

When designing or choosing measures of identity-related experience, including minority stress, researchers need to carefully consider whether the measures they have chosen take into account transgender experience, or if they are only a derivation from LGB research. At the least, the structure of measures translated to transgender research should be assessed. Even when a confirmatory factor analysis shows adequate fit, it is essential to acknowledge the measure may not be capturing a comparable or holistic perspective of the construct for transgender individuals. Additionally, unless the measure has been tested for structural invariance across groups, researchers also need to acknowledge the limitation of conducting any group comparisons using the 
measure. Currently, no measures of minority stress or identity-related experiences have been assessed for measurement invariance across LGB and transgender groups, but this has not stopped researchers from conducting group comparisons of minority stress across LGBT subgroups or identities.

Researchers investigating the experiences of transgender individuals, especially within the minority stress framework, should choose measures that match the research questions being asked. If the researcher is including LGB and T individuals in a combined study, an adequate sample should be collected to assess measurement invariance across LGB and T groups, if it has not already been established. If a researcher is specifically investigating transgender individuals, chosen measures should appropriately represent the transgender experience. Terminology around gender and identity needs to be inclusive, with caution towards using "LGBT" in a measure of community or connectedness. In that case, it may be more appropriate to use transgender or gender diverse. Finally, when designing new measures for transgender research, item development should be based on qualitative data, and follow-up focus groups should assess whether identity-language variation changes the meaning of items.

\section{Conceptualizing Transgender Experiences}

Current population data suggests sexual minorities make up approximately $3 \cdot 5^{-}$ $5 \%$ and transgender individuals are roughly $.3 \%$ (Gates, 2011; Steinmetz; 2016) of the overall population. When considered as a single LGBT population, transgender individuals are outnumbered. Even when LGBT researchers capture a representative sample of trans individuals $(5-10 \%)$ in combined research, their experiences are overshadowed since they remain a small minority within the larger sample. 
Historically, research was generalized to represent the "LGBT community" (e.g. Bilodeau \& Renn, 2005; Almeida, Johnson, Corliss, Molnar \& Azrael, 2009; Smith \& Gray, 2009). This history forces trans researchers to build their investigation into trans experience based primarily on research conducted with LGB individuals. Current trans research is primarily informed by our understanding of sexual minorities. However, this community is diverse, and differentially identifies with experiences similar to LGB individuals. Understanding trans individuals requires recognizing past scientific biases and acknowledging the diversity of the population.

There is a common narrative that transgender persons have a gender identity that is different from their gender assigned at birth, and after "coming out", they transition socially and medically to present more consistently with their actual gender identity. However, approximately one third of transgender individuals are nonbinary (James, Herman, Rankin, Keisling, Mottet \& Anafi, 2016). There is currently no literature on how nonbinary individuals experience minority stress in comparison to male and female-identified transgender individuals, but the needs and community among nonbinary individuals may be different from binary-identified individuals. Specifically, many transgender individuals connect with community members through the navigation of social, legal, and medical resources. Trans persons who do not follow the common narrative of transitioning are sometimes excluded from these community spaces. They may find different communities, or be more likely to connect with the larger LGBT community. This further divides trans experiences and networks, and suggests transgender individuals, as a community, may be just as diverse as the larger LGBT community. Transgender researchers have only touched the surface of understanding this diversity within trans communities. 


\section{Future of Transgender Research}

In October of 2016 the National Institute of Minority Mental Health announced they regarded LGBT individuals as a minority group that experienced health disparities as a result of their minority status. This announcement opened the door for more funding and gave LGBT researchers credibility to pursue the research already being conducted. The number of LGB researchers has expanded over the last few years, with the increased acceptance of sexual minorities in academia, but transgender researchers are scarce. Among those who conduct research on transgender persons, a large portion were LGB researchers first.

Research into transgender individuals is a new field, based largely on bias of shared LGBT experience, with a scarce pool of researchers. Given the significant attention of trans persons in the media and legal system, there is a dire need to increase our understanding of this population. Mental health and medical training programs are being called on to educate future practitioners, but minimal research exists to support this training. As more researchers investigate transgender experience and health, it is essential the field effectively addresses the present bias and limitations of the current literature, while simultaneously expanding our understanding of transgender persons. The current dissertation was written with this quandary in mind.

\section{Current Research}

The purpose of this dissertation was to provide the foundation for expanding our understanding of transgender individuals by suggesting alternative approaches to LGBT research. Specifically, acknowledging transgender individuals were underrepresented in LGBT research, but continuing to theorize similar experiences perpetuates the bias. Additionally, conducting parallel research within an LGB 
framework, with transgender individuals, will stifle progress in understanding trans persons. There is limited information on the physical health risks for LGBT individuals, and the LGB Minority Stress Model was recently extended to explain health behaviors (Lick, Durso \& Johnson, 2013). Therefore, the current research investigated health risk behaviors across LGBT individuals with a more trans inclusive lens. The current research consists of three manuscripts that investigate minority stress measures, health-related behavior rates, and patterns of physical activity across gender among LGBT individuals.

Data was collected via an anonymous online survey (recruitment literature, anonymous consent, and entire survey included in appendices). Respondents were recruited from online social networks, email lists, and message boards related to transgender and LGBQ support and activism. A total of 460 transgender individuals and 523 LGBQ cisgender (nontransgender) individuals from 48 U.S. States and D.C. completed the survey. All three manuscripts utilized the same data.

Manuscript 1. The purpose of the first manuscript was to assess the structural invariance of two measures of minority stress: The Everyday Discrimination Scale (EDS) and The Discrimination-Related Vigilance Scale (DRVS). These measures were selected because they were brief measures, with previous strong reliability in both LGBQ and transgender samples. Additionally, both measures did not specify one identity so the same measure could be used for all respondents so there were no challenges in selecting identity language for transgender individuals.

Although not comprehensive, the EDS captures a component of distal stress, while the DRVS captures a component of proximal stress. Together, the establishment 
of invariance across LGBT groups will provide psychometrically similar measures for conducting combined research with LGBT individuals, or comparing across identities.

Manuscript 2. The purpose of the second manuscript was to compare the health behavior rates across transgender status and gender identity for LGBT individuals. All health behaviors were assessed using validated measures for population research. The primary objective of this manuscript was to provide a brief report of health-related behaviors to identify similarities and differences in health risk across groups.

By conducting a nonprobability data collection of health behavior rates, results cannot be generalized to the entire LGBT population. However, there are currently no national data available that captures transgender identity/status, but there is for LGBQ individuals. By collecting data from both LGBQ and T persons, we are able to compare rates across two nonprobability samples that used the same recruitment methods.

Manuscript 3. The third manuscript presents cluster analyses of physical activities for transgender and cisgender (LGBQ) groups. The diversity among transgender individuals is as complex as the diversity across all subgroups within the "LGBT community", classifying people by health patterns can identify homogeneity relevant to health-risk. Uncovering underlying physical activity subtypes across all LGBT individuals can identify health risk beyond comparing health rates across identities.

If individuals who demonstrate similar high-risk patterns can be identified on factors not related to identity, there may be alternative ways to inclusively address or prevent physical inactivity, than by specifically targeting individuals LGBT subgroups. 


\section{MANUSCRIPT 1}

Measurement Invariance of Everyday Discrimination Scale and Discrimination-Related Vigilance across Transgender and Cisgender LGBQ Individuals

Intended Journal for Submission: Psychology of Sexual Orientation and Gender

Diversity 


\begin{abstract}
.
The Minority Stress Model posits that experiences of proximal and distal stress increase gender and sexual minority risk for poor mental and physical health outcomes. Psychological researchers of minority stress have utilized a variety of measures to capture these stressors, but currently no measures have been assessed for invariance across transgender and LGBQ individuals. The present study assessed the measurement invariance of the Everyday Discrimination Scale (EDS) and the Discrimination-Related Vigilance Scale (DRVS) across transgender $(n=460)$ and cisgender LGBQ $(n=523)$ individuals. The EDS demonstrated partial metric invariance across transgender and cisgender, and within gender identities of transgender individuals. While the DRVS demonstrated complete metric invariance across transgender and cisgender, and partial within gender identities among transgender respondents. In general, transgender individuals reported more discrimination and vigilance than cisgender LGBQ individuals. This research is the first to compare the structure of measures of LGBTQ-related minority stress. Uncovered noninvariance provides evidence for unique stressors for transgender women and men. Future research should assess measurement invariance of minority stress measures before comparing across LGBTQ identities.
\end{abstract}


Measurement Invariance of Everyday Discrimination Scale and Discrimination-Related Vigilance across Transgender and Cisgender LGBQ Individuals

For more than a decade, gender and sexual minority (GSM) researchers have utilized the Minority Stress Model (Meyer, 2003) to investigate the relationship between GSM-related stress and mental health outcomes. The evidence supporting the relationship between distal stressors (i.e. experiences of discrimination, victimization, and violence) and proximal stressors (i.e. vigilance, internalized negativity, and identity concealment) with depression, anxiety, and substance use are extensive for both sexual minorities and gender minorities. GSM researchers have utilized a variety of self-report measures to capture minority stressors. These measures have been modified from research conducted with other minority statuses (e.g. Everyday Discrimination Scale: Gamerel, Reisner, Laurenceau, Nemoto \& Operio, 2014), created specifically for sexual minority research (e.g. Internalized Homophobia Scale: Ross \& Rosser, 1996) or gender minority research (e.g. Gender Minority Stress and Resilience Measure: Testa, Habarth, Peta, Balsam \& Bockting, 2015).), or extended from sexual minority research to transgender research (i.e. Antitransgender Discrimination: Breslow, Brewster, Velez, Wong, Geiger \& Soderstrom, 2015). Fewer cases have designed minority stress measures for use across both populations (i.e. Daily Heterosexist Experiences Questionnaire: Balsam, Beadnell \& Molina, 2013).

Researchers seek parsimonious measures that account for as many components of distal and/or proximal stressors as possible, to aid in the conceptualization of the Minority Stress Model. Although the measure development within this field has significantly improved our understanding of the different types of minority stress, the utilization of different measures for gender minority stress and sexual minority stress 
reduces the ability to compare minority stress across groups, or conduct research including both populations. The purpose of the current research was to assess the measurement invariance of the Everyday Discrimination Scale and the DiscriminationRelated Vigilance Scale (Williams et al., 1997) across transgender and cisgender LGBQ persons.

\section{Measurement Invariance}

Self-report measures of minority stress, consist of multiple scale items that together capture latent constructs of minority stress. Generally, these measures are created from several items capturing experiences we know to be true for LGBT individuals (e.g. "I was rejected by my classmates." or "I always look to see who is around me before I hold my partners' hand.”). Researchers test these items in surveys, and establish the psychometric properties of a final scale through exploratory and confirmatory factor analyses. Once the psychometric properties have been established, future research utilizing measures tends to only report internal reliability of a scale for the represented sample. However, a scale structure may be different across groups and identities, especially among LGBT individuals who have diverse experiences of identity and social presentation.

Utilizing multiple-item self-report measures can capture a more comprehensive picture of the construct being studied. However, when comparing values and variances of a construct across groups it is essential to ensure group differences are a true result of increased rates, and not an artifact of measurement items holding different meanings across groups (Gregorich, 2006). For example, if I want to compare the relationship between identity concealment and comfort with one's own identity across transgender and nontransgender LGBQ individuals, I would need to measure both 
constructs for each group. For me to compare this relationship across groups I have to be measuring the same construct. However, one of the items on my identity concealment measure might be: "When I am dating someone, I have no problem telling my friends." If I only tested this item in an identity concealment measure with gay men, this item may not mean the same thing, in the context of identity concealment, for lesbians or transgender individuals. It is possible, sharing information about dating someone has nothing to do with identity disclosure for women, but is about level of openness with friends. Or, in the case of transgender individuals, sharing information about dating has nothing to do with disclosing one's gender identity or transgender status. However, unless the measurement structure of constructs is compared across groups, it would remain unclear whether any one (or multiple) items measuring a construct have different meanings and/or function differently across groups. Performing confirmatory factor analyses of a measure within a new group only confirms that the structure of the scale is a good fit, not whether the structure is invariant across groups.

Establishing measurement invariance across groups ensures the items in a scale are capturing the same construct across the groups. Minority Stress is an identityrelated experience, that we know may be different across identities, however, currently no measures of minority stress have been assessed for measurement invariance across LGBT subgroups.

\section{The Current Study}

The purpose of the current study was to assess the measurement invariance of two constructs of minority stress: experiences of discrimination and vigilance, across cisgender and transgender LGBQ individuals. We selected the Everyday Discrimination 
Scale (Williams et al., 1997) and the Discrimination-Related Vigilance Scale (Clark et.

al., 2006) to assess invariance because both measures are brief and do not contain specific identity language. The design of these measures is perfect for research with diverse LGBT identities, and does not place significant burden on participants.

\section{Methods}

\section{Participants}

The sample consisted of approximately 986 LGBTQ-identified individuals, 461 who identified as transgender and/or as having a gender minority experience (for succinctness this group will be referred to as "trans" for the rest of the paper) and 525 who identified as a sexual minority, but not having a gender minority experience (this group will be referred to as cisgender or "cis" for the rest of the paper). The average age was $32.6(S D=12.1)$, with no significant difference between trans and cis respondents. In general, participants were highly educated, with slightly higher degrees among cis respondents (38\% with graduate or professional degree vs. $23 \%$ among the trans responders). Sample demographics including: gender, sexual orientation, education and income are presented in Table 1.1.

\section{Procedure}

All procedures for this study were approved by the University of Rhode Island's Institution Review Board for human subjects' protections. Participants were recruited via social media and electronic mailing lists for LGBT and transgender-specific support, social and activist focused groups. Individuals interested in participating accessed the survey from an Internet link included in the recruitment information. The survey included several questions related to health, health behaviors, mental health, and stress, but only measures pertinent to this study are described. The responses were 
completely anonymous, and the only incentive was a one dollar donation to an LGBTrelated nonprofit of the participant's choosing.

\section{Measures}

Everyday Discrimination Scale (Overall $\alpha=.90$, Trans $\alpha=.90$, Cis $\alpha=.88$ ). The EDS (Williams et al., 1997) measures the frequency of experiences of mistreatment in comparison to others. Participants were asked to rate on a five-point scale ( $\mathrm{o}=\mathrm{Never}, 1$ = Once or twice, 2 = At least once a month, $3=$ Often $/$ On a weekly basis, $4=$ Everyday) how often they experienced poor treatment in comparison to others. The original 9 items from the Detroit Area Study were used, but the instructions were modified to eliminate a specific minority status: "In the past 6 months, how often did these things happen to you?" Item responses were summed, with higher scores reflecting greater mistreatment/ discrimination and possible values ranging from $0-36$.

Discrimination-Related Vigilance (Overall $\alpha=.88$, Trans $\alpha=.86$, Cis $\alpha=.86$ ). Vigilance was measured using a six-item Discrimination-Related Vigilance Scale (DRVS: designed by Williams, unpublished; and first published by Clark et. al., 2006) to measure heightened vigilance in response to experiences of racial discrimination. This six-item scale was asked as a follow-up to the EDS to assess the extent to which a person is vigilant in their surroundings because of previous mistreatment they experienced. Instructions read: "In dealing with these day-to-day experiences that you just told me about, how often do you:" Items included: (1) Think in advance about the kinds of problems you experience? (2) Try to prepare for possible insults before leaving home? (3) Feel that you always have to be very careful about your appearance to get good service or avoid being harassed? (4) Carefully watch what you say and how you say it? (5) Carefully observe what happens around you? (6) Try to avoid certain social 
situations and places? Participants rated these items on a five-point scale $(\mathrm{o}=$ Never, $\mathbf{1}=$ Hardly Ever, 2 = Not too often, 3= Fairly often, 4= Very often). Item responses were summed, with higher scores represented more vigilance and possible values ranging from $0-24$.

\section{Data Analysis}

Preliminary analyses were conducted to assess the structure of the EDS and DRVS including exploratory factor analysis (EFA), item correlations, and normality assessments. Confirmatory factor analysis (CFA) was conducted using Mplus 7.o (Muthen \& Muthen, 2012) to estimate measurement fit with the overall, transgender, and cisgender sample. Most items did not meet univariate normality (items were positively skewed), therefore CFA and subsequent invariance models were conducted using maximum likelihood estimator with robust estimation (MLR). This approach is also consistent with the invariance assessment of the EDS across race/ethnicity groups (Kim, Sellbom \& Ford, 2014).

We assessed measurement invariance at three levels in sequential order. The first, Configural Invariance, is the baseline model that is used for comparison with the stricter levels of invariance. Configural Invariance assumes the same factor structure across groups, but does not restrict any non-zero loadings. The second, Metric Invariance, sometimes called Weak Factorial Invariance, restricts the factor loadings to be equal across groups. Third, Scalar, or Strong Factorial Invariance, constrains both factor loadings and error variances to be equal across groups (Meredith, 1993).

Overall model fit for CFA and Invariance levels was evaluated using the Comparative Fit Index (CFI), the Root-Mean Square Error Approximation (RMSEA) and its 90\% Confidence Interval. CFI values fall between o and 1, with larger values 
indicating a better fit. Values greater than .90 indicate good fit and values greater than .95 indicate very good fit (Hu \& Bentler, 1999; Kline, 2011). For RMSEA, smaller values indicate better fit: values less than 0.10 indicate good fit and values less than 0.05 indicate very good fit (Browne \& Cudeck, 1993; Kline, 2011). Last, we used two methods to assess invariance between levels, the difference in CFI ( $\Delta$ CFI) between levels of invariance and the $\chi^{2}$ difference test. A $\Delta$ CFI of 0.01 or less indicates a null hypothesis model of invariance should not be rejected and that there is invariance between subgroups (Cheung \& Rensvold, 2002; Kline, 2011). Because we used MLR estimation, a typical $\chi^{2}$ difference test between invariance levels was not appropriate, so we followed the $-2 L L$ rescaled difference guidelines recommended by Satorra and Bentler (2011), where a significant difference indicates the stricter fitting model is significantly worse than the less strict model. Additionally, we used recommended modification indices from Mplus to further assess the structural fit of the models at each invariance level.

\section{Results}

\section{Everyday Discrimination Scale}

Using the entire sample, we conducted a CFA with all 9 items loading on one factor, but found poor fit: CFI $=.87$, RMSEA $=.14(.13, .16)$. Modification indices suggested a correlation between items 1 and 2 would increase fit, which resulted in significant improvement: $\mathrm{CFI}=.94$ and RMSEA $.10(.09, .11)$. Although this model fit was improved, modification indices suggested correlating items 8 and 9, which also resulted in substantial improvement: $\mathrm{CFI}=.98$ and RMSEA .06(.05, .08). The resulting model was consistent with the structure suggested by Kim, Sellbom and Ford (2014), so we selected this model as our final model for testing invariance. Follow-up CFAs with 
the transgender and cisgender subsamples demonstrated similar fit CFIs $=.98$ and RMSEA .06-.07 (see Table 1.1 for all fit indices).

Invariance. First, we assessed invariance between transgender and cisgender groups. Model fit at the Configural level was acceptable CFI $=.97, \mathrm{RMSEA}=.07$ (.o6, .o8). Model fit at the Metric level was acceptable, but the -2LL rescaled difference test was significant $35.82(8), p<.001$, and modification indices suggested freeing the item 5 loading between transgender and cisgender groups. After freeing item 5 the -2LL rescaled difference test between the Configural level and the Partial Metric level was not significant, $13.95(7)=.052$. We continued with a Partial Scalar level, keeping the item 5 loadings and intercepts free between groups. The Partial Scalar level demonstrated acceptable fit, however -2LL rescaled difference test was significant at the .05 level. There were no modification indices suggested, so we accepted this Partial Scalar invariance between transgender and cisgender groups.

Gender within Transgender Respondents. Respondents had the option of selecting one or more gender identity (man, woman, and nonbinary). Everyone who selected nonbinary, or a combination of nonbinary and man and woman were included in the nonbinary group. The 8 respondents who selected man and woman only were not included in these analyses. The partially overlapping groups for invariance testing were: man (123), woman (100), and nonbinary (237).

The Configural level demonstrated adequate fit, but fit was significantly worse at the Metric level. Modification indices suggested freeing item 5 factor loading for transwomen, which improved fit, and reduced $\Delta C F I$ to within the recommended range (.oog), but still yielded a significant result for the -2LL rescaled difference test. No additional modification indices were suggested so we moved to Partial Scalar 
invariance with item 5 factor loading and intercept free for transwomen. There were no significant differences in the final model, so we accepted Partial Scalar Invariance across gender identities within the transgender group.

Gender within Cisgender Respondents. There were not enough cisgender individuals who identified as nonbinary to include them in their own group, so we limited the invariance analysis to only men and women. Configural and Metric levels yielded acceptable fit with no significant difference. At the Scalar level there was a decrease of .o11 of CFI and a significant -2LL rescaled difference test. Modification indices suggested freeing the intercept for item 9. With the intercept of item 9 freely loading between men and women, the EDS demonstrated Partial Scalar invariance across cisgender men and women.

\section{Vigilance Scale}

The Vigilance Scale has not been used in research as extensively as the EDS, and less is known about the psychometric properties of the scale, so a preliminary EFA was conducted to determine whether the scale was unidimensional. Our analyses supported a two-factor scale ( 3 items in each factor). The first 3 items loaded on a factor we called "preparation" and the last 3 items loaded on a factor we called “caution".

To confirm the scale structure, we first used a single-factor model, with all items loading on one factor. This model had poor fit with CFI $=.94$ and RMSEA $=.12$ (.11, .14). Then we ran a 2-factor correlated model, which yielded good fit (CFI $=.98$, RMSEA $=.07(.05, .09)$. Using the 2-factor model, we assessed fit in transgender and cisgender groups independently and found similar results $(\mathrm{CFA}=.98, \mathrm{RMSEA}=.07$; all 
values in Table 1.2). Based on these results, we decided the 2 -factor correlated model was the appropriate model, all subsequent invariance testing utilized this model.

Invariance. We tested invariance between cisgender and transgender respondents for the DRVS at the Configural, Metric, and Scalar levels (see all values in Table 3). All levels yielded acceptable fit, with the highest $\Delta \mathrm{CFI}=-.004$ between the Metric and Scalar levels. No modification indices were suggested, therefore results supported invariance of the DRVS across transgender/ cisgender status.

Gender within Transgender Respondents. We used the same gender groups for our invariance analyses of the DRVS. The Configural Model demonstrated acceptable fit, but the Metric level yielded $\Delta C F I=.013$, and a significant $-2 L L$ rescaled difference test. Modification indices suggested freeing item 5 loading on factor 2 across all groups. We ran the Partial Metric Invariance, and although fit improved, and was within acceptable criteria, modification indices suggested freeing item 3 loading on factor 1 for women. After freeing item 3, fit improved again. We continued with this model for the Partial Scalar Invariance, leaving item 5 intercepts free across groups, and item 3 intercept free for transwomen. The Partial Scalar Model had acceptable fit, with no significant differences from the Partial Metric Model.

Gender within Cisgender Respondents. Configural, Metric, and Scalar levels of invariance all demonstrated acceptable fit, and no significant differences in CFI or the $-2 \mathrm{LL}$ rescaled difference test. Therefore, results supported a complete invariance to the Scalar level across gender in cisgender respondents.

\section{Comparison of Discrimination and Vigilance Across Identities}

We conducted ANOVAs of the scale and subscale means across gender groups. Initial exploration suggested nonbinary persons who did not endorse a transgender 
status had similar means across all scales, so we combined anyone who was nonbinary identified into one group, but did not combine any other gender groups. Means were compared across the following gender categories: transgender woman, transgender man, nonbinary, cisgender woman, and cisgender man.

ANOVA of the overall EDS yielded a significant result $F(4,1)=\mathbf{2 0 . 8 2}, \eta^{2}=.09$. Trans women, trans men, and nonbinary individuals reported significantly more experiences of discrimination than cisgender women and cisgender men, but there were no significant differences among transgender or cisgender genders. We decided to compare the means of item 5 from the EDS and run an ANOVA of EDS scores with item 5 removed to see if this item may be confounding group differences. There was a significant difference in item 5 across identity $F(4,1)=24.85, \eta^{2}=.10$. Transwomen reported people acting as if they were afraid of them more than everyone else, including transgender men and nonbinary individuals. Transgender men and nonbinary individuals reported this more than cisgender men and women, but there were no differences between cisgender individuals. As expected, a significant difference in EDS scores remained when item 5 was removed, $F(4,1)=17.89, \eta^{2}=.08$. The same group differences existed, but the mean difference was smaller.

An ANOVA across gender of discrimination-related vigilance yielded a significant difference, $F(4,1)=\mathbf{2 7} \cdot 35, \eta^{2}=.11$. Again, transgender women, men and nonbinary individuals reported more vigilance than cisgender men and women. Additionally, the preparation subscale yielded significant differences $F(4,1)=29.04, \eta^{2}=$ .12. Transgender women prepared more for potential discrimination events than all other gender groups except for transgender men. However, the difference between transgender men and women approached significance (Tukey HSD yielded p-value of 
.o7). Transgender men prepared more than cisgender men and women, and cisgender women prepared more than cisgender men (Tukey HSD yielded p-value of .o6). Finally, we compared the means for the caution subscale, $F(4,1)=17 \cdot 74, \eta^{2}=.08$. Transgender and nonbinary individuals reported being more cautious than cisgender individuals.

\section{Discussion}

The purpose of this research was to assess whether the Everyday Discrimination Scale and Discrimination-related Vigilance Scale held a similar measure structure between cisgender sexual minorities and transgender individuals. We found the EDS to hold partial scalar invariance across transgender status, and across genders within transgender identified individuals. Partial Scalar Invariance also held between sexual minority men and women (cisgender). Additionally, we uncovered a two-factor structure of the DRVS, which held measurement invariance across transgender status, and partial scalar invariance across gender identities within the transgender group.

\section{Everyday Discrimination}

One item: "People acted as if they were afraid of you." from the EDS was the source of noninvariance across transgender identities. Specifically, transgender women endorsed this item more consistently with other experiences of discrimination, unlike any of the other gender groups. In comparison to other experiences of discrimination, this experience was uniquely high in transgender women, but does not impact researchers' ability to utilize this measure as invariant across LGBTQ identities. Transgender women reported the highest rates of discrimination, regardless of whether this item was included in the EDS score. This item noninvariance may provide evidence for an experience of discrimination more frequently experienced by transgender women, and future research should replicate this finding. When considering the EDS 
for future research with LGBTQ individuals, investigators should note the item and decide whether to include the item in their analyses. However, we encourage the inclusion and future investigation of this item with transgender women.

Metric invariance held across cisgender men and women, with the item "You were threatened or harassed" having a different intercept between men and women. Women were more likely to report being threatened or harassed than men. This resulted in partial scalar invariance, but does not impact the strength of the scale as a discrimination measure. Cisgender men and women are still reporting each of the nine items consistently, representing a composite measure of overall perceived discrimination.

\section{Discrimination-Related Vigilance}

Discrimination-Related Vigilance is a less understood construct within the LGBTQ experience, and may more often be referred to as "expectation of rejection" within the minority stress literature. This research supported two "types" of vigilance within this LGBT sample suggesting there is a difference between expecting, or "preparing" for how you may be treated when you are in public, and how you act, or are "on alert" when in public spaces. The DRVS held complete scalar invariance across transgender and cisgender groups, and within men and women in the cisgender sample, suggesting the two subscales are consistent across these populations. However, there were two items that loaded differently across gender within the transgender group.

Results found that the item "Carefully observe what happens around you?" loaded differently for all three gender groups. This item had the highest loading for nonbinary (.75), followed by transmen (.62), and the lowest loading for transwomen 
(.48). When this item was compared with the two other items in the subscale, it was clear this item was about observing your surroundings, while the other two items were about being careful with your own behaviors. The differences in loadings across gender may point towards a different relationship between caution about one's own behaviors and caution about what is happening around you across gender in trans persons that is not different across gender in cisgender people. Specifically, for transwomen, their caution with their own behavior may be less related to the safety of their surroundings, and more related to wanting to make sure their behaviors and presentation are closely resembling that of a woman. In contrast, for nonbinary persons, how they act and present themselves, may be more directly related to the security and safety of their surroundings.

Another item that held a different loading for just transgender women was "Feel that you always have to be careful about your appearance to get good service or avoid being harassed?". For trans men and nonbinary individuals, this item held the highest loading on the "preparation" factor, while for transwomen, this item had the lowest loading (.69). The other two items in the subscale were about preparing or thinking about what may happen when you are in public, while this item was more about being careful with your appearance/presentation. Similar to the different loadings on item 5 , this points towards a difference for transwomen in worrying about safety and worrying about presentation. Specifically, although there was a relationship between preparing for discriminatory encounters, being careful about presentation was not as interrelated in those encounters as it was for transmen and nonbinary individuals.

\section{Limitations}


This study is the first to assess invariance of minority stress measures across LGBTQ identities, and the results demonstrate the importance of understanding measurement equivalence across LGBTQ genders. However, invariance was only assessed across transgender status and gender identity, and was limited by sample size. All respondents were accessed voluntarily using social media and online support services, so the samples are not representative of the entire LGBTQ community. Both transgender and cisgender respondents were accessed using similar recruitment methods, so the samples were similar in age, income, and education status. In general, our samples were not racially diverse, and did not represent the full range of income and educational disparity present in the larger LGBTQ population.

We chose to use measures of minority stress that were developed to investigate racism related discrimination to lend towards future comparative research across different types of minority stress (e.g. racial, sexual orientation, gender, medical status), but both measures are brief and only capture general perceptions of discrimination and vigilance. These measures will be ideal for researchers who need a simple and brief assessment of current discrimination experience, and resulting vigilance. Even within these short measures, we were able to discern differences in how experiences were reported across transgender individuals. Future research in minority stress should include invariance assessment, especially within gender among transgender individuals.

\section{Conclusion}

Our results support the use of the Everyday Discrimination Scale and Discrimination-Related Vigilance Scale for research in both cisgender sexual minorities and transgender individuals. These scales represent similar constructs of minority 
stress across populations, with subtle differences in item relevance for transgender women. This study is the first to utilize measurement invariance in discriminationrelated measures across LGBTQ identities, but was able to discern unique differences in items across transgender identities. We suggest recognizing the complex dynamic between presentation, appearance, and discrimination in transgender individuals, especially transgender women. The EDS and DRVS measures are good options for brief, simple, measures of minority stress when conducting research across trans and cis identities, but new measures should be developed and tested that incorporate more comprehensive assessment of minority stress. 


\section{References}

Balsam, K. F., Beadnell, B., \& Molina, Y. (2013). The Daily Heterosexist Experiences Questionnaire: Measuring minority stress among lesbian, gay, bisexual, and transgender adults. Measurement and Evaluation in Counseling and Development, 46(1), 3-25.

Browne, M. W. \& Cudeck, R. (1993). Alternative ways of assessing model fit. In K. A. Bollen \& J. S. Long (Eds.), Testing structural equation models (pp. 136-162). Newbury Park, CA: Sage.

Breslow, A. S., Brewster, M. E., Velez, B. L., Wong, S., Geiger, E., \& Soderstrom, B. (2015). Resilience and collective action: Exploring buffers against minority stress for transgender individuals. Psychology of Sexual Orientation and Gender Diversity, 2(3), 253

Gamarel, K. E., Reisner, S. L., Laurenceau, J. P., Nemoto, T., \& Operario, D. (2014). Gender minority stress, mental health, and relationship quality: A dyadic investigation of transgender women and their cisgender male partners. Journal of Family Psychology, 28(4), 437.

Gregorich, S. E. (2006). Do self-report instruments allow meaningful comparisons across diverse population groups? Testing measurement invariance using the confirmatory factor analysis framework. Medical care, 44(11 Suppl 3), S78-S94.

Hu, L., \& Bentler, P. M. (1999). Cutoff criteria for fit indexes in covariance structure analysis: Conventional criteria versus new alternatives. Structural Equation Modeling, 6, 1-55. 
Kim, G., Sellbom, M., \& Ford, K.-L. (2014). Race/ethnicity and measurement equivalence of the Everyday Discrimination Scale. Psychological Assessment, 26(3), 892-90o. doi:10.1037/aoo36431

Kline, R. B. (2011). Principles and practice of structural equation modeling ( $3^{\text {rd }}$ ed.) New York: The Guilford Press, NY.

Meredith, W. (1993). Measurement invariance, factor analysis, and factorial invariance. Pschometrika, 58, 521-543.

Meyer, I. H. (2003). Prejudice, social stress, and mental health in lesbian, gay, and bisexual populations: conceptual issues and research evidence. Psychological bulletin, 129, 674-697.

Muthén, L. K. \& Muthén B. O. (2012). Mplus User’s Guide. Seventh Edition. Los Angeles, CA.

Ross, M. W., \& Rosser, B. R. (1996). Measurement and correlates of internalized homophobia: A factor analytic study. Journal of clinical psychology, 52(1), 15-21.

Satorra, A., \& Bentler, P.M. (2010). Ensuring positiveness of the scaled difference chisquare test statistic. Psychometrika, 75, 243-248.

Testa, R. J., Habarth, J., Peta, J., Balsam, K., \& Bockting, W. (2015). Development of the Gender Minority Stress and Resilience Measure. Psychology of Sexual Orientation and Gender Diversity, 2(1), 65. 
Table 1.1: Demographics of Analytic Sample

\begin{tabular}{|c|c|c|c|c|c|c|}
\hline & \multicolumn{2}{|c|}{ Transgender } & \multicolumn{2}{|c|}{ Cisgender } & \multicolumn{2}{|c|}{ Total Sample } \\
\hline & Mean or $\%$ & $\mathrm{~N}$ & $\mathrm{M}$ or $\%$ & $\mathrm{~N}$ & $\mathrm{M}$ or $\%$ & $\mathrm{~N}$ \\
\hline Age & $32.5(12.7)$ & & $32.7(11.5)$ & & $32.6(12.1)$ & \\
\hline \multicolumn{7}{|l|}{ Gender } \\
\hline Man & 26.7 & 123 & $27 \cdot 9$ & 146 & 27.3 & 269 \\
\hline Woman & 21.7 & 100 & 65.0 & 340 & 44.7 & 440 \\
\hline Nonbinary & 33.0 & 152 & 2.9 & 15 & 17.0 & 167 \\
\hline Man + Nonbinary & $9 \cdot 5$ & 44 & .4 & 2 & $4 \cdot 7$ & 46 \\
\hline Woman + Nonbinary & 6.9 & 32 & 3.8 & 20 & $5 \cdot 3$ & 52 \\
\hline Man + Woman & .4 & 8 & o & o & .8 & 8 \\
\hline Man +Woman + Nonbinary & 1.7 & 2 & o & o & .2 & 2 \\
\hline \multicolumn{7}{|l|}{ Sexual Orientation } \\
\hline Asexual & 8.9 & 41 & 3.0 & 16 & 5.8 & 57 \\
\hline Bisexual & 11.5 & 53 & 22.9 & 120 & 17.6 & 173 \\
\hline Gay/Lesbian & 13.0 & 60 & 45.6 & 244 & 30.9 & 304 \\
\hline Heterosexual & 6.1 & 28 & .4 & 2 & 3.0 & 30 \\
\hline Pansexual & 21.3 & 98 & 7.6 & 40 & 14.0 & 138 \\
\hline Queer & 31.7 & 146 & 16.6 & 87 & 23.7 & 233 \\
\hline Other & 3 & 34 & 7.4 & 16 & 5.1 & 50 \\
\hline \multicolumn{7}{|l|}{ Education } \\
\hline Did not complete High school & 1.7 & 8 & 2 & .4 & 1.0 & 10 \\
\hline High School or GED & 8 & 37 & 2.9 & 15 & $5 \cdot 3$ & 53 \\
\hline Some college, no degree & $25 \cdot 4$ & 117 & $19 \cdot 3$ & 101 & 22.2 & 218 \\
\hline Associate or Vocational Degree & 11.7 & 54 & 8.0 & 42 & 9.8 & 96 \\
\hline Bachelor's Degree & 25.9 & 119 & $29 \cdot 3$ & 253 & $27 \cdot 7$ & 272 \\
\hline Graduate or Professional Degree & 23.0 & 106 & 38.0 & 199 & 31.0 & 305 \\
\hline Other & 4.1 & 19 & 2.1 & 11 & 3.1 & 30 \\
\hline \multicolumn{7}{|l|}{ Income } \\
\hline Unemployed, seeking work & 9.6 & 49 & $4 \cdot 3$ & 25 & 6.8 & 74 \\
\hline Less than 30,000 & 44.5 & 226 & 25.9 & 150 & 39.1 & 376 \\
\hline $30,000-49,999$ & 18.1 & 92 & 19.2 & 111 & 21.1 & 203 \\
\hline $50,000-79,999$ & 13.8 & 70 & 20.7 & 120 & 19.8 & 190 \\
\hline $80,000-100,000$ & 4.9 & 25 & 10.0 & 58 & 8.6 & 83 \\
\hline More than 100,000 & $7 \cdot 5$ & 38 & 12.4 & 72 & 11.4 & 110 \\
\hline
\end{tabular}


Table 1.2: Fit Indices for CFA Models of Discrimination and Vigilance Scales

\begin{tabular}{|c|c|c|c|}
\hline \multicolumn{4}{|c|}{ Everyday Discrimination Scale } \\
\hline Models & $\chi^{2}(d f)$ & RMSEA (9o\% CI) & CFI \\
\hline Single Factor & $448.85(20)$ & $.14(.13, .16)$ & .87 \\
\hline Items $1 \& 2$ correlated & $219 \cdot 32(19)$ & $.10(.09, .11)$ & .94 \\
\hline Items $1 \& 2,8 \& 9$ correlated & $91.76(18)$ & $.06(.05, .08)$ & .98 \\
\hline Transgender & $60.42(18)$ & $.07(.05, .09)$ & .98 \\
\hline Cisgender & $52.30(18)$ & $.06(.04, .08)$ & .98 \\
\hline \multicolumn{4}{|c|}{ Vigilance Scale } \\
\hline Single Factor & $147 \cdot 41(9)$ & $.12(.11, .14)$ & .94 \\
\hline Two- Factor & $50.01(8)$ & $.07(.05, .09)$ & .98 \\
\hline Transgender & $27 \cdot 35(8)$ & $.07(.04, .10)$ & .98 \\
\hline Cisgender & $26.48(8)$ & $.07(.04, .09)$ & .98 \\
\hline
\end{tabular}


Table 1.3: Invariance Models for Discrimination and Vigilance Scales

\begin{tabular}{|c|c|c|c|c|c|c|}
\hline \multicolumn{7}{|c|}{ Everyday Discrimination Scale } \\
\hline Model & $\chi^{2}(d f)$ & RMSEA(9o CI) & $\chi^{2}(d f)^{*}$ & $p$ & CFI & $\Delta C F I$ \\
\hline \multicolumn{7}{|l|}{ Transgender vs. Cisgender } \\
\hline Configural & $166.40(50)$ & $.07(.06, .08)$ & - & - & .966 & \\
\hline Metric & $201.92(58)$ & $.07(.06, .08)$ & $35.82(8)$ & .00 & .958 & -.008 \\
\hline Partial Metric - item 5 free & $180.86(57)$ & $.07(.05, .08)$ & $13.95(7)$ & .05 & .964 & -.002 \\
\hline Partial Scalar - item 5 free & $199.29(64)$ & $.06(.05, .07)$ & $17 \cdot 48(7)$ & .01 & .961 & -.003 \\
\hline \multicolumn{7}{|l|}{ Gender (transgender) } \\
\hline Configural & $160.77(75)$ & $.09(.07, .11)$ & - & - & .955 & - \\
\hline Metric & $205.82(91)$ & $.09(.07, .11)$ & $45.68(16)$ & .00 & .940 & -.015 \\
\hline Partial Metric - item 5 free for women & $193.78(90)$ & $.09(.07, .10)$ & $33.08(15)$ & .00 & .946 & -.009 \\
\hline Partial Scalar - item 5 free for women & $210.54(105)$ & $.08(.07, .10)$ & $14.54(15)$ & .48 & .945 & -.001 \\
\hline \multicolumn{7}{|l|}{ Gender (cisgender) } \\
\hline Configural & $93.13(50)$ & $.06(.04, .08)$ & - & - & .966 & - \\
\hline Metric & $99.28(58)$ & $.05(.04, .07)$ & $6.99(8)$ & & .967 & +.001 \\
\hline Scalar & $121.46(66)$ & $.06(.04, .08)$ & $25.62(8)$ & .00 & .956 & -.011 \\
\hline Partial Scalar - item 9 intercept free & $111.05(65)$ & $.05(.04, .07)$ & $11.66(7)$ & .11 & .964 & -.003 \\
\hline \multicolumn{7}{|c|}{ Vigilance Scale } \\
\hline Model & $\chi^{2}(d f)$ & $\operatorname{RMSEA}(90 \mathrm{CI})$ & $\chi^{2}(d f)^{*}$ & $p$ & CFI & $\Delta C F I$ \\
\hline \multicolumn{7}{|l|}{ Transgender vs. Cisgender } \\
\hline Configural & $53.88(16)$ & $.07(.05, .09)$ & - & - & .981 & - \\
\hline Metric & $62.26(20)$ & $.06(.05, .08)$ & $7.05(4)$ & .13 & .979 & -.002 \\
\hline Scalar & $74.22(24)$ & $.06(.05, .08)$ & $11.89(4)$ & .02 & .975 & -.004 \\
\hline \multicolumn{7}{|l|}{ Gender (transgender) } \\
\hline Configural & $48.62(24)$ & $.08(.05, .12)$ & - & - & .973 & - \\
\hline Metric & $69.03(32)$ & $.09(.06, .12)$ & $21.23(8)$ & .01 & .960 & -.013 \\
\hline Partial Metric - Item 5 free for women & $61.89(30$ & $.08(.05, .11)$ & $13.63(6)$ & .03 & .965 & -.008 \\
\hline Partial Metric - Item $5 \& 3$ free for women & $55.44(29)$ & $.08(.05, .11)$ & $5.66(5)$ & .34 & .971 & -.002 \\
\hline Partial Scalar & $63.63(34)$ & $.08(.05, .10)$ & $8.14(5)$ & .15 & .968 & -.003 \\
\hline \multicolumn{7}{|l|}{ Gender (cisgender) } \\
\hline Configural & $36.97(16)$ & $.07(.04, .11)$ & - & - & .979 & - \\
\hline Metric & $42.41(20)$ & $.07(.04, .10)$ & $4.73(4)$ & .32 & .978 & -.001 \\
\hline Scalar & $52.62(26)$ & $.07(.04, .09)$ & $10.05(6)$ & .12 & .974 & -.004 \\
\hline
\end{tabular}


Table 1.4: Means and Standard Deviations of the EDS and DRVS

\begin{tabular}{|c|c|c|c|c|c|c|}
\hline & Overall & Trans woman & Trans man & Nonbinary & Cis woman & Cis man \\
\hline EDS & $8.52(7.20)$ & $12.10(9.01)$ & $10.06(7.87)$ & $10.58(7.3)$ & $7.10(6.09)$ & $5.80(5.53)$ \\
\hline Item 5 of EDS & $.66(1.01)$ & $1.35(1.38)$ & $.76(1.11)$ & $.93(1.074)$ & $.41(.76)$ & $.39(.71)$ \\
\hline EDS without item 5 & $7.85(6.62)$ & $10.76(7.87)$ & $9.30(7.33)$ & $9.60(6.71)$ & $6.69(5.75)$ & $5.38(5.32)$ \\
\hline Vigilance & $13.24(6.16)$ & $16.76(5.76)$ & $15.06(6.13)$ & $14.92(5.20)$ & $11.85(6.04)$ & $10.68(5.73)$ \\
\hline Preparation & $5.59(3.39)$ & $7.69(3.32)$ & $6.57(3.50)$ & $6.43(3.04)$ & $4.89(3.22)$ & $4.05(2.92)$ \\
\hline Caution & $7.65(3.30)$ & $9.10(3.01)$ & $8.49(3.09)$ & $8.45(2.74)$ & $6.96(3.36)$ & $6.63(3.37)$ \\
\hline
\end{tabular}




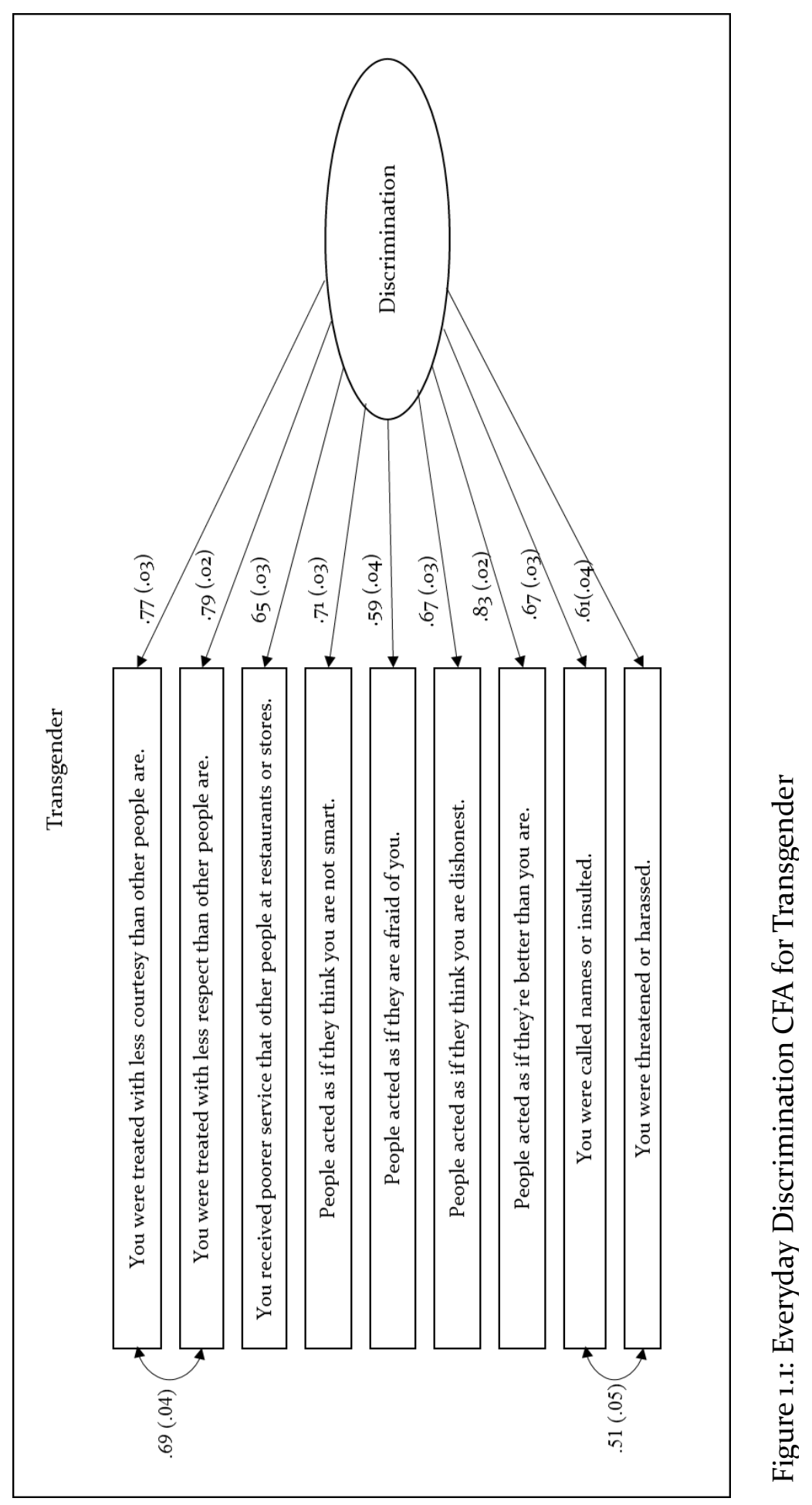




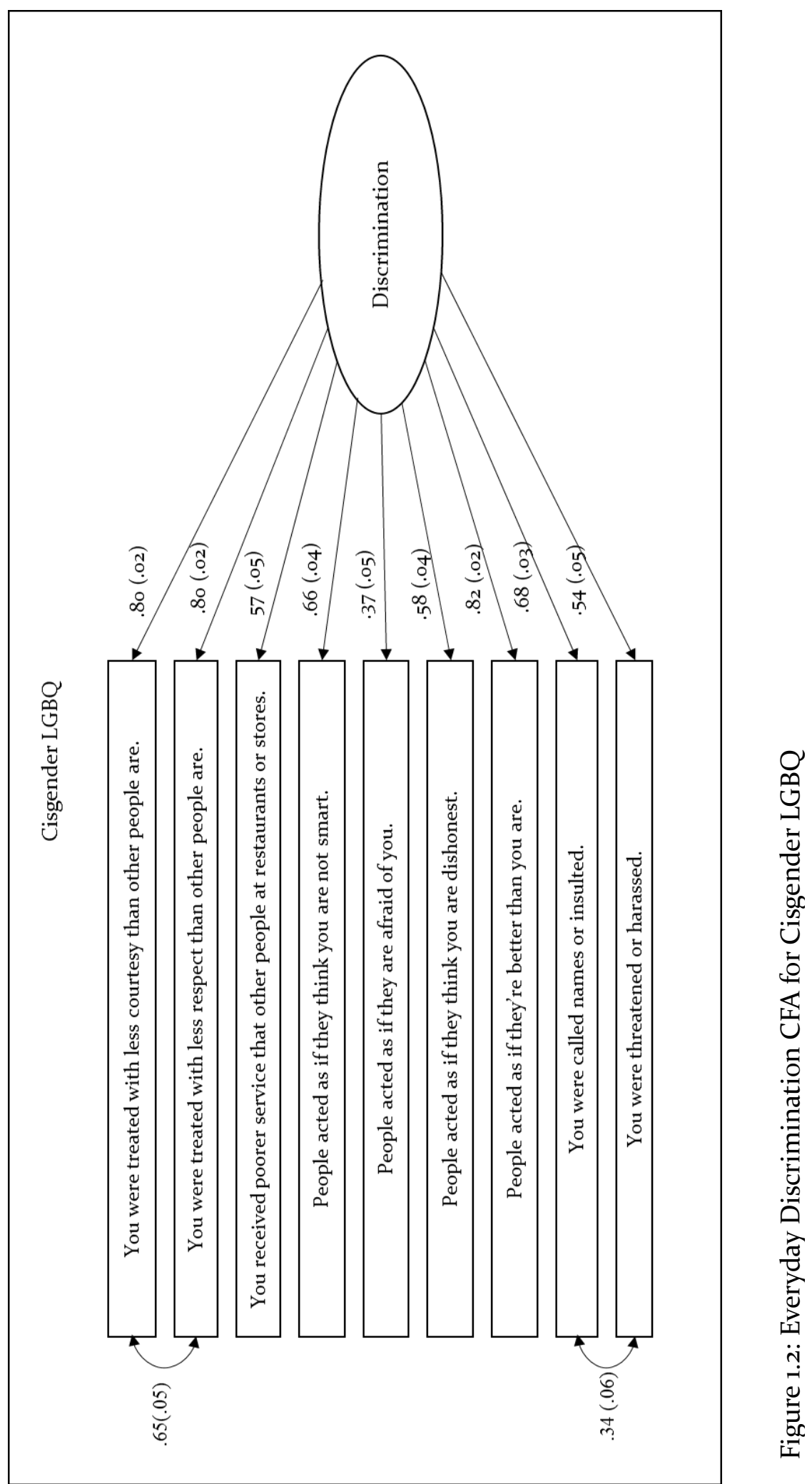




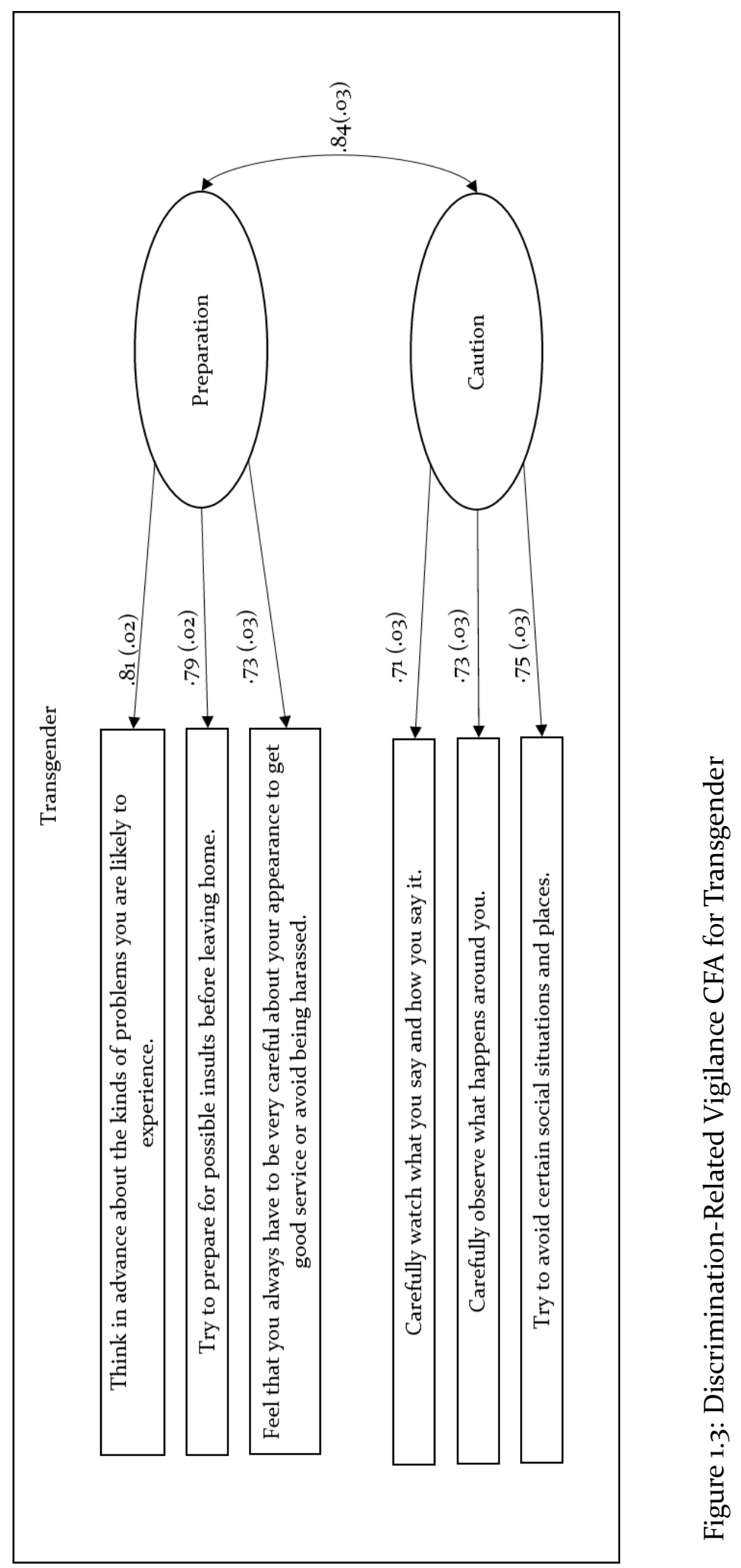




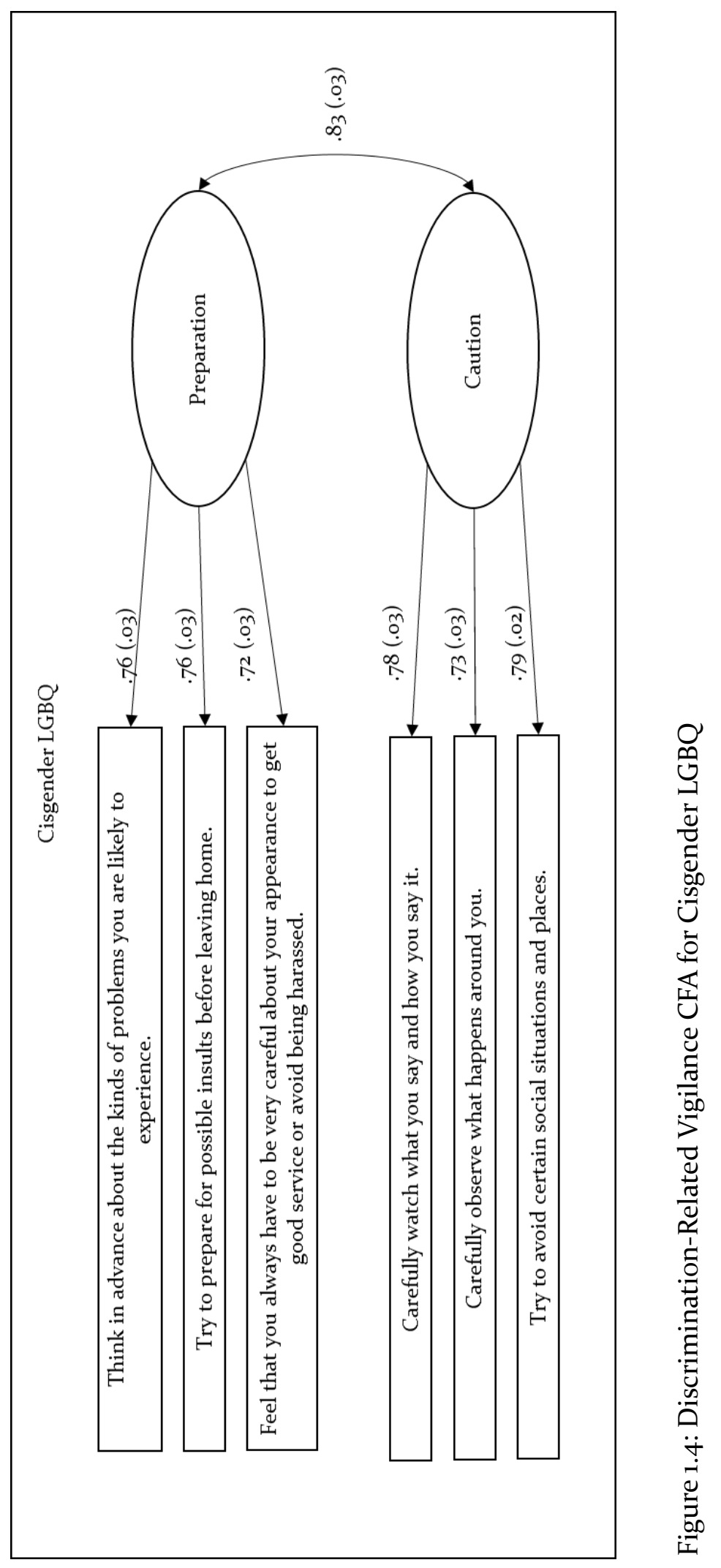




\section{MANUSCRIPT 2}

Comparison of Health Behaviors across Gender in a Nonprobability Sample of Sexual Minority and Transgender Individuals

Intended Journal for Submission: LGBT Health 


\begin{abstract}
.
LGBT individuals experience mental health disparities, as a direct result of minority stress. This chronic stress and higher rates of psychological distress put this population at greater risk for physical health disparities, and suggest they may be at increased risk for poor health-related behaviors (e.g. physical inactivity, lack of fruits and vegetables, smoking). However, there is limited research on the health behaviors of LGBQ and transgender individuals. The current research used a nonprobability sample of 460 transgender individuals and 523 LGBQ individuals to compare rates of healthrelated behaviors across gender. Anonymous responses included representation from 48 US States and the District of Columbia. Results supported an interaction between gender identity and transgender status on BMI, physical activity, and vegetable consumption. In general, transgender individuals experienced more psychological stress and had higher rates of smoking than LGBQ individuals. The current research suggests health behaviors may be related to social group identification and gender behavior in addition to stress. Future research should investigate how health behaviors may be perceived within the context of one's identity.
\end{abstract}


Comparison of Health Behaviors across Gender in a Nonprobability sample of Sexual Minority and Transgender Individuals

Health-related behaviors are the greatest predictor of many health outcomes including cancer, cardiovascular disease, and diabetes. Individuals who are at risk on multiple health behaviors are even more likely to experience poor health. LGBT people experience added stress (e.g. Meyer, 2003), and report higher rates of psychological distress, that may increase their risk for not engaging in health behaviors such as physical activity and fruit and vegetable consumption, or engaging in health-risk behaviors such as smoking or binge drinking. However, there is limited research into the health behaviors of lesbian, gay, bisexual, and transgender (LGBT) individuals beyond substance use and sexual risk. The current research compares rates of healthrelated indicators across gender among LGBT individuals.

\section{Energy Balance Behaviors}

Sexual minority women face higher rates of obesity than heterosexual women (e.g. Boehmer, Bowen \& Bauer, 2007; Fredriksen-Goldsen, Kim, Barkan, Muraco \& HoyEllis, 2013), and while sexual minority men's weight patterns were similar to their heterosexual counterparts in an adult sample (e.g. Kaminski, Chapman, Haynes \& Own, 2005), they demonstrated higher rates of being underweight or grade 2 obese in a college sample (Laska, VanKim, Erickson, Lust, Eisenberg \& Rosser, 2015). Similar patterns were found in a small sample of transgender college students, with transgender individuals having a higher likelihood of being in either the underweight or obese category (results were limited, as no gender identity was collected for transgender individuals: VanKim, Erickson, Eisenberg, Lust, Rosser \& Laska, 2014). 
Despite these weight patterns, there is limited research into physical activity among LGBT individuals. Gay and bisexual men are more likely to engage in unhealthy weight control behaviors and have distorted views of their weight (e.g. Kaminski, Chapman, Haynes \& Own, 2005; Laska et. al, 2015), and less likely to engage in vigorous or strength training exercises (also found in young sexual minority men: Rosario, Corliss, Everett, Reisner, Austin, Buchting \& Birkett, 2014). Similar physical activity patterns were found in the same small sample of transgender individuals listed above (VanKim et. al, 2014). No differences in physical inactivity were found in adult sexual minority women (Aaron, Markovic, Danielson, Honnold, Janosky \& Schmidt, 2001) or young sexual minority women (Rosario, Corliss, Everett, Reisner, Austin, Buchting \& Birkett, 2014).

As of 2013 (Bilyk, Wellington \& Kapica), there was no research on the nutrition and dietary behaviors among LGBT individuals, but population data supported high rates of food insecurity in LGBT populations (about 20\%: Gates, 2014). The combination of added minority stressors and many unsure about accessing food, may put this population at greater risk for malnutrition, or less able to access fruits and vegetables. In the last year, Smalley, Warren, and Barefoot (2016) assessed differences in single item indicators of health behaviors and found across LGBT identities, sexual minority men were most likely to consume fried foods, while transgender women were at greatest risk for several other nutrition risks (including not meeting recommended fruit or vegetable consumption and most likely to consume sugary beverages), some of which were different from the results from VanKim et al. (2014). Additionally, in a comparison of dietary behaviors in female nurses, minimal to no differences were found in nutrients and fat consumption between heterosexual and sexual minority 
nurses, but the difference that did appear suggested sexual minority female nurses had healthier diets than heterosexual nurses (VanKim, Austin, Jun, Hu \& Corliss, 2016). More research on physical activity and nutrition behaviors is needed to assess whether behaviors account for weight-related disparities among LGBT individuals.

\section{Smoking and Alcohol Use}

Smoking disparities are well established for transgender (e.g. Conron, Scott, Stowell \& Landers, 2012; Reisner, White, Bradford \& Mimiaga, 2014) and LGB individuals (e.g. Balsam, Beadnell \& Riggs, 2012; Fallin, Goodin, Lee \& Bennett, 2015), with rates almost double for transgender individuals. In contrast, alcohol use disparities are less consistent. Reisner and colleagues (2014) found no difference in substance use for transgender individuals in comparison to cisgender individuals in a nested-matched pair study, while Coulter, Blosnich, Bukowski, Herrick, Siconolfi and Stall (2015) found higher rates of heavy episodic drinking for younger transgender (1829) persons compared to cisgender. Additionally, a review of substance use literature for LGBs also found mixed results for sexual minority men, but identified increased rates of substance use disorders and alcohol related problems for lesbians and bisexual women (Green \& Feinstein, 2012).

\section{Purpose}

There is limited research on health-risk behaviors across LGBQ identities, and even less for transgender individuals. The LGBT population is at increased risk for health disparities, and understanding how subpopulations within this group experience their health, and engage in health behaviors will provide insight into the unique needs of the community. The purpose of the current research is to explore health-related behaviors, and self-report ratings of health across genders within the LGBT population. 
Although previous research has identified some differences across bisexual and monosexual minority statuses, gender plays a significant role in health-related behavior. Given the dynamics of the LGBT population, we believe comparing across transgender and gender identities is the best approach to understanding health differences.

\section{Methods}

\section{Procedure}

All procedures were approved by the University of Rhode Island for human subjects' protections. Participants were recruited from online social support email lists, forums, and Facebook Groups. All groups were self-identified as LGBT, Queer, or Transgender-specific, and the majority were local groups, designed to connect people to local information, shared interests (i.e. gaming, parenting), or promote activism. To be eligible, participants had to indicate they were either Transgender/ gender diverse and/or a sexual minority (with a sexual orientation other than heterosexual), and were at least 18 years old. Surveys were collected via Qualtrics Software, responses were anonymous, no tracking was included for how participants heard about the survey. The only compensation was selection of a nonprofit organization serving the LGBT to receive a one-dollar donation. The health behavior survey took approximately 30-40 minutes to complete, and included additional questions related to minority stressors not included in the current paper.

\section{Participants}

Participants $(N=983)$ included $100(10.1 \%)$ transgender women, $123(12.5 \%)$ transgender men, 274 (27.9\%) nonbinary-identified individuals (37 of whom did not

identify as transgender), 340 (34.6\%) cisgender women, and 146 (14.9\%) cisgender men. 
Ages ranged from 18 to $77(m=32.6, s d=12.1)$, transgender women $(m=40.3, s d=14.8)$ and cisgender men $(m=36.8, s d=14.1)$ were significantly older, with the greatest variability, and nonbinary persons were the youngest $(m=29.1, s d=10.3)$. Participants were primarily white (transgender $=79.8 \%$, cisgender $=82 \%$ ), and the majority had health insurance (transgender $=84.7 \%$, cisgender $=91.2 \%)$. Reported incomes were higher among cisgender (29.4\% below 30,00oo) than transgender ( $50.2 \%$ below 30,000), but many held incomes exceeding 50,0oo (transgender $=29.6 \%$, cisgender $=48.8 \%$ ). For a review of all demographic information by transgender status and gender identity see Table 2.1.

\section{Measures}

Fruit, Vegetable, Dietary Consumption. Fruit and vegetable consumption was measured using the All-day Screener from the Eating at America's Table Study (Thompson, Subar, Smith, Midthune, Radimer, Kahle, \& Kipnis, 2002). The screener includes 10 questions related to the frequency of consumption (in the last month), and the average portion size of each food category each time. The scoring procedure recommended on the National Cancer Institute's (NCI) website (accessed February 2017; https://epi.grants.cancer.gov/diet/screeners/fruitveg/scoring/allday.html) was used to estimate daily average consumption. Previous research demonstrated this measure to overestimate actual consumption, we limited our calculation of average fruit and average vegetable consumption to the food categories most characteristic to healthful eating and adequate access. Average fruit consumption was only measured with the 2 fruit items (frequency and portion size). Average vegetable consumption was measured using the similar 6 items regarding leafy greens, beans, and other vegetables. The single item related to frequency of eating fried potatoes was used to assess frequency of consuming high fat foods. 
Physical Activity. Physical activity was measured using the International Physical Activity Questionnaire (IPAQ: Booth, Ainsworth, Pratt, Ekelund, Yngve, Sallis, \& Oja, 2003). The IPAQ has been used to assess levels of physical activity in gay men (Cary, Brittain, Dinger, Ford, Cain \& Sharp, 2016) and lesbians (Eliason, McElroy, Garbers, Radix \& Barker, 2016), but not with transgender individuals. The Brief 7 -item measure asks how many times you engaged in vigorous, moderate, and light/walking activity for more than 10 minutes in the last week. Each question is followed by a question asking, on average, how many minutes you exercised at that rate each time. The final question was related to time sitting and was not included in any analyses. We followed the algorithm by the IPAQ group for calculating total active minutes (accessed February 2017: http://www.institutferran.org/documentos/scoring_short_ipaq_aprilo4.pdf). Respondents were classified into "inactive", "minimally active" and "HEPA active" (or meeting recommendations).

Alcohol Use. The 10-item Alcohol Use Disorders Identification Test (AUDIT: Saunders, Aasland, Babor, De la Fuente \& Grant, 1993), was used to assess alcohol use. The AUDIT has been used in other studies with sexual minorities (e.g Livingston, Oost, Heck \& Cochran, 2015; Mason \& Lewis, 2015), but has not been used in a transgender study. Internal reliability for the 10-item scale was satisfactory for both transgender respondents $\alpha=.838$ and cisgender LGBQ respondents $\alpha=.839$. Alcohol-related problems were too low for analyses $(<1-2 \%)$ across latter questions, so we only used the first 3 questions, the AUDIT Consumption version (AUDIT-C: Bush, Kivlahan, McDonell, Fihn \& Bradley, 1998). Internal reliability for the AUDIT-C: $\alpha=.678$ for cisgender LGBQ and $\alpha=.687$ for transgender. 
Smoking. Smoking behavior was assessed with 3 questions: "Have you smoked at least 100 cigarettes in your life?" (Yes/no), "Are you a current smoker?" (Yes, No, I quit within the last 3 months, No, I quit within the last year, No, I have not smoked in a year or more, and No, I have never smoked), and "Do you use electronic cigarettes?" (No, No, but I used to, Yes, I use them from time-to-time, Yes, I use electronic cigarettes daily).

Health Indicators and Perceived Stress. Single-item questions were included to assess general health, and stress. Questions included: [On a scale from 1-10] "Please rate your ability to effectively manage your stress over the last month?", "How stressed have you felt in the last month?", and "How would you rate your overall health?". One question was asked related to energy level: "In the past week, how often did you feel too tired, or lack the energy to complete daily activities?" (1=Never to $5=$ All the time).

Psychological Distress. Symptoms of psychological distress were measured using the 21-item Depression, Anxiety, and Stress Scale (DASS-21: Henry \& Crawford, 2005). The DASS-21 includes 7 items each capturing symptoms of depression, anxiety, and stress. Each item described a symptom and respondents were asked to indicate the extent that the symptoms applied to them in the last week. Responses were on a 4-pt likert scale: $\mathrm{o}=$ "Did not apply to me at all" to $3=$ " Applied to me very much or most of the time”. This scale demonstrated acceptable measurement invariance across transgender and cisgender respondents (results reported separately). Transgender $\alpha=.94$, Cisgender LGBQ $\alpha=.93$.

Gender. Respondents were asked multiple questions related to their gender, sexual orientation, and identities. For this study, we categorized people by transgender status and the gender selected. Before beginning the survey, participants indicated 
whether they were (1) a sexual minority, and/or (2) identify as transgender, and/or have a gender identity different from my gender assigned at birth. Anyone who selected 2 were considered "transgender", anyone who did not select 2 were categorized as "cisgender" or not transgender. At the end of the survey, participants were asked to select their primary gender identity from three options: "man", "woman", and "nonbinary". Anyone who selected "nonbinary", regardless of whether they also selected man/woman, was categorized as nonbinary. Transgender status and gender identity were combined to create gender categories for the comparison groups.

Demographics (table 2.1) are broken down as people self-identified. However, demographics were similar between nonbinary people who selected transgender and those who did not select transgender, so we grouped these people together into one category for the health rates table (Table 2.2). All nonbinary respondents were included as "transgender and gender nonconforming" (TGNC).

\section{Analyses}

Health Indicator Categorization. All health indicators were converted to meaningful categories to present group rates. Physical Activity categories: Inactive, Minimally Active, and HEPA Active were based on recommendations in the IPAQ scoring. Group proportions for health-risks are reported in Table 2.2.

Group Differences. We performed separate 2 (transgender, cisgender LGBQ) by 3 (gender: woman, man, nonbinary) MANCOVAs across related variables (physical activity, nutrition, psychological distress, and well-being indicators), with age as a covariate. Variables were standardized to t-scores $(\mathrm{M}=50, \mathrm{SD}=10)$ to provide a consistent metric for interpreting group differences. All standardized scores and effect sizes are presented in table 2.3. 


\section{Results}

\section{Smoking}

Transgender men had the highest rates of current smoking (22\%), followed by transgender women (18\%) and cisgender men (17.9\%). Transgender women had the highest lifetime history of smoking 100 or more cigarettes (48.5) followed by transgender men $(46.3 \%)$.

\section{Physical Activity}

A 2 (transgender status) by 3 (gender identity) MANCOVA with vigorous, moderate, and low-impact activity levels, covaried for age was significant Wilks' $\Lambda=$ $.984, F(6,1908)=2.56, \mathrm{p}<.01, \eta^{2}=.008$. Follow-up ANOVAs across activity levels found an interaction between trans status and gender identity for low impact activity $F(2,956)=6.12, \mathrm{p}<.01, \eta^{2}=.013$. Transgender women reported more time walking than cisgender women, and transgender men and transgender nonbinary individuals reported less time walking than cisgender men and cisgender nonbinary individuals (see Figure 3). There was also a significant difference across gender identity and vigorous activity $F(2,956)=4.27, p<.05, \eta^{2}=.009$. Men were more likely to engage in vigorous activity than women and nonbinary individuals. Figure 2.1 displays standard score means of physical activity by gender identity.

\section{Nutrition}

A 2 by 3 MANCOVA with fruit and vegetable consumption, covaried by age was significant Wilks' $\Lambda=.983, F(4,1928)=4.22, p<.01, \eta^{2}=.009$. Follow-up ANOVAs found an interaction between trans status and gender identity for vegetable consumption $F(2$, $965)=7.43, p<.01, \eta^{2}=.015$. Cisgender women consumed more vegetables than transgender women, while transgender men consumed more vegetables than cisgender 
men (see Figure 2.2). There were no differences in fruit consumption.

\section{Psychological Distress}

A 2 by 3 MANCOVA with depression, anxiety, and stress scores, covaried by age was significant Wilks' $\Lambda=.976, F(6,1890)=3.79, p<.01, \eta^{2}=.012$. Follow-up ANOVAs found an interaction between trans status and gender identity for depression scores $F(2,947)=8.30, p<.001, \eta^{2}=.017$. Transgender women reported higher rates of depression than cisgender women, but there were no significant differences between transgender and cisgender men and nonbinary individuals. There were main effects of transgender status for anxiety $F(1,947)=13.88, p<.01, \eta^{2}=.014$ and stress $F(1,947)=9.00, p<.01$, $\eta^{2}=$.oog. Transgender persons reported more symptoms of anxiety and stress. There were no differences in symptoms between transgender and cisgender nonbinary individuals across transgender status for depression, anxiety of stress. Figure 2.3 is a visual graph of transgender* gender groups, with nonbinary individuals combined.

\section{Well Being}

A 2 by 3 MANCOVA with self-rated health, self-rated ability to manage stress, and reported number of days waking well rested was not significant Wilks' $\Lambda=.990, F(6$, 1646) $=1.35, p=.232, \eta^{2}=.005$. All differences in ratings were accounted for by covarying Age: Wilks' $\Lambda=.937, F(3,823)=18.54, p<.001, \eta^{2}=.063$. Standard score means are still reported in table 2.3, but no additional analyses were conducted.

\section{BMI}

A 2 by 3 ANCOVA with BMI was significant $F(2,950)=4.98, p<.01, \eta^{2}=.010$. Transgender men and nonbinary individuals reported higher BMIs than cisgender men and nonbinary individuals.

\section{Discussion}


The current study is the second study to assess health behaviors across LGBT genders, and the first to use validated population measures. Comparing multiple health-related behaviors provides a more comprehensive understanding of health for

these populations. However, in our sample, we found alarming rates of physical inactivity, smoking, and poor nutrition across most identities. When we found health differences within groups, the effects were small, and may have been accounted for by large sample sizes. An important finding from our research was nonbinary individuals self-reported the lowest overall health, despite being the youngest group, and transgender men and women reported more engagement in physical activity overall, then other genders. Additionally, our research did not identify alarming alcohol use across any of the groups, but found all TGNC identities reported less alcohol use than cisgender LGBQ persons.

\section{Transgender women}

Transgender women had the highest rate of lifetime smoking, which may be related to their average age being roughly 10 years higher than other gender groups. However, the current smoking rate was still high at $18 \%$. They were least likely to meet the daily recommendations for vegetable consumption, but were most likely to meet physical activity recommendations. Despite having the highest rate of meeting recommendations, many trans women were achieving their activity minutes by engaging in moderate activity, not vigorous activity. Additionally, they did not rate their current stress levels as high as cisgender women and other transgender people, but still indicated comparable perceptions of being able to handle their stress and feeling tired. When age was controlled, their systems of stress, depression, and anxiety were the highest. 


\section{Transgender men}

Transgender men had the highest rate of being a current smoker, and lifetime rates similar to transgender women. They were the least likely to be physically inactive, after cisgender LGBQ women, and reported the highest average of their overall stress. Their ability to manage stress was low, and they reported feeling tired almost half the time (on average). Interestingly, their rates of vigorous activity were comparable to cisgender men, with the highest median of vigorous minutes. This survey did not collect data on physical transition and feelings about one's body. But, given the high rates of insurance and outness to physicians (90.8\%), it is possible the group of trans men who participated in this survey were more likely to have access to trans-related

care. In this case, physical activity may be serving as a way to achieve more masculine/ muscular bodies consistent with their gender identity. Additional research should investigate the physical activity patterns within this group, to understand the physical activity patterns found among both transgender men and women.

\section{Nonbinary}

Nonbinary individuals had the lowest lifetime smoking rate, rated their stress on the higher end, while feeling the least able to manage stress. They also reported the greatest frequency of feeling tired and lacking energy, further suggesting this group is at risk for overall negative health outcomes. However, when distress symptoms were compared, with controlling for age, their symptoms were lower than transgender men and women. The high rates may partially be explained by being younger. Health outcomes and behaviors are least understood among nonbinary individuals, as this group is difficult to identify in population surveys, but based on our survey demographics and in the recent US Trans Survey (2017), nonbinary individuals 
represent over $30 \%$ of the transgender and gender nonconforming population. Given the higher reports of stress, future research should explore whether nonbinary individuals are at increased risk of psychological distress.

\section{Cisgender LGBQ Women}

Previous research on sexual minority women has consistently demonstrated increased risk for obesity and alcohol use. We did find higher rates of obesity for cisgender women in comparison to men, but not quite as high as transgender men and women. However, over $41 \%$ of LGBQ women were meeting their daily recommendations for vegetable consumption, which was the highest across the groups analyzed. Women were the least likely to be physically inactive, but were on the lower end of average physically active minutes. Another interesting finding among LGBQ women, were the lowest current smoking rates, and the highest rates of having quit for more than a year. Research in physical activity among LGBQ women, has found a desire to be healthy, but a need to be in environments less focused on unhealthy body image messages they've heard in the past (Brittain, Baillargeon, McElroy, Aaron \& Gyurcsik, 2006). Given the high rates of quitting smoking, and vegetable consumption, LGBQ women continue to be an interesting group in regard to health and health behavior. It is possible the higher obesity rates may be related to biological factors, like Polycystic Ovarian Syndrome (PCOS: Agrawal, Sharma, Bekir, Conway, Bailey, Balen \& Prelevic, 2004).

Also, given the low reports of alcohol consumption, which are inconsistent with previous research showing high rates of alcohol problems in LGBQ women (Green \& Feinstein, 2012), our results may specifically represent health behaviors among 
primarily white/Caucasian LGBQ women with significant resources (based on income rates, education, and health insurance) and willing to participate in research.

\section{Cisgender GBQ Men}

On average, cisgender GBQ men had the highest overall rating of health, they were least likely to be obese, and most likely to be normal weight. GBQ men reported lowest rates for meeting recommended vegetable consumption, and highest rates of physical inactivity similar to transgender women. In contrast, they were also least likely to meet recommended physical activity, unlike transgender women. GBQ men also had high rates of current smoking (17.9\%), and reported consuming the most alcohol (although still not large amounts). GBQ men reported the lowest amount of stress, and the greatest confidence in managing their stress. Given the poorer rates of weightrelated behaviors, but lower BMIs and stress, it is possible this group is less focused on their health, and their engagement with health is not related to stress. Although, each gender group is distinct, the combination of lower stress and poorer weight-related behaviors for GBQ men may suggest that weight-related behaviors are not specifically related to stress for GBQ men.

\section{Primary Care Provider}

Transgender individuals face significant barriers to accessing competent healthcare (e.g. NTDS, 2007; US Trans Survey, 2017), but less is known about healthcare for LGBQ persons. We compared indicators of primary care and routine care across genders. Among our sample, accessing care and having a primary care doctor were high, regardless of gender. An interesting finding was more transgender men and women knew their gender identity and history, in comparison to PCPs knowing sexual orientation of LGBQ men and women, and PCPs knowing gender and/or sexual 
orientation for nonbinary persons. The necessity of receiving gender-related medical care may serve as a facilitator for seeking competent providers, or the necessity of sharing one's identity with a provider. This is particularly significant when considering LGBQ-related health concerns that may not be treated if sexual minorities are not sharing their orientation with their providers. Physicians should be asking questions about sexual behavior, gender, and identity of all patients to facilitate disclosure, and ensure appropriate healthcare is provided.

\section{Limitations}

Several limitations exist when generalizing the findings from our study. The current data was from a nonprobability voluntary sample, recruited from select social networks. Demographics from the sample suggested respondents were primarily high socioeconomic status, highly educated, and mostly white (8o\%). However, there were minimal differences across gender groups in regard to demographics. The primary differences were in education, ever being homeless, income level, and unemployment rate. These differences may be directly attributed to the increased stigma and discrimination experienced by transgender individuals. Being able to compare health across these genders, with similar demographic backgrounds, provides some foundation for understanding how health (in general) may be different for these groups. Although researchers should generalize these findings to understanding the overall health behaviors for these groups, this research provides further foundation for understanding LGBT health, and should be taken within the context of the research method and demographics.

Given the high socioeconomic status reported, we can assume actual health behaviors for these populations are likely worse than our current data, but hold similar 
trends across identities, particularly when considering physical activity, and fruit and vegetable consumption. These weight-related behaviors are less accessible to impoverished groups and previous data has shown LGBT individuals experience high rates of food insecurity (Gates, 2014), and are probably most concerned with accessing food, as opposed to other types of nutrients.

The current research provides a more comprehensive understanding of health across LGBT groups than previous research into specific health behaviors. Although we compared across genders and not within sexual orientations, this work provides a cross-sectional snapshot of health behavior patterns for LGBT individuals, and supports previous work that LGBT groups do not experience the same health barriers and do not engage in health behaviors in the same ways. Future research should investigate the pathways between minority stress, coping and current stress for these groups, especially given the high rates of reported stress in our research. 


\section{References}

Aaron, D. J., Markovic, N., Danielson, M. E., Honnold, J. A., Janosky, J. E., \& Schmidt, N. J. (2001). Behavioral risk factors for disease and preventive health practices among lesbians. American Journal of Public Health, 91(6), 972.

Agrawal, R., Sharma, S., Bekir, J., Conway, G., Bailey, J., Balen, A. H., \& Prelevic, G. (2004). Prevalence of polycystic ovaries and polycystic ovary syndrome in lesbian women compared with heterosexual women. Fertility and sterility, 82(5), 1352-1357.

Balsam, K. F., Beadnell, B., \& Riggs, K. R. (2012). Understanding Sexual Orientation Health Disparities in Smoking: A Population-Based Analysis. American Journal of Orthopsychiatry, 82(4), 482-493

Bilyk, H. T., Wellington, C., \& Kapica, C. (2013). Cultures with unique nutrition concerns: Lesbian, gay, bisexual, transgender. The FASEB Journal, 27(1 Supplement), 625-9.

Boehmer, U., Bowen, D. J., \& Bauer, G. R. (2007). Overweight and obesity in sexualminority women: evidence from population-based data. American Journal of Public Health, 97(6), 1134-1140.

Booth, M. L., Ainsworth, B. E., Pratt, M., Ekelund, U., Yngve, A., Sallis, J. F., \& Oja, P. (2003). International physical activity questionnaire: 12-country reliability and validity. Med sci sports Exerc, 195(9131/03), 3508-1381.

Brittain, D. R., Baillargeon, T., McElroy, M., Aaron, D. J., \& Gyurcsik, N. C. (2006). Barriers to moderate physical activity in adult lesbians. Women E health, 43(1), 75-92. 
Bush, K., Kivlahan, D. R., McDonell, M. B., Fihn, S. D., \& Bradley, K. A. (1998). The AUDIT alcohol consumption questions (AUDIT-C): an effective brief screening test for problem drinking. Archives of internal medicine, 158(16), 1789-1795.

Cary, M. A., Brittain, D. R., Dinger, M. K., Ford, M. L., Cain, M., \& Sharp, T. A. (2016). Barriers to Physical Activity Among Gay Men. American journal of men's health, 10(5), 408-417.

Conron, K. J., Scott, G., Stowell, G. S., \& Landers, S. J. (2012). Transgender health in Massachusetts: results from a household probability sample of adults. American journal of public health, 102(1), 118-122.

Coulter, R. W., Blosnich, J. R., Bukowski, L. A., Herrick, A. L., Siconolfi, D. E., \& Stall, R. D. (2015). Differences in alcohol use and alcohol-related problems between transgender-and nontransgender-identified young adults. Drug and alcohol dependence, 154, 251-259.

Eliason, M. J., McElroy, J. A., Garbers, S., Radix, A., \& Barker, L. T. (2016). Comparing women with and without disabilities in five-site "Healthy Weight" interventions for lesbian/bisexual women over 40. Disability and Health Journal.

Fallin, A., Goodin, A., Lee, Y. O., \& Bennett, K. (2015). Smoking characteristics among lesbian, gay, and bisexual adults. Preventive medicine, 74, 123-130.

Fredriksen-Goldsen, K. I., Kim, H. J., Barkan, S. E., Muraco, A., \& Hoy-Ellis, C. P. (2013). Health disparities among lesbian, gay, and bisexual older adults: results from a population-based study. American journal of public health, 103(10), 1802-1809.

Gates, G. (2014). LGBT People Are Disproportionately Food Insecure. UCLA: The Williams Institute. Retrieved from: http://escholarship.org/uc/item/4wt4102n 
Green, K. E., \& Feinstein, B. A. (2012). Substance use in lesbian, gay, and bisexual populations: An update on empirical research and implications for treatment. Psychology of Addictive Behaviors, 26(2), 265.

Henry, J. D., \& Crawford, J. R. (2005). The short-form version of the Depression Anxiety Stress Scales (DASS-21): Construct validity and normative data in a large non-clinical sample. British journal of clinical psychology, 44(2), 227-239.

Kaminski, P. L., Chapman, B. P., Haynes, S. D., \& Own, L. (2005). Body image, eating behaviors, and attitudes toward exercise among gay and straight men. Eating behaviors, 6(3), 179-187.

Livingston, N. A., Oost, K. M., Heck, N. C., \& Cochran, B. N. (2015). The role of personality in predicting drug and alcohol use among sexual minorities. Psychology of Addictive Behaviors, 29(2), 414.

Laska, M. N., VanKim, N. A., Erickson, D. J., Lust, K., Eisenberg, M. E., \& Rosser, B. S. (2015). Disparities in weight and weight behaviors by sexual orientation in college students. American journal of public health, 105(1), 111-121.

Mason, T. B., \& Lewis, R. J. (2015). Minority Stress, Depression, Relationship Quality, and Alcohol Use: Associations with Overweight and Obesity Among Partnered Young Adult Lesbians. LGBT health, 2(4), 333-340.

Reisner, S. L., White, J. M., Bradford, J. B., \& Mimiaga, M. J. (2014). Transgender health disparities: comparing full cohort and nested matched-pair study designs in a community health center. LGBT health, 1(3), 177-184.

Rosario, M., Corliss, H. L., Everett, B. G., Reisner, S. L., Austin, S. B., Buchting, F. O., \& Birkett, M. (2014). Sexual orientation disparities in cancer-related risk behaviors 
of tobacco, alcohol, sexual behaviors, and diet and physical activity: pooled Youth Risk Behavior Surveys. American journal of public health, 104(2), 245-254.

Saunders, J. B., Aasland, O. G., Babor, T. F., De la Fuente, J. R., \& Grant, M. (1993). Development of the alcohol use disorders identification test (AUDIT): WHO collaborative project on early detection of persons with harmful alcohol consumption-II. Addiction, 88(6), 791-804.

Smalley, K. B., Warren, J. C., \& Barefoot, K. N. (2016). Differences in health risk behaviors across understudied LGBT subgroups. Health Psychology, 35(2), 103.

Thompson, F. E., Subar, A. F., Smith, A. F., Midthune, D., Radimer, K. L., Kahle, L. L., \& Kipnis, V. (2002). Fruit and vegetable assessment: performance of 2 new short instruments and a food frequency questionnaire. Journal of the American Dietetic Association, 102(12), 1764-1772.

VanKim, N. A., Austin, S. B., Jun, H. J., Hu, F. B., \& Corliss, H. L. (2016). Dietary Patterns during Adulthood among Lesbian, Bisexual, and Heterosexual Women in the Nurses' Health Study II. Journal of the Academy of Nutrition and Dietetics.

VanKim, N. A., Erickson, D. J., Eisenberg, M. E., Lust, K., Rosser, B. R., \& Laska, M. N. (2014). Weight-related disparities for transgender college students. Health behavior and policy review, 1(2), 161-171. 
Table 2.1: Sample Demographics by Trans Status and Gender

\begin{tabular}{|c|c|c|c|c|c|c|c|c|}
\hline & \multicolumn{4}{|c|}{ Transgender } & \multicolumn{4}{|c|}{ Cisgender } \\
\hline & Women & Men & $\mathrm{NB}^{*}$ & Overall & Women & Men & $\mathrm{NB}^{*}$ & Overall \\
\hline $\mathrm{n}$ & 100 & 123 & 237 & 460 & 340 & 146 & 37 & 523 \\
\hline Age & $40.3(14)$ & $32.4(12)$ & $29.2(11)$ & $32.5(13)$ & $31.4(10)$ & $36.8(14)$ & 28.2(9) & $32.7(12)$ \\
\hline Race/ Ethnicity & & & & & & & & \\
\hline Asian & 1 & 1.6 & 1.3 & 1.3 & 2.6 & 2.7 & 2.7 & 2.7 \\
\hline Black or AA & o & 4.1 & 2.1 & 2.2 & 1.8 & .7 & 2.7 & 1.5 \\
\hline Latinx & 3 & $3 \cdot 3$ & .8 & 2.0 & 2.6 & $3 \cdot 4$ & o & 2.7 \\
\hline White & 77 & 78 & 81.9 & 79.8 & 81.8 & 83.6 & 78.4 & 82 \\
\hline Indian & 1 & .8 & .8 & .9 & .3 & 1.4 & o & .6 \\
\hline Multiracial & 17 & 11.4 & 12.2 & 13 & 10 & 6.2 & 16.2 & 9.4 \\
\hline Sexual Orient. & & & & & & & & \\
\hline Asexual & 4 & $7 \cdot 3$ & 11.8 & 8.9 & 4.1 & .7 & 2.7 & 3.1 \\
\hline Bisexual & 17 & 13.8 & 8 & 11.5 & 26.8 & 14.4 & 21.6 & 22.9 \\
\hline Gay/ Lesbian & 26 & 13.8 & 7.2 & 13.1 & $34 \cdot 7$ & $77 \cdot 4$ & $29 \cdot 7$ & 46.3 \\
\hline Heterosexual & 5 & 15.4 & 1.7 & 6.1 & 0 & o & o & o \\
\hline Pansexual & 26 & 14.6 & 22.4 & 21.1 & 10 & 1.4 & 10.8 & 7.6 \\
\hline Queer & 7 & 31.7 & 42.2 & 31.8 & 20.6 & 4.1 & 29.7 & 16.6 \\
\hline Homeless (Ever) & 31 & 34.1 & 28.7 & 30.7 & $14 \cdot 5$ & 15.8 & 35.1 & 16.3 \\
\hline $\begin{array}{l}\text { Unemployed** } \\
\text { Income }\end{array}$ & 12 & 12.2 & $9 \cdot 3$ & 10.7 & $4 \cdot 7$ & 4.8 & $5 \cdot 4$ & 4.8 \\
\hline$<30,000$ & 49 & 44.7 & 52.6 & 50.2 & 27.5 & 31.5 & 38.9 & 29.4 \\
\hline $30,000-49,999$ & 20 & 17.1 & 21.6 & 20.2 & 25.1 & 14 & 22.2 & 21.8 \\
\hline $50,000+$ & 30 & 36.9 & $25 \cdot 9$ & 29.6 & $57 \cdot 5$ & 54.6 & 38.9 & 48.8 \\
\hline Education & & & & & & & & \\
\hline Less than HS & 3 & 2.4 & .8 & 1.7 & o & 1.4 & o & .4 \\
\hline High School & 13 & 10.6 & $4 \cdot 7$ & 8.1 & 1.8 & 3.4 & 8.1 & 2.7 \\
\hline Grad/Prof. & 11 & 26.8 & 26.3 & 23.1 & 41.6 & 33.8 & $24 \cdot 3$ & 38.2 \\
\hline Health Insurance & 81 & 84.6 & 86 & 84.7 & 92.3 & 89 & 86.5 & 91.2 \\
\hline
\end{tabular}

*All individuals who selected nonbinary, or nonbinary and man or woman were included in nonbinary gender: NB; **Unemployed represents percentage of individuals unemployed and seeking work 
Table 2.2: Health Indicators Across Gender

\begin{tabular}{|c|c|c|c|c|c|c|c|}
\hline & \multicolumn{4}{|c|}{ Transgender and GNC } & \multicolumn{3}{|c|}{ LGBQ, Cisgender } \\
\hline Overall Health (1-10) & $\begin{array}{l}\text { Woman } \\
6.5(2.0)\end{array}$ & $\begin{array}{c}\text { Man } \\
6.5(1.8)\end{array}$ & $\begin{array}{c}\mathrm{NB}^{+} \\
6.1(1.9)\end{array}$ & $\begin{array}{l}\text { Overall } \\
6.3(1.9)\end{array}$ & $\begin{array}{l}\text { Woman } \\
6.6(1.8)\end{array}$ & $\begin{array}{c}\text { Man } \\
7.0(1.7)\end{array}$ & $\begin{array}{l}\text { Overall } \\
6.7(1.8)\end{array}$ \\
\hline \multicolumn{8}{|l|}{ BMI (\%) } \\
\hline Underweight & o & .9 & 2.3 & 1.5 & 1.8 & 2.9 & 2.2 \\
\hline Normal weight & 34.0 & 32.2 & 37.1 & 35.2 & 35.0 & 39.1 & 36.2 \\
\hline Overweight & 25.8 & 26.1 & 25.9 & 25.9 & 23.6 & 28.3 & 25.0 \\
\hline Obese & 40.2 & 40.9 & $34 \cdot 7$ & 37.4 & 39.6 & $29 \cdot 7$ & 36.6 \\
\hline \multicolumn{8}{|l|}{ Physical Activity (\%) } \\
\hline Inactive & 18.8 & 14.2 & 18.0 & $17 \cdot 7$ & 12.0 & 18.4 & 16.1 \\
\hline Minimally Active & 61.5 & 70.0 & $69 \cdot 5$ & 67.5 & 69.7 & 71.2 & 71.1 \\
\hline HEPA Active & 19.8 & 15.8 & 12.5 & 14.8 & 18.3 & 10.4 & 12.8 \\
\hline Vigorous $\mathrm{MET}^{++}$ & 40.0 & 82.5 & 17.5 & 30.0 & 35.0 & $67 \cdot 5$ & 50.0 \\
\hline Moderate MET & 95.0 & 60.0 & 60.0 & 60.0 & $45 \cdot 0$ & 60.0 & 50.0 \\
\hline Overall MET & 1798.0 & $1819 \cdot 5$ & 1453.0 & 1532.5 & $1519 \cdot 5$ & 1726.5 & 1599.5 \\
\hline \multicolumn{8}{|l|}{ Dietary Consumption (\%) } \\
\hline Met daily fruit rec & 26.0 & 21.4 & 18.8 & 20.9 & 22.8 & 33.8 & 26.1 \\
\hline Met daily vegetable rec & 25.0 & $29 \cdot 5$ & 30.2 & 29.0 & 41.4 & $25 \cdot 5$ & 36.6 \\
\hline \multicolumn{8}{|l|}{ Alcohol Use } \\
\hline AUDIT-C & $2.8(2.4)$ & $2.3^{(2.2)}$ & $2.8(2.2)$ & $2.7(2.3)$ & $3.0(2.0)$ & $3 \cdot 3(2.7)$ & $3.1(2.3)$ \\
\hline \multicolumn{8}{|l|}{ Smoking (\%) } \\
\hline Current Smoker & 18.0 & 22.0 & 14.2 & 16.9 & 12.4 & $17 \cdot 9$ & 14.0 \\
\hline Quit in the last year & 7 & 8.1 & 6.9 & 7.2 & 5.0 & 4.1 & 4.7 \\
\hline Quit over a year ago & 28 & 28.5 & 19.0 & 23.1 & 40.0 & $19 \cdot 3$ & 22.5 \\
\hline 100 cigs in lifetime & 48.5 & 46.3 & 31.4 & 38.5 & 32.6 & 39.0 & 34.6 \\
\hline E-cigarettes & 10.1 & 11.3 & 10.2 & 10.5 & 6.8 & 6.2 & 6.6 \\
\hline \multicolumn{8}{|l|}{ Stress and Energy $(m(s d))$} \\
\hline Feeling stressed (1-10) & $6.7(2.4)$ & $7.1(2.0)$ & $7.0(2.0)$ & $7.0(2.1)$ & $6.9(2.0)$ & $6.3(2.4)$ & $6.7(2.2)$ \\
\hline Ability Manage Stress (1-10) & $5 \cdot 9(2.2)$ & $5 \cdot 7(2.1)$ & $5.4(2.2)$ & $5.6(2.1)$ & $5 \cdot 9(2.1)$ & $6.4(2.3)$ & $6.0(2.2)$ \\
\hline Tired/ Lack energy (1-5) & $2.7(1.3)$ & $2.8(1.1)$ & $2.9(1.1)$ & $2.8(1.1)$ & $2.6(1.1)$ & $2.3^{(1.1)}$ & $2.5(1.1)$ \\
\hline \multicolumn{8}{|l|}{ Healthcare (\%) } \\
\hline Has PCP & 82.0 & 86.9 & 72.6 & 78.0 & $73 \cdot 5$ & $77 \cdot 9$ & 74.8 \\
\hline PCP knows orientation & 75.0 & 76.2 & 56.9 & 66.0 & $57 \cdot 5$ & 62.1 & 58.9 \\
\hline PCP knows gender & $85 \cdot 9$ & 90.8 & $54 \cdot 7$ & 71.4 & - & - & - \\
\hline Receives routine exams & 66.7 & 61.8 & 58.0 & 60.7 & 63.6 & 66.9 & 64.6 \\
\hline Unable to afford & 9.1 & 8.9 & $9 \cdot 9$ & $9 \cdot 5$ & 8.0 & 6.2 & $7 \cdot 5$ \\
\hline No Competent Care & 7.1 & $7 \cdot 3$ & 9.1 & 8.3 & 4.1 & o & 2.9 \\
\hline
\end{tabular}


Table 2.3: Standard Score Means and Effect Sizes for Health Indicators

\begin{tabular}{|c|c|c|c|c|c|c|c|c|c|}
\hline & \multicolumn{3}{|c|}{ Transgender } & \multicolumn{3}{|c|}{ LGBQ } & \multicolumn{3}{|c|}{$\eta^{2^{*}}$} \\
\hline & Woman & Man & Nonbinary & Woman & Man & Nonbinary & Trans & Gender & $\mathrm{T}^{\star} \mathrm{G}$ \\
\hline Physical Activity $\quad \mathrm{N}$ & 99 & 122 & 233 & 337 & 144 & 37 & .009 & .005 & .008 \\
\hline Vigorous & $49.90(10.10)$ & $51.75(10.41)$ & $48.29(9.32)$ & $49.73(9.91)$ & $51.71(10.09)$ & $49.09(9.80)$ & .000 & .009 & .000 \\
\hline Moderate & $52.5^{2}(11.21)$ & $50.92(10.33)$ & $50.04(10.07)$ & $48.59(9.02)$ & $49.81(9.98)$ & $50.70(10.65)$ & .003 & .000 & .006 \\
\hline Low-impact/ Walking & $50.14(10.86)$ & $49.11(9.79)$ & $49.69(10.13)$ & $49.35(9.70)$ & $51.31(9.92)$ & $53.20(9.43)$ & .002 & .000 & .013 \\
\hline Nutrition & & & & & & & .003 & .002 & .009 \\
\hline Fruit & $49.86(9.07)$ & $49.56(8.93)$ & $49.67(12.47)$ & $49.76(8.79)$ & $51.98(10.26)$ & $50.28(10.18)$ & $\begin{array}{l}.003 \\
.002\end{array}$ & .002 & .000 \\
\hline Vegetable & $47.99(7.62)$ & $48.94(8.68)$ & $49.15(8.90)$ & $51.12(8.94)$ & $48.34(7.73)$ & $48.76(7.78)$ & .002 & .002 & .015 \\
\hline Psychological Distress & & & & & & & .022 & .003 & .012 \\
\hline Depression & $53.88(10.70)$ & $51.32(10.73)$ & $51.61(9.72)$ & $47.85(9.31)$ & $48.77(9.80)$ & $50.70(9.99)$ & .020 & .002 & .017 \\
\hline Anxiety & $51.60(10.11)$ & $51.35(10.86)$ & $52.07(10.51)$ & $48.78(9.66)$ & $47.05(8.04)$ & $51.77(10.42)$ & .014 & .003 & .005 \\
\hline Stress & $51.47(10.35)$ & $51.29(10.31)$ & $51.03(9.56)$ & $49.47(10.00)$ & $47.03(9.43)$ & $51.46(11.70)$ & .009 & .004 & .005 \\
\hline Well-being & & & & & & & .004 & .003 & .005 \\
\hline Overall Health & $50.29(10.21)$ & $50.31(9.42)$ & $48.50(9.83)$ & $50.13(9.61)$ & $52.97(9.22)$ & $48.73(10.88)$ & .002 & .006 & .001 \\
\hline Manage Stress & $50.30(10.14)$ & $49.23(9.55)$ & $48.33(9.86)$ & $50.57(9.74)$ & $52.89(10.24)$ & $47.96(11.06)$ & .000 & .002 & .008 \\
\hline Feeling rested & 51.89 (11.02) & 49.58 (10.02) & $49.41(9.10)$ & $49.09(9.21)$ & $53.04(9.96)$ & $48.70(8.50)$ & .004 & .002 & .002 \\
\hline BMI & $49.84(8.36)$ & $50.54(8.60)$ & $50.45(11.36)$ & $50.66(10.58)$ & $48.15(7.97)$ & $47.41(10.40)$ & .003 & .001 & .010 \\
\hline
\end{tabular}




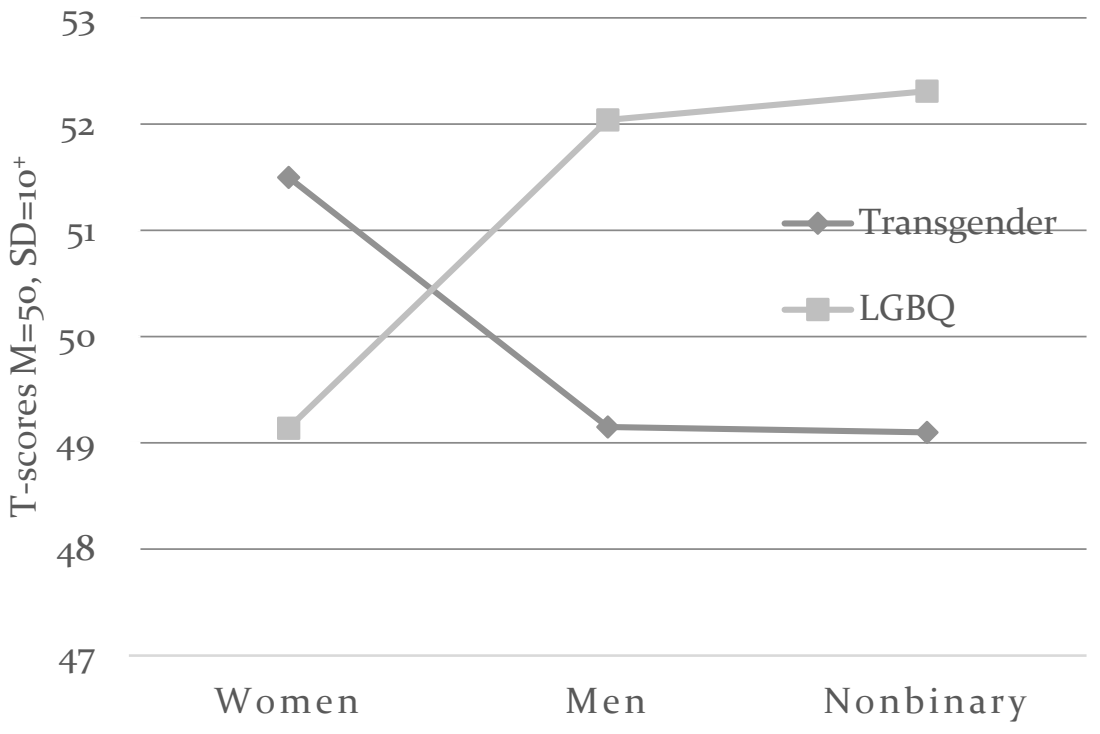

+Means in figure evaluated at sample mean of age $(M=32.50)$

Figure 2.1: Low Impact Activity by Gender for Trans and LGBQ. 


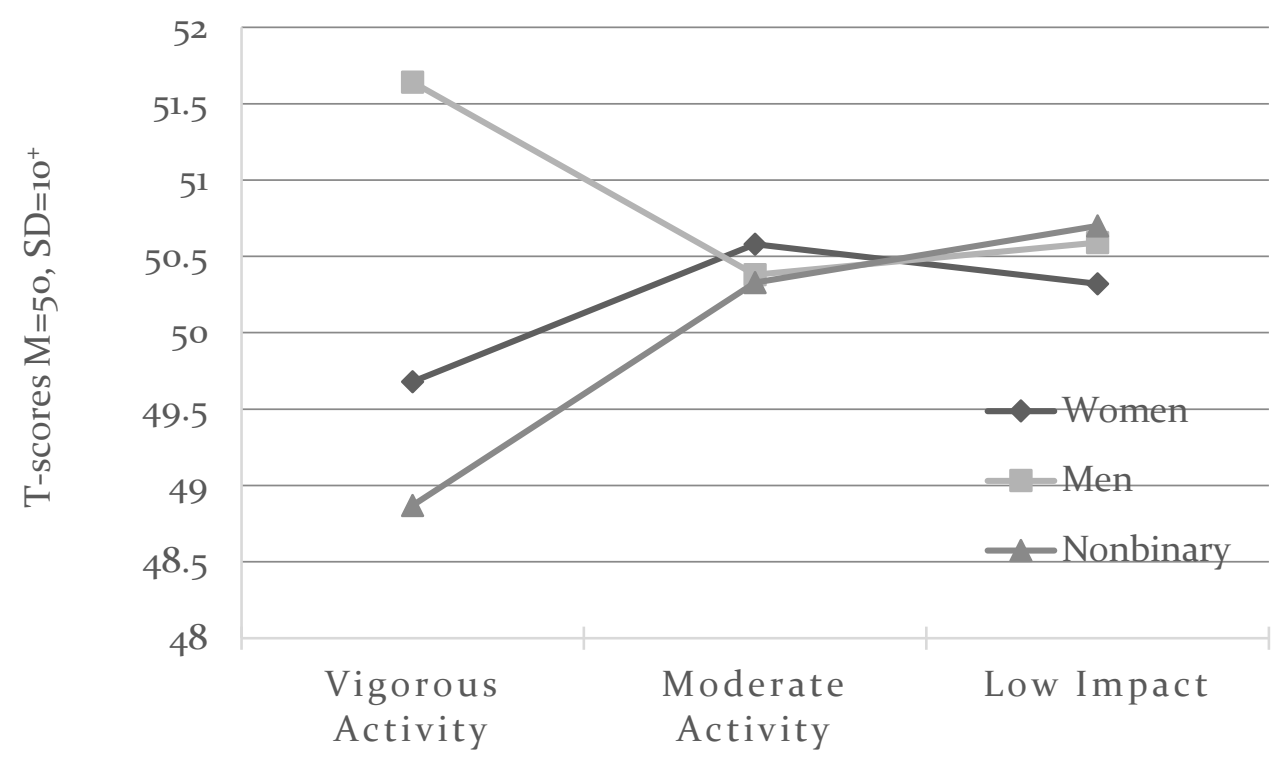

+ Means in figure evaluated at sample mean of age $(\mathrm{M}=32.50)$

Figure 2.2: Physical Activity by Gender 


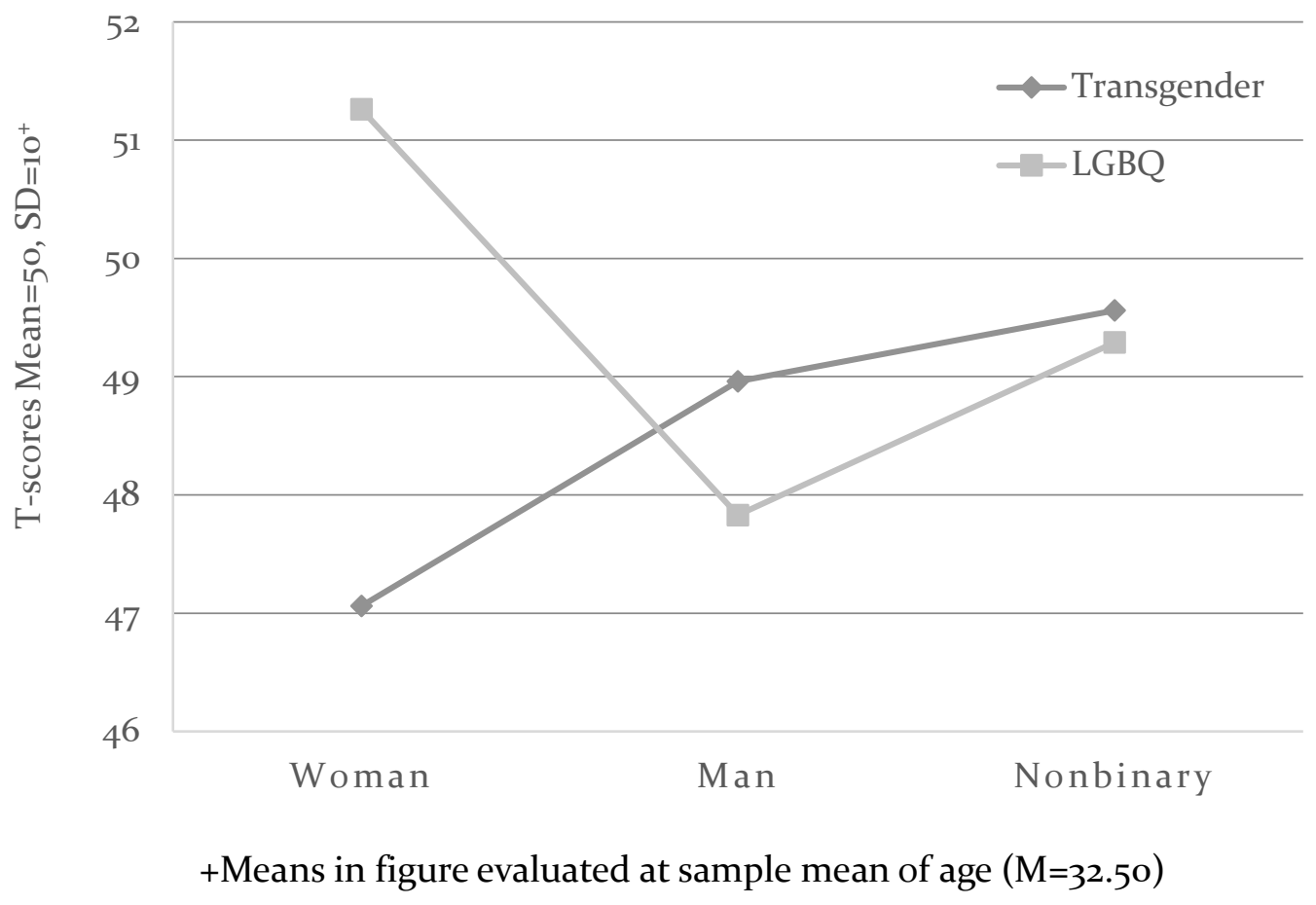

Figure 2.3: Vegetable Consumption by Gender for Trans and LGBQ 


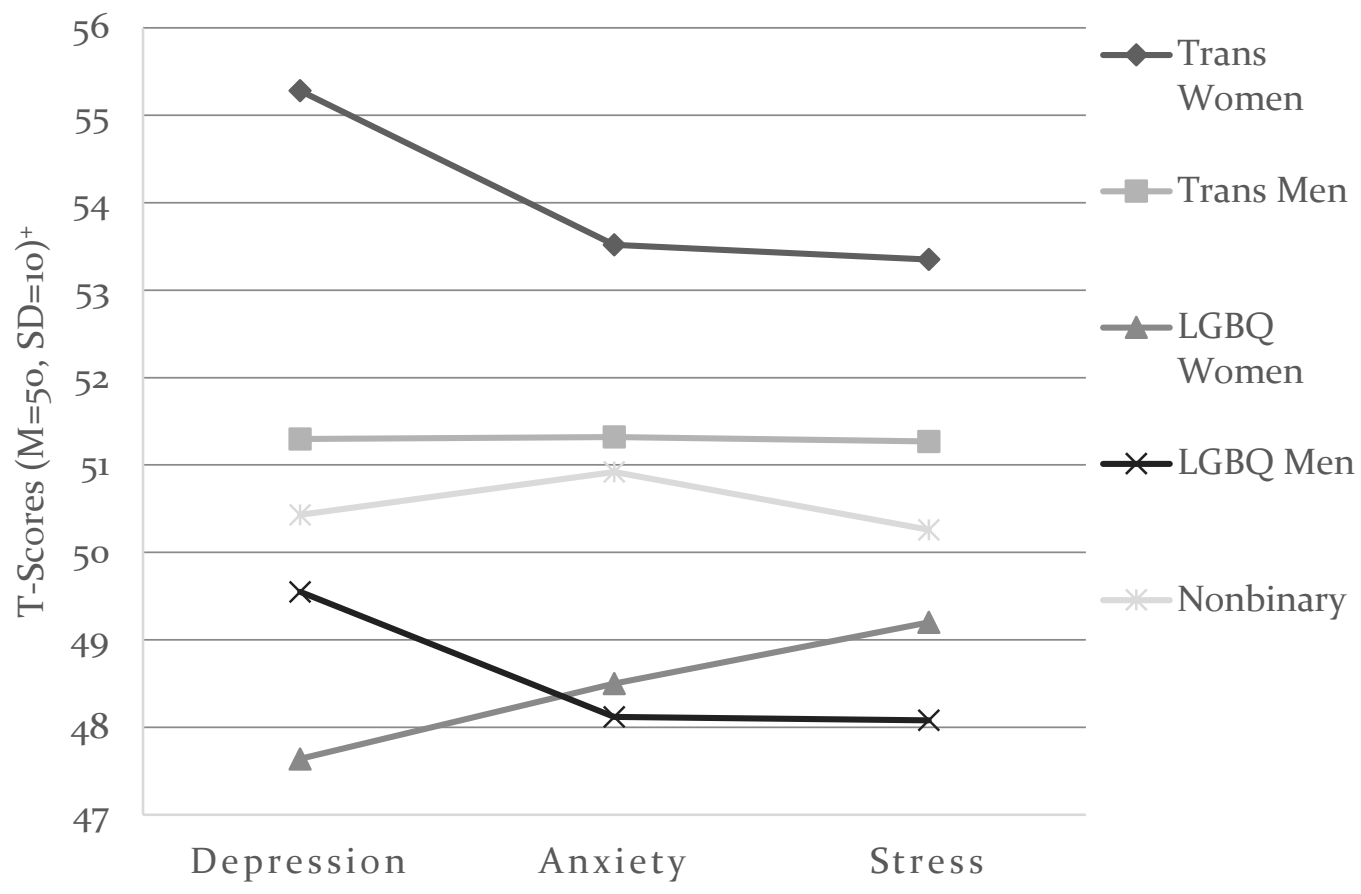

+Means in figure evaluated at sample mean of age $(\mathrm{M}=32.50)$

Figure 2.4: Depression, Anxiety, and Stress for Gender Groups. 


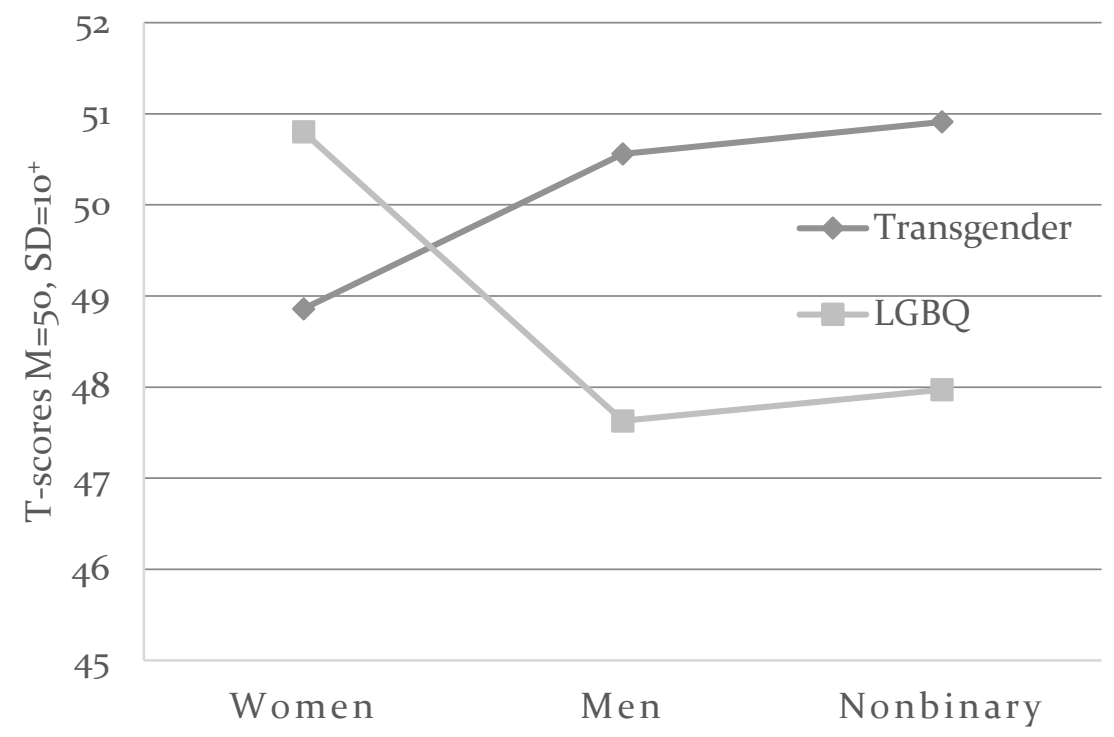

+Means in figure evaluated at sample mean of age $(\mathrm{M}=32.50)$

Figure 2.5: BMI Across Genders for Transgender and LGBQ 


\section{MANUSCRIPT 3}

Cluster Analysis of Physical Activity Behaviors Across

TGNC and LGBQ Identities

Intended Journal for Submission: Journal of Community Health 


\begin{abstract}
:
Engaging in physical activity promotes overall health and is associated with better mental health. LGBTQ individuals face barriers to engaging in organized physical activities, as a result of the gendered nature of sports. The current research explores patterns of physical activity across a nonprobability sample of transgender $(\mathrm{N}=460)$ and cisgender LGBQ ( $\mathrm{N}=523)$ individuals. Five clusters of physical activity were replicated across transgender and cisgender samples: Overall Active, Vigorous-level Active, Moderate-level Active, Walkers, and Inactive. Differences in overall health and BMI were found between the Overall Active, Vigorous-level Active and Inactive clusters. Over 50\% of all LGBTQ individuals clustered into the Walkers and Inactive group, suggesting this population has high rates of inactivity. Physical activity patterns and rates were similar across transgender and cisgender LGBQ groups. Future research should investigate factors contributing to inactivity among LGBTQ persons.
\end{abstract}




\section{Cluster Analysis of Physical Activity Across}

TGNC and LGBTQ Gender Identities

Engaging in moderate to vigorous physical activity promotes positive mental and physical health including weight management, decreased risk for cardiovascular disease and increased mood (WHO, 2010). Physical activity behaviors among youth predicts adult participation in exercise, and barriers to physical activity begin in youth for LGBTQ persons (Calzo, Roberts, Corliss, Blood, Kroshus, \& Austin, 2014). However, the patterns of physical activity among LGBTQ adults are unknown. The current research explored subtypes in physical activity engagement across transgender status among a sample of LGBTQ adults.

\section{Cluster Analysis}

Cluster analysis (CA) is a statistical technique designed to identify homogeneous subgroups within a population. This method has been used in health behavior research to identify subgroups and improve the tailoring of health interventions (e.g. Babbin, Velicer, Paiva, Brick \& Redding, 2015). Clustering techniques are able to identify individual risk patterns (Cleveland, Collins, Lanza, Greenberg, \& Feinberg, 2010) that can help account for outcomes. When it comes to researching a diverse population like LGBT individuals, cluster analysis can assess whether homogeneity exists superseding factors directly related to one's identity. Specifically, given LGBT individuals experience different health disparities, and they have some similar and dissimilar identity and stigma-related experiences, clustering provides a method for identifying commonalities across these groups.

Being able to identify commonalities may provide a unique approach to understanding individual factors that contribute to health. Cluster analysis is a common 
method employed within health psychology, because health-behaviors often demonstrate underlying patterns. Clustering health behaviors across LGBTQ identities may be an effective way to investigate whether health patterns are similar across this population.

\section{Purpose}

The purpose of the current research is to explore whether LGBTQ individuals have similar patterns of physical activity across identities. Given the known differences in these behaviors across gender, cluster analyses will be performed separately for transgender and cisgender LGBQ individuals and compared.

\section{Methods}

\section{Participants}

Participants $(\mathrm{n}=983)$ included $100(10.1 \%)$ transgender women, $123(12.5 \%)$ transgender men, 274 (27.9\%) nonbinary-identified individuals (37 of whom did not

identify as transgender), 340 (34.6\%) cisgender women, and 146 (14.9\%) cisgender men. Ages ranged from 18 to $77(m=32.6, s d=12.1)$, transgender women $(m=40.3, s d=14.8)$ and cisgender men ( $m=36.8, s d=14.1)$ were significantly older, with the greatest variability, and nonbinary persons were the youngest $(m=29.1, s d=10.3)$. Participants were primarily white (transgender $=79.8 \%$, cisgender $=82 \%$ ), and the majority had health insurance (transgender $=84.7 \%$, cisgender $=91.2 \%)$. Reported incomes were higher among cisgender (29.4\% below 30,0ooo) than transgender (50.2\% below 30,000), but many held incomes exceeding 50,ooo (transgender $=29.6 \%$, cisgender $=48.8 \%$ ). Demographic information by subsample is reported in Table 3.1.

\section{Measures}

Gender. Respondents were asked multiple questions related to their gender, 
sexual orientation, and identities. For this study, we categorized people by transgender status and the gender selected. Before beginning the survey, participants indicated whether they (1) "identify as a sexual minority and/or have same-gender sexual attraction. (I am not heterosexual)", and/or (2) "identify as transgender, and/or have a gender identity different from my gender assigned at birth". Anyone who selected 2 was categorized as "transgender", anyone who did not select 2 was categorized as "cisgender" or not transgender. At the end of the survey, participants were asked to select their primary gender identity from three options: “man”, “woman”, and "nonbinary”. Anyone who selected "nonbinary", regardless of whether they also selected man/woman were categorized as nonbinary. Transgender status was used to separate groups as "transgender" or "cisgender LGBQ”.

Fruit and Vegetable Consumption. Fruit and vegetable consumption was measured using the All-day Screener from the Eating at America's Table Study (Thompson, Subar, Smith, Midthune, Radimer, Kahle, \& Kipnis, 2002). The screener includes 10 questions related to the frequency of consumption (in the last month), and the 9 questions related to the average portion size of each food category each time. The scoring procedure recommended on the National Cancer Institute's (NCI) website (accessed February 2017; https://epi.grants.cancer.gov/diet/screeners/fruitveg/scoring/allday.html) was used to estimate daily average consumption. Previous research demonstrated this measure to overestimate actual consumption, we limited our calculation of average fruit and average vegetable consumption to the food categories most characteristic to healthful eating and adequate access. Average fruit consumption was measured with the 2 fruit items (frequency and portion size). Average vegetable consumption was measured using the 
similar 6 items regarding leafy greens, beans, and other vegetables.

Physical Activity. Physical activity was measured using the International Physical Activity Questionnaire (IPAQ: Booth, Ainsworth, Pratt, Ekelund, Yngve, Sallis, \& Oja, 2003). The IPAQ has been used to assess levels of physical activity in gay men (Cary, Brittain, Dinger, Ford, Cain \& Sharp, 2016) and lesbians (Eliason, McElroy, Garbers, Radix \& Barker, 2016), but not with transgender individuals. The Brief 7-item measure asks how many times you engaged in vigorous, moderate, and light/walking activity for more than 10 minutes in the last week. Each question is followed by a question asking, on average, how many minutes you exercised at that rate each time. The final question was related to time sitting and was not included in any analyses. We followed the algorithm by the IPAQ group for calculating total active minutes (accessed February 2017: http://www.institutferran.org/documentos/scoring_short_ipaq_aprilo4.pdf). Average amount of minutes was calculated for each type of exercise, and an overall total metabolic rate minutes was calculated (weighting more vigorous activity).

Overall Health, Stress and BMI. Single-item questions were used to assess how a person rated their overall health and feelings of stress. Questions included: [On a scale from 1-10] "How stressed have you felt in the last month?", "How would you rate your overall health?", and "How would you rate your ability to effectively manage your stress?”. BMI was calculated based on self-report height and weight. Finally, one question was asked related to energy: "In the past week, how often did you feel too tired or lack the energy to complete daily activities" (1=Never, 5=Always).

\section{Analyses}

The entire sample was randomly divided into two subsamples to allow for 
replication of cluster analyses. Cluster analyses were performed separately for transgender and cisgender LGBQ (referred to as cisgender for the rest of the results section), for a total of four cluster analyses. Cluster analyses were conducted using the three levels of physical activity: vigorous, moderate, light/walking. Variables were standardized to T-scores $($ mean $=50$, standard deviation $=10)$.

Hierarchical clustering with a squared Euclidean distance metric (Cronbach \& Gleser, 1953) and Ward's minimum variance clustering (Ward, 1963) were used to conduct initial cluster enumeration. To determine the number of clusters we inspected the dendogram plot and utilized the inverse scree test (Lathrop \& Williams, 1989). Kmeans clustering determined the final cluster solution through visual inspection and comparison of cluster profiles. Cluster profiles were replicated to establish internal reliability.

We evaluated the external validity of the clusters by comparing the cluster subtypes on variables not included in our clustering. Specifically, we wanted to investigate whether the subtypes of physical activity differentiated other health behaviors and indicators. We included self-report measures of: overall health, stress, energy (lack of energy), overall physical activity, and BMI.

\section{Results}

\section{Cisgender Subtypes}

A five-cluster solution captured the types of physical activity among LGBQ respondents. Both subsamples revealed analogous cluster profiles of activity. Figures 3.1 and 3.2 visually display the cluster subtypes. Means and standard deviations are listed in table 3.2.

\section{Transgender Subtypes}


A five-cluster solution best characterized the subtypes of physical activity among transgender respondents. Both subsamples uncovered the same subtypes of physical activity. Figures 3.3 and 3.4 visually display the cluster subtypes. Means and standard deviations are listed in table 3.2.

\section{Cluster Descriptions}

The cluster subtypes for the cisgender and transgender solutions represented similar behavior patterns, thus we were able to characterize them with the same descriptions. Cluster 1 was named "Active". Across all four solutions, this group demonstrated high levels of all physical activity. This cluster was characterized by a high line across the top of all the plots.

Cluster 2 was named "Vigorous Active". Across all four solutions, this group demonstrated high engagement with vigorous activity, and low to average engagement in moderate and low-impact activity. This cluster was characterized by an "L shape" tilted to the left.

Cluster 3 was named "Moderate Active". Across all four solutions, this cluster demonstrated high moderate activity and low to average levels of vigorous and lowimpact activity. In all the cluster plots, this group is characterized by an inverted V shape.

Cluster 4 was named the "Walking” group. This subtype was characterized by high rates of low-impact activity (walking), but low to average rates of vigorous and moderate activity. The shape of this group was characterized by a backwards $\mathrm{L}$ in all plots.

Cluster 5 was named "Inactive". This cluster would be characterized as "at risk" for not meeting even minimal levels of physical activity. This cluster demonstrated low 
rates of all types of physical activity, and was characterized by a low line across all the cluster plots.

\section{External Validity for Cisgender Subtypes}

We combined the respective matching clusters from the two cisgender subsamples to create a large sample $(N=570)$ to conduct an external validity analysis. A one-way MANOVA with Wilks' Lambda criteria, with ratings of stress, health, stress management, lack of energy, BMI, vegetable consumption, and fruit consumption was significant $F(28,1515 \cdot 754)=2.46$, Wilks' $\Lambda=.852, \eta^{2}=.039$. Follow-up ANOVAs were reported in table 3.3. The active subtype reported better overall health than inactive, and the respondents in the vigorous active reported the highest overall health which was significantly greater than moderate active and inactive. As expected, we found a significant difference in BMI. However, the only difference in BMI was between active and inactive subtypes. Additionally, we found people in the walking subtype reported the lowest vegetable consumption.

\section{External Validity for Transgender Subtypes}

We combined the respective matching clusters from the two transgender subsamples to create a large sample $(N=493)$.

A one-way MANOVA with Wilks' Lambda criteria, with ratings of stress, health, stress management, lack of energy, BMI, vegetable consumption, and fruit consumption was significant $F(28,1284.998)=1.55$, Wilks' $\Lambda=.887, \eta^{2}=.029$. Follow-up ANOVAs were reported in table 3.3. Overall health ratings were lowest among people clustered in the inactive subtype, significantly lower than active and vigorous subtypes. As expected, BMI was highest in the inactive group, but there were no differences in vegetable consumption. 


\section{Cluster Membership Across Demographics}

Cluster subtypes were compared across gender identities (table 3.4), there were no differences $\chi^{2}(16)=24.78, p=.07$. No differences in race $\chi^{2}(28)=36.26, p=.136$, or smoking status $\chi^{2}(16)=25.25, p=.066$ were found.

\section{Discussion}

Five distinct clusters were uncovered using vigorous, moderate, and low-impact physical activity levels. These clusters were replicated across two samples among transgender and two samples among cisgender LGBQ groups. Similar clusters suggest physical activity patterns may be the same across LGBTQ identities. External validity analyses only found differences in overall health and BMI. Measuring physical activity in types served to distinguish how types of physical activity may differentially impact health, and an overall active lifestyle may be related to better health.

\section{Clusters for Energy Balance}

The Overall Active (A) subtype was characterized by high vigorous. moderate activity, and low-impact activity. The subtype was related to the best health outcomes. Binary transgender individuals were more likely to be overall active than nonbinary or cisgender individuals.

The Vigorous Activity (V) subtype was characterized by individuals who reported above average vigorous activity, but average to low moderate and low-impact activity. Among LGBQ individuals, this subtype reported the highest overall health, but this finding was not consistent among transgender individuals. This may be due to the higher proportion of cisgender men (in comparison to cisgender women) in the vigorous activity subtype, as men had higher ratings of overall health in this sample (see Bauerband \& Velicer, 2017 for entire overview). 
The Moderate Active (M) subtype was characterized by individuals who reported above average moderate activity, but not vigorous activity or low-impact activity. There were no significant health indicators for this subtype, but only $13.7 \%$ of cisgender individuals were placed in this cluster, compared to $16 \%$ of transgender individuals. In total, $18.8 \%$ of transgender women were categorized in the M subtype, which is higher than any other group/subtype besides inactive.

The Walkers (W) subtype was characterized by high low-impact activity, and low to average moderate and vigorous activity levels. About 16-23\% of all LGBTQ individuals were clustered into this subtype. Limited information can be understood about this subtype from the analyses and data available, but despite this group reporting more physical activity than people clustered as inactive, there were no differences found in health. This supports the evidence that moderate and vigorous activity have the best health benefits.

The Inactive (I) subtype was characterized by low physical activity. Although this subtype is at highest risk for weight-related concerns (e.g. higher BMI), this subtype included the largest proportion of transgender (29-31\%) and cisgender (29-37\%) individuals, suggested LGBTQ individuals do not only have higher BMIs, but are at risk behaviorally for negative health outcomes.

\section{Limitations}

Data for these cluster analyses were collected from a nonprobability voluntary sample of LGBTQ individuals, who provided self-reported health behaviors. The sample demographics were highly educated, with higher incomes than typically observed among LGBTQ individuals. These clusters, or at least, the proportions found, may not be consistent with nor representative of those of the general LGBTQ population. 
Additionally, the sample was large enough to run single replications for both transgender and cisgender groups, but not large enough for multiple replications, or separate analyses within gender identities. Given how differently energy balance behaviors manifest across gender, future research should cluster within gender identities.

The utilization of cluster analysis limits the ability to assess posterior cluster memberships, or measure overall model classification accuracy that might be available in other methods such as latent class analysis (LCA; e.g. Masyn, 2013), however, the utilization of cluster analyses resulted in more comprehensive subtypes. LCA would not have had the ability to capture the distinguished clusters presented in this paper.

\section{Conclusions}

Clustering is a valuable research method for assessing health subtypes. The current research captured similar physical activity patterns across LGBTQ identities. By identifying cluster subtypes, the researchers were able to compare health indicators across behavior patterns. Future research should utilize clustering as a method to understanding underlying health patterns in LGBTQ individuals. This research supports the idea that physical activity may manifest similarly across groups, regardless of minority stressors. 


\section{References}

Babbin, S. F., Velicer, W. F., Paiva, A. L., Brick, L. A. D., \& Redding, C. A. (2015). Replicating cluster subtypes for the prevention of adolescent smoking and alcohol use. Addictive behaviors, 40, 57-65.

Bauerband, L. A. and Velicer, W. F. (2017). Comparison of Health Behaviors across Gender in a Nonprobability Sample of Sexual Minority and Transgender Individuals. Unpublished Manuscript.

Booth, M. L., Ainsworth, B. E., Pratt, M., Ekelund, U., Yngve, A., Sallis, J. F., \& Oja, P. (2003). International physical activity questionnaire: 12-country reliability and validity. Med sci sports Exerc, 195(9131/03), 3508-1381.

Calzo, J. P., Roberts, A. L., Corliss, H. L., Blood, E. A., Kroshus, E., \& Austin, S. B. (2014). Physical activity disparities in heterosexual and sexual minority youth ages 12-22 years old: roles of childhood gender nonconformity and athletic selfesteem. Annals of behavioral medicine, 47(1), 17-27.

Cary, M. A., Brittain, D. R., Dinger, M. K., Ford, M. L., Cain, M., \& Sharp, T. A. (2016). Barriers to Physical Activity Among Gay Men. American journal of men's health, 10(5), 408-417.

Cleveland, M. J., Collins, L. M., Lanza, S. T., Greenberg, M. T., \& Feinberg, M. E. (2010). Does individual risk moderate the effect of contextual-level protective factors? A latent class analysis of substance use. Journal of prevention $\mathcal{E}$ intervention in the community, 38(3), 213-228.

Eliason, M. J., McElroy, J. A., Garbers, S., Radix, A., \& Barker, L. T. (2016). Comparing women with and without disabilities in five-site "Healthy Weight" interventions for lesbian/bisexual women over 40. Disability and Health Journal. 
Lathrop, R. G., \& Williams, J. E. (1989). The shape of the inverse scree test for cluster analysis. Educational and Psychological Measurement, 49(4), 827-834.

Lick, D. J., Durso, L. E., \& Johnson, K. L. (2013). Minority stress and physical health among sexual minorities. Perspectives on Psychological Science, 8(5), 521-548.

Masyn, K. E. (2013). Latent class analysis and finite mixture modeling. The Oxford handbook of quantitative methods in psychology, 2, 551-611.

Smalley, K. B., Warren, J. C., \& Barefoot, K. N. (2016). Differences in health risk behaviors across understudied LGBT subgroups. Health Psychology, 35(2), 103.

Thompson, F. E., Subar, A. F., Smith, A. F., Midthune, D., Radimer, K. L., Kahle, L. L., \& Kipnis, V. (2002). Fruit and vegetable assessment: performance of 2 new short instruments and a food frequency questionnaire. Journal of the American Dietetic Association, 102(12), 1764-1772.

Ward Jr, J. H. (1963). Hierarchical grouping to optimize an objective function. Journal of the American statistical association, 58(301), 236-244.

World Health Organization. (2010). Global recommendations on Physical Activity for health. World Health Organization. 
Table 3.1: Demographics for total sample.

\begin{tabular}{|c|c|c|c|c|}
\hline & \multicolumn{2}{|c|}{ Transgender } & \multicolumn{2}{|c|}{ Cisgender } \\
\hline & Subsample 1 & Subsample 2 & Subsample 1 & Subsample 2 \\
\hline $\mathbf{N}$ & 250 & 247 & 303 & 267 \\
\hline Age & $31.12(12.34)$ & $33 \cdot 77(12.89)$ & $33.41(11.3)$ & $31.74(11.53)$ \\
\hline \multicolumn{5}{|l|}{ Gender (\%) } \\
\hline Man & $24 \cdot 7$ & 23.5 & 28.7 & 20.6 \\
\hline Woman & 15.2 & 23.5 & 56.4 & 62.2 \\
\hline Nonbinary & 51.2 & 43.7 & $5 \cdot 3$ & $7 \cdot 5$ \\
\hline \multicolumn{5}{|l|}{ Sexual Orientation } \\
\hline Asexual & 7.6 & 8.9 & 2.9 & 3.0 \\
\hline Bisexual & 11.6 & 9.3 & 24.6 & 20.7 \\
\hline Gay/Lesbian & 10.0 & 13.4 & 46.7 & 45.2 \\
\hline Heterosexual & 5.2 & $5 \cdot 7$ & .4 & .4 \\
\hline Pansexual & 18.8 & 20.2 & 5.8 & 10.0 \\
\hline Queer & 30.8 & 27.1 & 14.5 & 17.8 \\
\hline \multicolumn{5}{|l|}{ Income } \\
\hline Unemployed, seeking work & 11.6 & 8.1 & 3 & 6 \\
\hline Less than 30,000 & 50.7 & 49.1 & 30.2 & $27 \cdot 7$ \\
\hline $30,000-49,999$ & 21.3 & 19.7 & 19.2 & 24.8 \\
\hline $50,000-79,999$ & 13.3 & $17 \cdot 9$ & 25.7 & 21.0 \\
\hline $80,000-100,000$ & 5.8 & 5.0 & 10.9 & 11.8 \\
\hline More than 10o,ooo & 8.9 & 8.3 & 14.0 & $14 \cdot 7$ \\
\hline
\end{tabular}


Table 3.2: Standard score means and standard deviations for the five clusters.

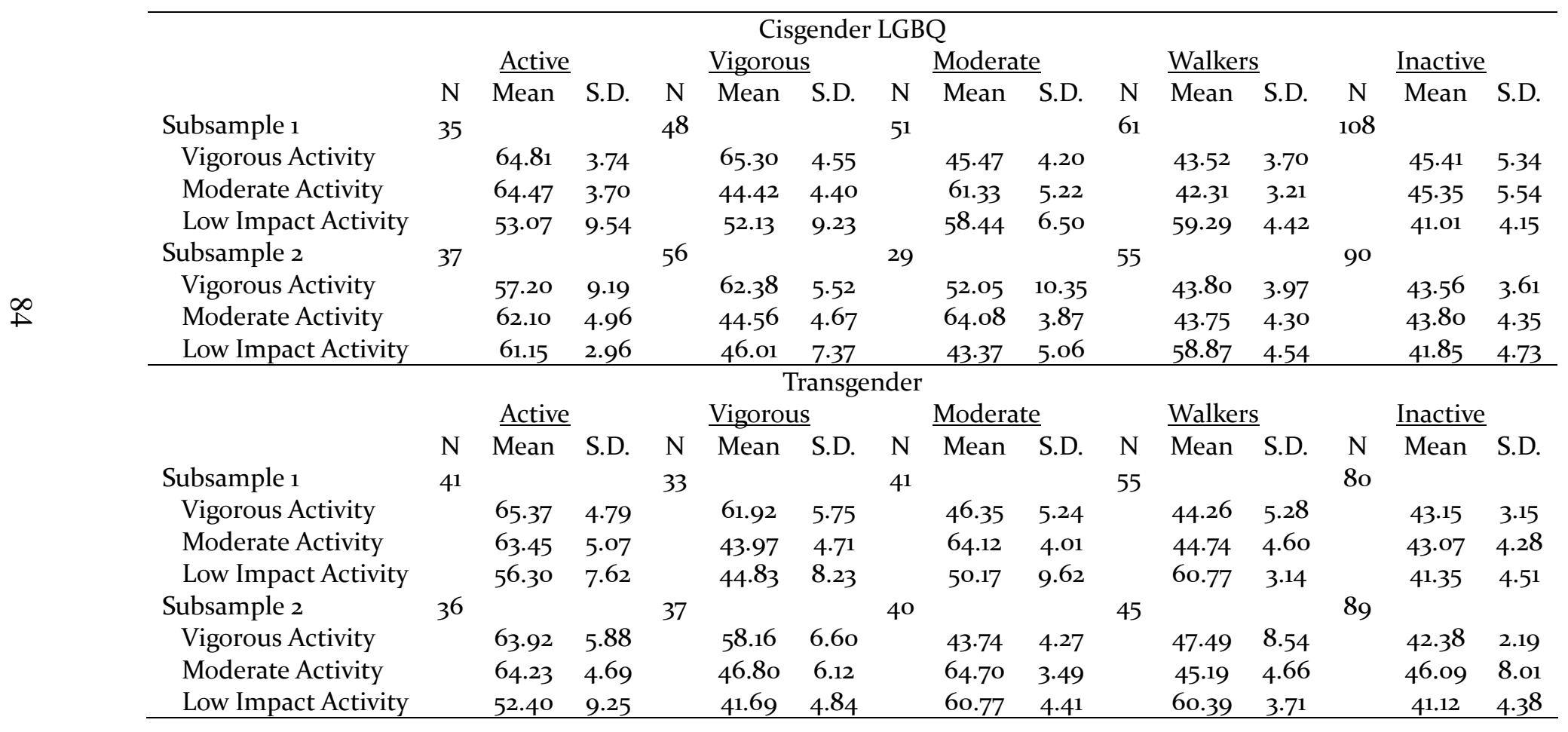


Table 3.3: Health validity analyses for clusters.

\begin{tabular}{|c|c|c|c|c|c|c|c|}
\hline \multicolumn{8}{|c|}{ Cisgender LGBQ } \\
\hline & Active $(\mathrm{N}=57)$ & Vigorous $(\mathrm{N}=73)$ & Moderate $(\mathrm{N}=60)$ & Walkers $(\mathrm{N}=89)$ & Inactive $(\mathrm{N}=152)$ & $\eta^{2}$ & Tukey HSD* \\
\hline Health rating (1-10) & $6.70(1.91)$ & $7.27(1.83)$ & $6.62(1.75)$ & $6.28(1.73)$ & $6.47(1.79)$ & .032 & $\mathrm{~V}=\mathrm{A}=\mathrm{M}>\mathrm{I}=\mathrm{LI}$ \\
\hline Stress rating & $7.14(2.16)$ & $6.70(2.06)$ & $6.33(2.42)$ & $7.16(2.09)$ & $6.86(2.06)$ & .016 & \\
\hline Manage stress & $6.00(2.54)$ & $6.34(2.19)$ & $6.48(2.03)$ & $5.54(2.31)$ & $5.93(2.08)$ & .020 & \\
\hline Lack energy (1-5) & $2.51(1.17)$ & $2.41(1.15)$ & $2.53(1.11)$ & $2.54(1.01)$ & $2.49(1.07)$ & .002 & \\
\hline BMI & $28.05(7.64)$ & $27.58(5.57)$ & $28.50(8.98)$ & $28.18(7.22)$ & $31.57(9.63)$ & .041 & $\mathrm{~V}=\mathrm{A}=\mathrm{LI}=\mathrm{M}>\mathrm{I}$ \\
\hline $\begin{array}{l}\text { Vegetable (T- } \\
\text { score) }\end{array}$ & $52.38(8.73)$ & $53.27(9.63)$ & $52.29(10.25)$ & $47.49(7.04)$ & $49.70(7.90)$ & .057 & $\mathrm{~V}=\mathrm{A}=\mathrm{M}=\mathrm{I}>\mathrm{LI}$ \\
\hline Fruit (T-score) & 52.55 (11.15) & $50.44(11.10)$ & $50.81(9.93)$ & $49.70(7.54)$ & $49.26(9.05)$ & .014 & \\
\hline \multicolumn{8}{|c|}{ Transgender } \\
\hline & Active $(\mathrm{N}=57)$ & Vigorous $(\mathrm{N}=52)$ & Moderate $(\mathrm{N}=60)$ & Walkers $(\mathrm{N}=79)$ & Inactive $(\mathrm{N}=119)$ & $\eta^{2}$ & Tukey HSD \\
\hline Health rating (1-10) & $7.02(1.84)$ & $6.92(1.79)$ & $6.53(1.97)$ & $6.11(1.65)$ & $5.92(1.68)$ & .059 & $\mathrm{~A}=\mathrm{V}>\mathrm{M}=\mathrm{LI}>\mathrm{I}$ \\
\hline Stress rating & $7.00(2.06)$ & $6.67(2.19)$ & $6.87(2.02)$ & $7.13(1.83)$ & $7.01(2.00)$ & .005 & \\
\hline Manage stress & $5.89(2.09)$ & $5.83(2.25)$ & $5.73(1.97)$ & $5.42(2.02)$ & $5.38(2.28)$ & .010 & \\
\hline Lack energy (1-5) & $2.56(1.10)$ & $2.58(1.02)$ & $2.78(1.14)$ & $2.86(1.05)$ & $2.88(1.19)$ & .014 & \\
\hline BMI & $27.01(6.55)$ & $28.28(6.84)$ & $29.80(9.84)$ & $29.54(8.59)$ & $32.05(8.81)$ & .044 & $\mathrm{~A}=\mathrm{V}=\mathrm{LI}=\mathrm{M}<\mathrm{W}$ \\
\hline Vegetable & $50.23(8.43)$ & $48.85(10.00)$ & $51.25(10.58)$ & $48.61(7.92)$ & $47.93(8.06)$ & .019 & \\
\hline Fruit & $49.44(6.92)$ & $48.34(7.27)$ & $51.10(11.01)$ & $47.68(5.42)$ & $49.72(9.11)$ & .016 & \\
\hline
\end{tabular}

+Tukey HSD analyses use Harmonic Mean Sample Size=76.08 (cisgender) and 67.11 (transgender)

$\mathrm{A}=$ Active, $\mathrm{V}=$ Vigorous, $\mathrm{M}=$ Moderate, $\mathrm{W}=$ Walkers, $\mathrm{I}=$ Inactive 
Table 3.4: Cluster membership proportions for ascribed gender groups

\begin{tabular}{lccccc}
\hline & Active & Vigorous & Moderate & Walkers & Inactive \\
\hline Trans woman & 19.8 & 10.4 & 18.8 & 19.8 & 31.3 \\
Trans man & 19.2 & 19.2 & 15.8 & 16.7 & 29.2 \\
Nonbinary & 12.9 & 11.8 & 14.7 & 23.2 & 37.5 \\
LGBQ woman & 10.1 & 18.7 & 13.6 & 20.2 & 37.4 \\
GBQ man & 16.9 & 19.0 & 14.1 & 21.1 & 28.9 \\
\hline
\end{tabular}




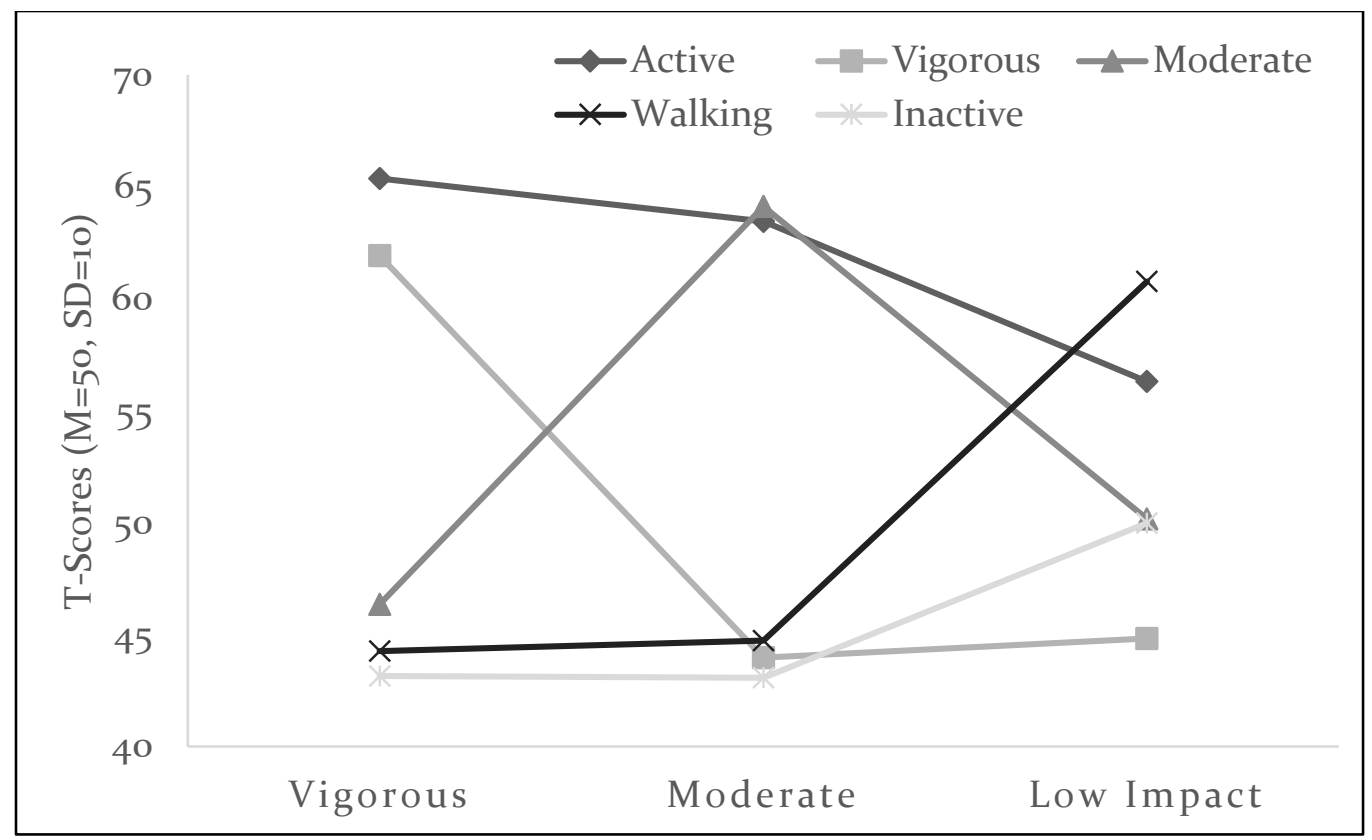

Figure 3.1: Five Cluster Subtypes for Transgender subsample $1(\mathrm{~N}=\mathbf{2 5 0})$. 


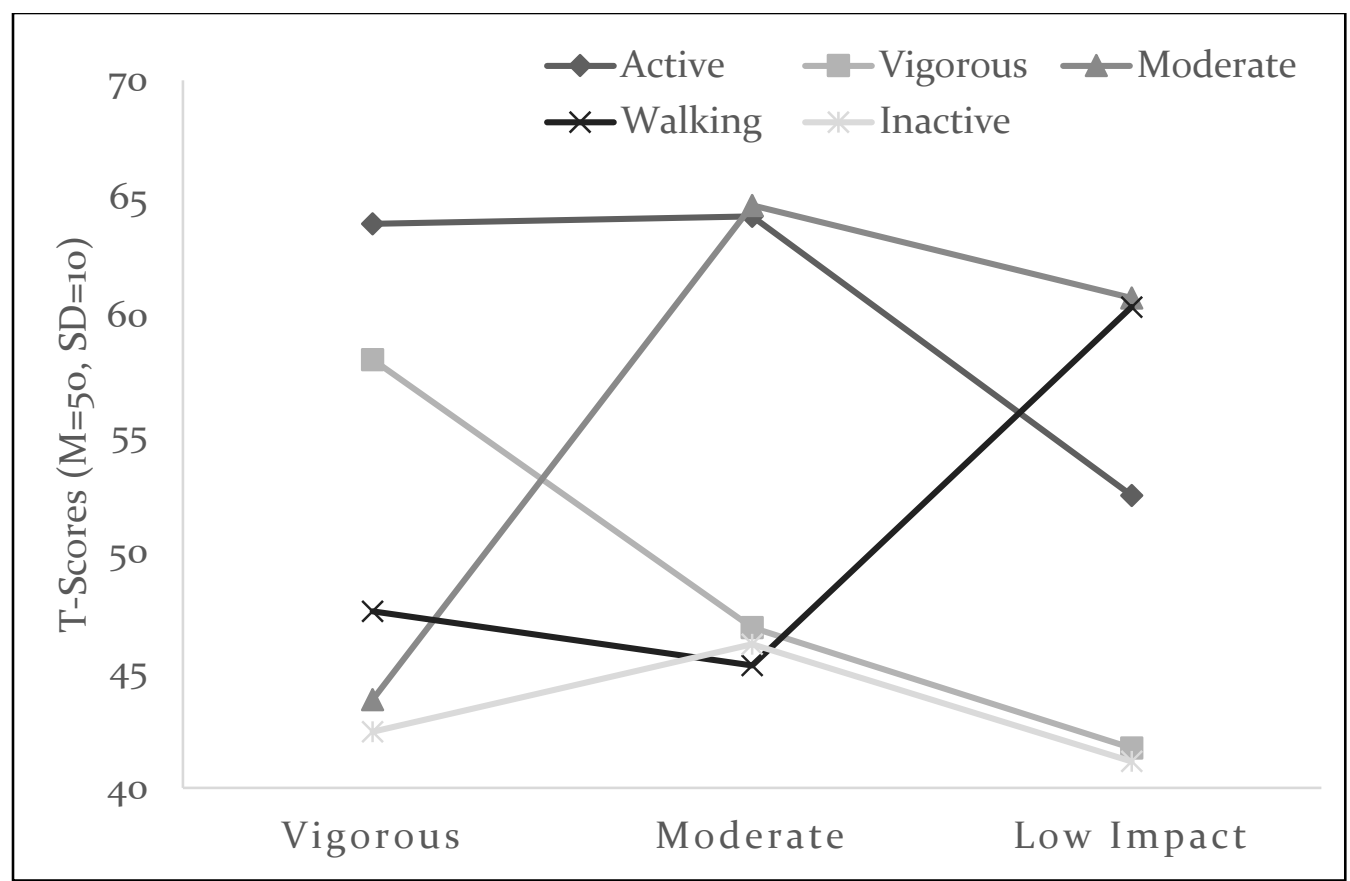

Figure 3.2: Five Cluster Subtypes for Transgender Subsample $2(\mathrm{~N}=\mathbf{2 4 7})$. 


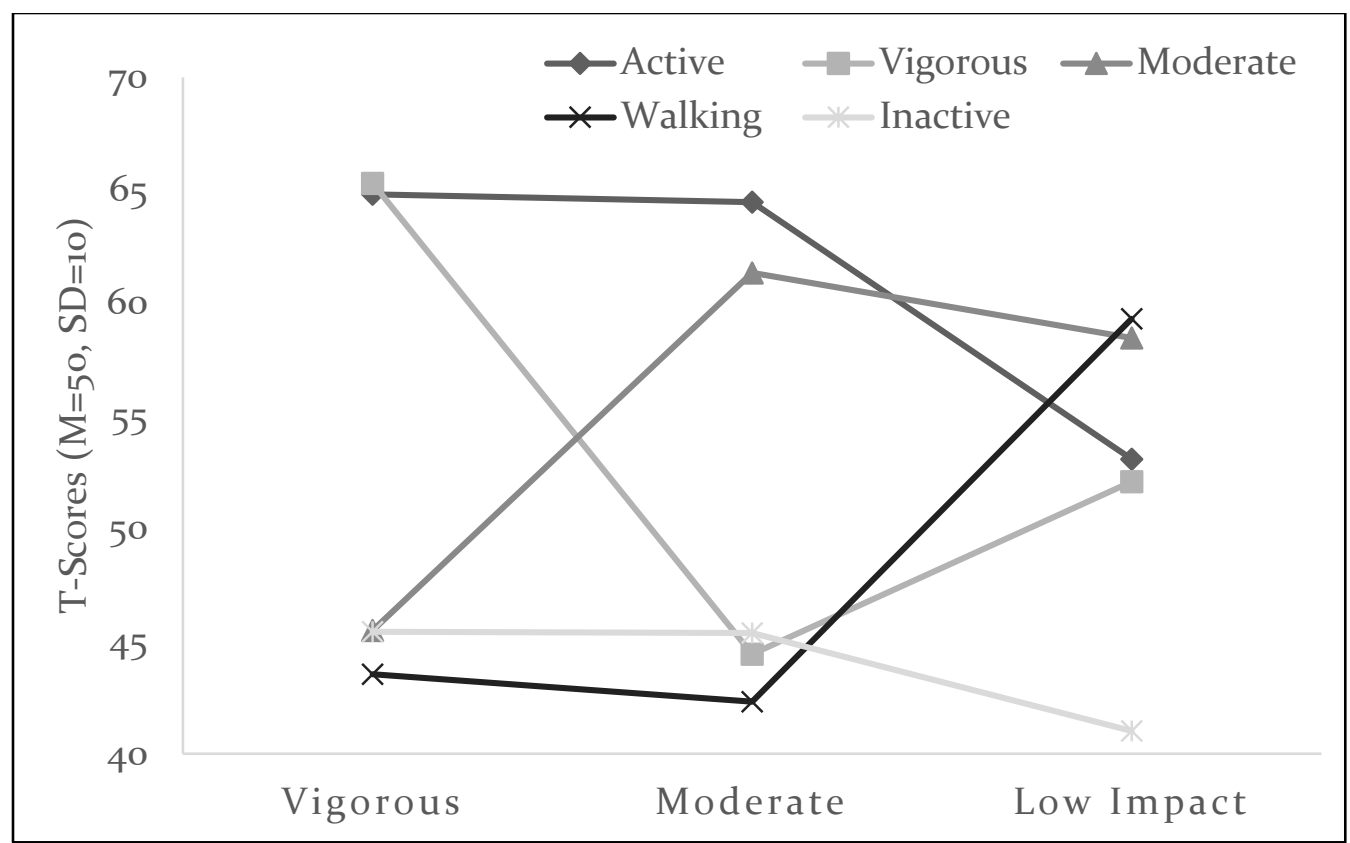

Figure 3.3: Five Cluster Subtypes for Cis LGBQ Subsample $1(\mathrm{~N}=303)$. 


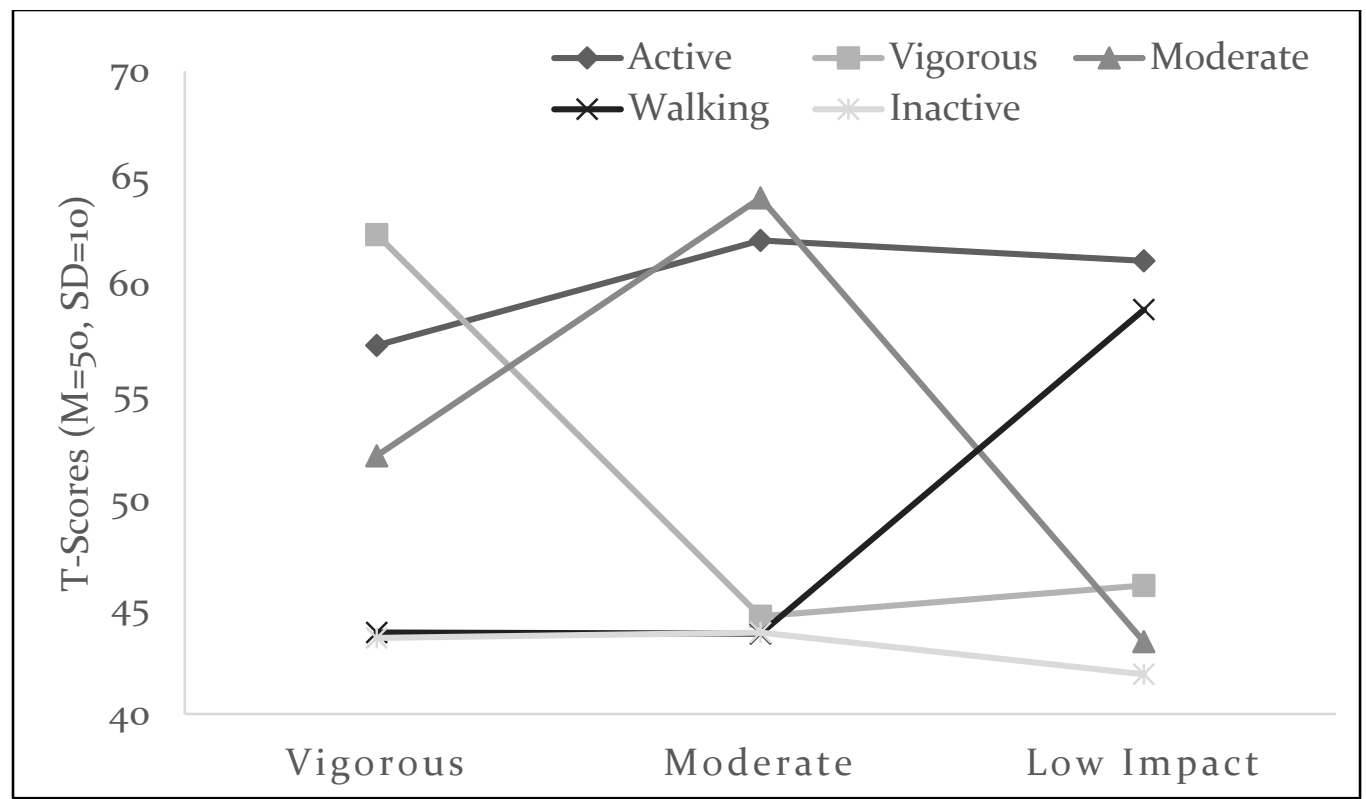

Figure 3.4: Five Cluster Subtypes for Cis LGBQ Subsample $2(\mathrm{~N}=\mathbf{2 6} 7)$. 


\section{APPENDICES}

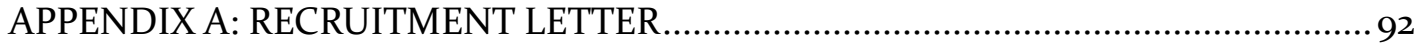

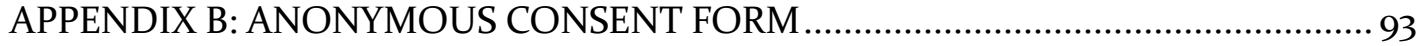

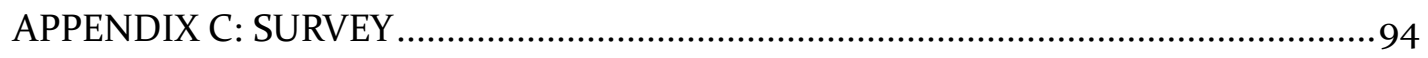

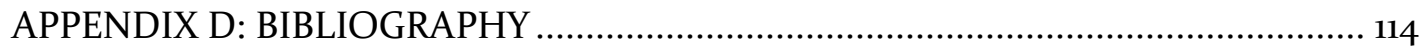




\section{APPENDIX A: RECRUITMENT LETTER}

\section{Invitation to Participate in Gender and Sexual Minority Health Survey}

My name is Loren Bauerband and I am a doctoral candidate from the University of Rhode Island (URI). I am conducting a research study to investigate health lifestyles and stress experienced by sexual and gender minorities. This study is being conducted via a completely anonymous survey, approved by URI's Institutional Review Board. If you have any questions, you can contact me (Email: lorenbauerband@gmail.com) or the Principal Investigator, Wayne Velicer in the Department of Psychology (Email: velicer@uri.edu or Phone: 401.874.4254).

Eligibility: To be eligible to complete this survey you must be over the age of 18 and identify as a sexual minority (have a sexual orientation other than heterosexual) and/or identify, or have an experience, of being a gender minority (identify or express your gender different from the gender you were assigned at birth).

The survey takes about 30-40 minutes to complete and includes questions related to health behaviors, experiences of discrimination, and stress management strategies. For each survey completed, one dollar will be donated to an LGBT non-profit organization. Once you have completed the survey, you will be able to select an organization you would like to receive one dollar.

To complete this survey, go follow this link.

Thank you! 


\section{APPENDIX B: ANONYMOUS CONSENT FORM}

\section{Health Behavior Survey}

My name is Loren Bauerband and I am a graduate student from the University of Rhode Island. I am writing to invite you to participate in my research study about health, gender and sexual minority experience, and resilience. To be eligible for this study you must be over the age of 18 and identify as a sexual minority (have a sexual orientation other than heterosexual) and/or identify, or have an experience, of being a gender minority (identify with a gender different from the gender you were assigned at birth).

If you decide to participate in this study you will be asked a series of questions about your health behaviors and experiences related to being a sexual or gender minority. This study is completely anonymous, unless you choose to give your contact information for follow-up studies.

Remember, completing these survey questions is completely voluntary and you may choose to exit the survey at any time. If you have any questions or concerns about this survey please email me at Lorenbauerband@gmail.com.

Please check all the boxes below that are true for you:

I identify as a sexual minority and/or have same-gender sexual attraction. (I am not heterosexual)

I identify as transgender and/or have a gender identity different from my gender assigned at birth.

By selecting to "begin survey", below, you understand that your participation is completely voluntary and you can exit the survey at any time.

Begin survey 


\section{APPENDIX C: SURVEY}

\section{International Physical Activity Questionnaire}

1. During the last 7 days, on how many days did you do vigorous physical activities like heavy lifting, digging, aerobics, or fast bicycling?

2. How much time did you usually spend doing vigorous physical activities on one of those days? Please enter time in minutes.

3. Think about all the moderate activities that you did in the last 7 days. Moderate activities refer to activities that take moderate physical effort and make you breathe somewhat harder than normal. Think only about those physical activities that you did for at least 10 minutes at a time. During the last 7 days, on how many days did you do moderate physical activities like carrying light loads, bicycling at a regular pace, or doubles tennis? Do not include walking.

4. How much time did you usually spend doing moderate physical activities on one of those days? Please enter time in minutes.

5. Think about the time you spent walking in the last 7 days. This includes at work and at home, walking to travel from place to place, and any other walking that you might do solely for recreation, sport, exercise, or leisure. During the last 7 days, on how many days did you walk for at least 10 minutes at a time?

6. How much time did you usually spend walking on one of those days? Please enter time in minutes.

7. The last question is about the time you spent sitting on week days during the last 7 days. Include time spent at work, at home, while doing course work and during leisure time. This may include time spent sitting at a desk, visiting friends, reading, or sitting or lying down to watch television. During the last 7 days, how much time did you spend sitting on a week day? Please enter your time in minutes. 


\section{Quick Food Scan}

Think about what you usually ate last month. Please think about all the fruits and vegetables that you ate last month. Include those that were:

- Raw and cooked

- Eaten as snacks and at meals

- Eaten at home and away from home (restaurants, friends, take-out)

- Eaten alone and mixed with other foods.

Report how many times per month, week, or day you ate each food, and if you ate it, how much you usually had. If you mark "Never" for a question, follow the "Go to" instruction.

Over the last month, how many times per month, week, or day did you drink $100 \%$ juice such as orange, apple, grape, or grapefruit juice? Do not count fruit drinks like Kool-Aid, lemonade, Hi-C, cranberry juice drink, Tang, and Twister. Include juice you drank at all mealtimes and between meals.

$\begin{array}{ll}\text { Never (Go to question 2) } & 1 \text { time per day } \\ 1-3 \text { times last month } & 2 \text { times per day } \\ \text { 1-2 times per week } & 3 \text { times per day } \\ \text { 3-4 times per week } & 4 \text { times per day } \\ 5-6 \text { times per week } & 5 \text { or more times per day }\end{array}$

1a. Each time you drank $100 \%$ juice, how much did you usually drink?

Less than 3/4 cup (less than 6 ounces)

$3 / 4$ to $11 / 4$ cup (6-10 ounces)

$11 / 4$ to 2 cups (10-16 ounces)

More than 2 cups (more than 16 ounces)

2. Over the last month, how many times per month, week, or day did you eat fruit?

Count any kind of fruit-fresh, canned, and frozen. Do not count juices. Include fruit you ate at all mealtimes and for snacks.
Never (Go to Question 3)
1-3 times last month
1-2 times per week
1 time per day
3-4 times per week
2 times per day
3 times per day
5-6 times per week
4 times per day
5 times per day

2a. Each time you ate fruit, how much did you usually eat?

Less than 1 medium fruit OR Less than $1 / 2$ cup

1 medium fruit OR about $1 / 2$ cup

2 medium fruits OR about 1 cup

More than 2 medium fruits OR More than 1 cup 
3. Over the last month, how often did you eat lettuce salad (with or without other vegetables)?

$\begin{array}{ll}\text { Never (Go to Question 4) } & 1 \text { time per day } \\ 1-3 \text { times last month } & 2 \text { times per day } \\ 1-2 \text { times per week } & 3 \text { times per day } \\ \text { 3-4 times per week } & 4 \text { times per day } \\ 5-6 \text { times per week } & 5 \text { or more times per day }\end{array}$

3a. Each time you ate lettuce salad, how much did you usually eat?

About $1 / 2$ cup

About 1 cup

About 2 cups

More than 2 cups

4. Over the last month, how often did you eat French fries or fried potatoes?

Never (Go to Question 5)

1-3 times last month

1-2 times per week

3-4 times per week

5-6 times per week
1 time per day

2 times per day

3 times per day

4 times per day

5 or more times per day

4a. Each time you ate French Fries of fried potatoes how much did you eat?

Small order or less (1 cup or less)

Medium order (1 $1 / 2$ cup or less)

Large order (About 2 cups)

Super size order (About 3 cups or more)

5. Over the last month, how often did you eat other white potatoes? Count baked,

boiled, and mashed potatoes, potato salad, and white potatoes that were not fried.

Never (Go to Question 6)

1-3 times last month

1-2 times per week

3-4 times per week

5-6 times per week

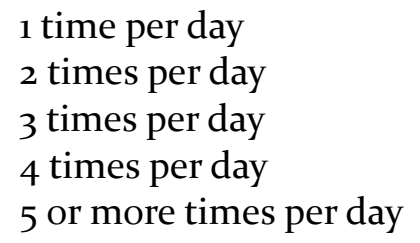

5a. Each time you ate these potatoes how much did you eat?

1 small potato or less ( $1 / 2$ cup or less)

1 medium potato ( $1 / 2$ cup to 1 cup)

1 large potato (1 cup to $11 / 2$ cup)

2 medium potatoes or more ( $11 / 2$ cups or more)

6. Over the last month, how often did you eat cooked dried beans? Count baked beans, bean soup, refried beans, pork and beans and other bean dishes?

Never (Go to Question 7)

1-3 times last month

1-2 times per week

3-4 times per week

5-6 times per week
1 time per day

2 times per day

3 times per day

4 times per day

5 or more times per da 
6a. Each time you ate these beans, how much did you eat?
$1 / 2$ cup or less
$1 / 2$ cup to 1 cup
1 cup to $11 / 2$ cup
$11 / 2$ cup or more

7. Over the last month, how often did you eat other vegetables?
Never (Go to Question 8)
1-3 times last month
1-2 times per week
1 time per day
3-4 times per week
2 times per day
3 times per day
5-6 times per week
4 times per day
5 or more times per day

7a. Each time you ate these vegetables, how much did you usually eat?

Less than $1 / 2$ cup

$1 / 2$ cup to 1 cup

1 to 2 cups

More than 2 cups

8. Over the last month, how often did you eat tomato sauce? Include tomato sauce on pasta or macaroni, rice, pizza and other dishes?

$\begin{array}{ll}\text { Never (Go to Question 9) } & 1 \text { time per day } \\ 1-3 \text { times last month } & 2 \text { times per day } \\ 1-2 \text { times per week } & 3 \text { times per day } \\ \text { 3-4 times per week } & 4 \text { times per day } \\ 5-6 \text { times per week } & 5 \text { or more times per day }\end{array}$

8a. Each time you ate tomato sauce, how much did you eat?
About $1 / 4$ cup
About $1 / 2$ cup
About 1 cup
More than 1 cup

9. Over the last month, how often did you eat vegetable soups? Include tomato soup, gazpacho, beef with vegetable soup, minestrone soup, and other soups made with vegetables?
Never (Go to Question 10)
1 time per day
1-3 times last month
1-2 times per week
2 times per day
3-4 times per week
3 times per day
5-6 times per week
4 times per day
5 or more times per day

9a. Each time you ate vegetable soup, about how much did you usually eat?

Less than 1 cup

1 to 2 cups

2 to 3 cups

More than 3 cups 
10. Over the last month, how often did you eat mixtures that included vegetables? Count such foods as sandwiches, casseroles, stews, stir-fry, omelets, and tacos.

Never

1-3 times last month

1-2 times per week

3-4 times per week

5-6 times per week
1 time per day

2 times per day

3 times per day

4 times per day

5 or more times per day 


\section{Smoking}

The following questions ask about your current and past history with smoking.

Have you smoked at least 100 cigarettes in your life?

- Yes

- No

Do you use electronic cigarettes? The electronic cigarette (e-cigarette) is a device that looks like a cigarette or cigar, with a battery and an electronic system that produces a vapor that often contains nicotine.

- No

- No, but I used to

- Yes, I use them from time-to-time

- Yes, I use electronic cigarettes daily

Are you currently a cigarette smoker?

- Yes

- No, I quit within the last 3 months

- No, I quit within the last year

- No, I have not smoked in a year or more

- No, I have never smoked

How old were you when you first started smoking regularly?

In the last 30 days, how often have you smoked?

- Every day

- More than 15 days

- Less than 15 days

- I have not had a cigarette in 30 days

How soon after waking do you smoke your first cigarette?

- Within 5 minutes

- Within 5-30 minutes

- Within 31-6o minutes

- After 6o minutes

- Not Applicable

On average, how many cigarettes do you smoke a day? (Please skip or mark "o" if you do not currently smoke) 


\section{Alcohol Use Disorders Identification Test (AUDIT)}

The following questions are all about your use of alcohol. Your answers to these questions will only be used to understand how drinking is related to other health behaviors. Please be honest with your responses.

How often do you have a drink containing alcohol?

- Never

- Monthly or less

- 2-4 times a month

- 2-3 times a week

- 4 or more times a week

How many drinks containing alcohol do you have on a typical day when you are drinking?

- 1 or 2

- 3 or 4

- 5 or 6

- 7 to 9

- 10 or more

- N/a

How often do you have six or more drinks on one occasion?

- Never

- Less than monthly

- Monthly

- Weekly

- Daily or almost daily

How often during the last year have you found that you were not able to stop drinking once you started?

- Never

- Less than monthly

- Monthly

- Weekly

- Daily or almost daily 
How often during the last year have you failed to do what was normally expected of you because you were drinking?

- Never

- Less than monthly

- Monthly

- Weekly

- Daily or almost daily

How often during the last year have you needed a first drink in the morning to get yourself going after a heavy drinking session?

- Never

- Less than monthly

- Monthly

- Weekly

- Daily or almost daily

How often during the last year have you had a feeling of guilt or remorse after drinking?

- Never

- Less than monthly

- Monthly

- Weekly

- Daily or almost daily

How often during the last year have you been unable to remember what happened the night before because you were drinking?

- Never

- Less than monthly

- Monthly

- Weekly

- Daily or almost daily

Have you or someone else been injured because of your drinking?

- No

- Yes, but not in the last year

- Yes, during the last year 
Has a relative, friend, doctor, or other health care worker been concerned about your drinking or suggested you cut down?

- No

- yes, but not in the last year

- Yes, during the last year 


\section{What is your current relationship status?}

- Single- not sexually active in the last 6 months

- Single - sexually active in the last 6 months

- Asexual (or otherwise non-sexual relationship)

- Monogamous (both you and your partner) - less than 6 months

- Monogamous (both you and your partner) - 6 months or longer

- Polyamorous relationship (you and/or your partner are sexually active with other people)

- Other

\section{Sexual Activity}

The following questions will ask you about your sexual behavior. Sex can sometimes be sensitive or hard to talk about, especially for transgender and gender non-conforming people because not everyone uses the same words or names to talk about their body parts. This makes it hard for us to ask questions about sex that everyone who is participating in this study can relate to.

In this survey, we use the medical words that refer to your specific anatomy - words like penis, anus, and vagina. These may not be the words you use. We do not want to disrespect you, or cause you feelings of dysphoria or unease. For the purpose of this research project, it is important that we use words that are clear so that everyone understands what question we are asking.

How many individuals have you had any form of sexual contact with in the last 6 months? This includes mutual masturbation (sex with hands), oral sex, vaginal sex, anal sex, and sex using toys.

Of those sexual partners, how many did you have vaginal and/or anal sex with? This does not include sex using toys.

Of those sexual partners that you had vaginal and/or anal sex with, how many partners did you have unprotected vaginal or anal sex with (sex without a condom or other physical barrier method)?

How many times, in the last 6 months, did you have sexual contact when you or your partner were under the influence of alcohol or drugs? 


\section{General Health Questions}

On a scale from 1-10, please rate your ability to effectively manage your stress over the last month? ( $1=$ very poor, $10=$ Excellent $)$

On a scale from 1-10, how would you rate your overall health? $(1=$ very poor, $10=$ Excellent)

On a scale from 1-10, how stressed have you felt in the last month? (1= not stressed at all, $10=$ completely stressed)

In the past week, how many days did you wake up feeling rested when you started your day?

In the past week, how often did you feel too tired, or lack the energy to complete daily activities?

- Never

- Sometimes

- About half the time

- Most of the time

- All the time

We asked you about several questions related to your lifestyle. Are there any behaviors you would like to change? Below we have listed several behavior changes. Please select all the behaviors you would like to make.

Increase physical activity (e.g. learn to run, walk more, etc.)

Eat more fruits and vegetables

Reduce fat or calories in diet

Cook more/ Eat out less

Decrease alcohol consumption

Quit/ Reduce frequency of smoking

Use protection when having sex

Improve Stress Management

Get more sleep/ Improve quality of sleep

I do not want to change any of my health behaviors

Other

OPTIONAL: When it comes to your health is there anything else we didn't ask, that you would have liked included or want to share? 


\section{Depression, Anxiety, and Stress Scale}

Please read each statement and circle a number $0,1,2$ or 3 that indicates how much the statement applied to you over the past week. There are no right or wrong answers. Do not spend too much time on any statement. The rating scale is as follows:

o Did not apply to me at all

11 Applied to me to some degree, or some of the time

22 Applied to me to a considerable degree, or a good part of time

33 Applied to me very much, or most of the time

Please rate:

I found it hard to wind down

I was aware of dryness of my mouth

I couldn't seem to experience any positive feeling at all

I experienced breathing difficulty (Eg, excessively rapid breathing, breathlessness in the absence of physical exertion)

I found it difficult to work up the initiative to do things

I tended to over-react to situations

I experienced trembling (eg, in the hands)

I felt that I was using a lot of nervous energy

I was worried about situations in which I might panic and make a fool of myself

I felt that I had nothing to look forward to

I found myself getting agitated

I found it difficult to relax

I felt down-hearted and blue

I was intolerant of anything that kept me from getting on with what I was doing

I felt I was close to panic

I was unable to become enthusiastic about anything

I felt I wasn't worth much as a person

I felt that I was rather touchy

I was aware of the action of my heart in the absence of physical exertion (eg. sense of heart rate increase, heart missing a beat)

I felt scared without any good reason

I felt that life was meaningless 


\section{Experiences of Discrimination}

The next set of questions ask you about experiences you have encountered and how you have responded to these experiences. For these questions, we want to know about experiences that have happened in the last 6 months. Please rate the items carefully and respond truthfully.

In the past 6 months, how often did any of the following things happen to you?

\begin{tabular}{|c|c|c|c|c|c|}
\hline & Never & $\begin{array}{l}\text { Once } \\
\text { or } \\
\text { twice }\end{array}$ & $\begin{array}{l}\text { At least } \\
\text { once a } \\
\text { month }\end{array}$ & $\begin{array}{l}\text { Often/ On a } \\
\text { weekly basis }\end{array}$ & Everyday \\
\hline $\begin{array}{l}\text { You were treated with less } \\
\text { courtesy than other people } \\
\text { are }\end{array}$ & 0 & 0 & 0 & 0 & 0 \\
\hline $\begin{array}{l}\text { You were treated with less } \\
\text { respect than other people } \\
\text { are }\end{array}$ & 0 & 0 & 0 & 0 & 0 \\
\hline $\begin{array}{l}\text { You received poorer service } \\
\text { than other people at } \\
\text { restaurants or stores }\end{array}$ & 0 & 0 & 0 & 0 & 0 \\
\hline $\begin{array}{l}\text { People acted as if they think } \\
\text { you are not smart }\end{array}$ & 0 & 0 & 0 & 0 & 0 \\
\hline $\begin{array}{l}\text { People acted as if they are } \\
\text { afraid of you }\end{array}$ & 0 & 0 & 0 & $\mathrm{O}$ & 0 \\
\hline $\begin{array}{l}\text { People acted as if they think } \\
\text { you are dishonest }\end{array}$ & 0 & 0 & 0 & 0 & 0 \\
\hline $\begin{array}{l}\text { People acted as if they're } \\
\text { better than you are }\end{array}$ & 0 & 0 & 0 & 0 & 0 \\
\hline $\begin{array}{l}\text { You were called names or } \\
\text { insulted }\end{array}$ & O & 0 & O & 0 & 0 \\
\hline $\begin{array}{l}\text { You were threatened or } \\
\text { harassed }\end{array}$ & 0 & O & 0 & 0 & 0 \\
\hline
\end{tabular}




\section{Discrimination-Related Vigilance}

In dealing with these day-to-day experiences that you just told me about, how often do you:

\begin{tabular}{|c|c|c|c|c|c|}
\hline & Never & $\begin{array}{c}\text { Hardly } \\
\text { Ever }\end{array}$ & $\begin{array}{c}\text { Not too } \\
\text { often }\end{array}$ & $\begin{array}{l}\text { Fairly } \\
\text { often }\end{array}$ & $\begin{array}{l}\text { Very } \\
\text { often }\end{array}$ \\
\hline $\begin{array}{c}\text { Think in advance about the kinds of problems you are likely } \\
\text { to experience? }\end{array}$ & $\mathrm{O}$ & $\mathrm{O}$ & $\mathrm{O}$ & $\mathrm{O}$ & $\mathrm{O}$ \\
\hline Try to prepare for possible insults before leaving home? & $\mathrm{O}$ & $\mathrm{O}$ & $\mathrm{O}$ & $\mathrm{O}$ & $\mathrm{O}$ \\
\hline $\begin{array}{l}\text { Feel that you always have to be very careful about your } \\
\text { appearance to get good service or avoid being harassed? }\end{array}$ & O & $\mathrm{O}$ & $\mathrm{O}$ & $\mathrm{O}$ & $\mathrm{O}$ \\
\hline Carefully watch what you say and how you say it? & $\mathrm{O}$ & $\mathrm{O}$ & $\mathrm{O}$ & $\mathrm{O}$ & $\mathrm{O}$ \\
\hline Carefully observe what happens around you? & $\mathrm{O}$ & $\mathrm{O}$ & $\mathrm{O}$ & O & $\mathrm{O}$ \\
\hline Try to avoid certain social situations and places? & $\mathrm{O}$ & $\mathrm{O}$ & $\mathrm{O}$ & $\mathrm{O}$ & $\mathrm{O}$ \\
\hline
\end{tabular}




\section{School Age Victimization}

The following statements are related to experiences you faced while you were in school (think about middle and high school) as a result of your sexual orientation, gender identity and/or gender expression.

For the purpose of these questions, gender identity refers to the gender you identify with and gender presentation refers to your physical appearance (clothing, hairstyle, etc.) and presentation of typical masculine and feminine perceived behaviors.

For each statement, please rate how frequently these happened when you were school age (roughly age 11-17):

\begin{tabular}{|c|c|c|c|c|c|}
\hline & Never & $\begin{array}{l}\text { Once or } \\
\text { twice } \\
\text { only }\end{array}$ & $\begin{array}{l}\text { Every once } \\
\text { in awhile }\end{array}$ & $\begin{array}{l}\text { On a } \\
\text { regular } \\
\text { basis }\end{array}$ & Frequently \\
\hline $\begin{array}{l}\text { I was rejected or made to feel unwelcome } \\
\text { by a religious community }\end{array}$ & $\mathrm{O}$ & $\mathrm{O}$ & $\mathrm{O}$ & O & $\mathrm{O}$ \\
\hline $\begin{array}{l}\text { I was rejected or made to feel unwelcome } \\
\text { in my ethnic/racial community }\end{array}$ & O & O & O & O & O \\
\hline $\begin{array}{c}\text { I was rejected or made to feel unwelcome } \\
\text { in extracurricular activities (clubs, sports } \\
\text { teams, etc.) }\end{array}$ & $\mathrm{O}$ & $\mathrm{O}$ & O & O & $\mathrm{O}$ \\
\hline I was rejected or distanced from family & $\mathrm{O}$ & $\mathrm{O}$ & $\mathrm{O}$ & $\mathrm{O}$ & $\mathrm{O}$ \\
\hline $\begin{array}{l}\text { I was verbally harassed or teased (For } \\
\text { example, being called "it") }\end{array}$ & O & O & O & O & $\mathrm{O}$ \\
\hline $\begin{array}{l}\text { I was threatened with being outed or } \\
\text { blackmailed }\end{array}$ & O & O & O & O & O \\
\hline My personal property was damaged & $\mathrm{O}$ & $\mathrm{O}$ & O & $\mathrm{O}$ & $\mathrm{O}$ \\
\hline I was threatened with physical harm & $\mathrm{O}$ & $\mathrm{O}$ & $\mathrm{O}$ & O & $\mathrm{O}$ \\
\hline $\begin{array}{l}\text { I was pushed, shoved, hit, or had } \\
\text { something thrown at me }\end{array}$ & O & $\mathrm{O}$ & O & O & $\mathrm{O}$ \\
\hline $\begin{array}{l}\text { I had sexual contact with someone against } \\
\text { my will }\end{array}$ & O & O & O & O & O \\
\hline I was rejected or distanced from friends & $\mathrm{O}$ & $\mathrm{O}$ & O & O & $\mathrm{O}$ \\
\hline
\end{tabular}




\section{Coping with Stress}

Everyone experiences stress. These items deal with ways you've been coping with the stress in your life. Each item says something about a particular way of coping. I want to know to what extent you've been doing what the item says. Don't answer on the basis of whether it helps or not - just whether or not you are doing it. Try to rate each item separately in your mind from the others. Make your answers as true FOR YOU as you can. In the last 6 months:

\begin{tabular}{|c|c|c|c|c|}
\hline & Never & $\begin{array}{l}\text { I did this a } \\
\text { little bit }\end{array}$ & $\begin{array}{l}\text { I did this a } \\
\text { medium amount }\end{array}$ & $\begin{array}{l}\text { I did this } \\
\text { a lot }\end{array}$ \\
\hline $\begin{array}{l}\text { I turned to work or other activities to take my mind off } \\
\text { things }\end{array}$ & O & O & $\mathrm{O}$ & $\mathrm{O}$ \\
\hline $\begin{array}{l}\text { I concentrated my efforts on doing something about the } \\
\text { stress in my life }\end{array}$ & $\mathrm{O}$ & O & $\mathrm{O}$ & $\mathrm{O}$ \\
\hline I said to myself "this isn't real" & O & $\mathrm{O}$ & $\mathrm{O}$ & $\mathrm{O}$ \\
\hline I used alcohol or other drugs to make myself feel better & $\mathrm{O}$ & $\mathrm{O}$ & $\mathrm{O}$ & $\mathrm{O}$ \\
\hline I gave up trying to deal with my stress & O & $\mathrm{O}$ & O & $\mathrm{O}$ \\
\hline I took action to try to make the situation better & $\mathrm{O}$ & $\mathrm{O}$ & O & $\mathrm{O}$ \\
\hline I refused to believe that my stress was happening & $\mathrm{O}$ & $\mathrm{O}$ & $\mathrm{O}$ & $\mathrm{O}$ \\
\hline I said things to let my unpleasant feelings escape & O & O & O & $\mathrm{O}$ \\
\hline I got help and advice from other people & $\mathrm{O}$ & $\mathrm{O}$ & $\mathrm{O}$ & $\mathrm{O}$ \\
\hline I used alcohol or other drugs to help me get through & O & $\mathrm{O}$ & $\mathrm{O}$ & $\mathrm{O}$ \\
\hline $\begin{array}{l}\text { I tried to see things in a different light, to make it seem more } \\
\text { positive }\end{array}$ & $\mathrm{O}$ & O & $\mathrm{O}$ & O \\
\hline I criticized myself & O & $\mathrm{O}$ & $\mathrm{O}$ & $\mathrm{O}$ \\
\hline I tried to come up with a strategy about what to do & O & $\mathrm{O}$ & $\mathrm{O}$ & $\mathrm{O}$ \\
\hline I received comfort and understanding from someone & $\mathrm{O}$ & $\mathrm{O}$ & $\mathrm{O}$ & O \\
\hline I gave up attempting to cope & $\mathrm{O}$ & $\mathrm{O}$ & O & O \\
\hline I looked for something good in the stress I was experiencing & O & $\mathrm{O}$ & O & $\mathrm{O}$ \\
\hline I made jokes about my struggles or stress & $\mathrm{O}$ & $\mathrm{O}$ & $\mathrm{O}$ & $\mathrm{O}$ \\
\hline I did something good in the stress I was experiencing & $\mathrm{O}$ & $\mathrm{O}$ & O & O \\
\hline $\begin{array}{l}\text { I did something to think about it less, such as go to the } \\
\text { movies, watch TV, read, daydream, sleep or shop }\end{array}$ & $\mathrm{O}$ & O & $\mathrm{O}$ & $\mathrm{O}$ \\
\hline I accepted the reality of my situation & $\mathrm{O}$ & O & O & $\mathrm{O}$ \\
\hline I expressed my negative feelings & $\mathrm{O}$ & $\mathrm{O}$ & O & O \\
\hline I tried to find comfort in my spiritual beliefs & $\mathrm{O}$ & $\mathrm{O}$ & $\mathrm{O}$ & $\mathrm{O}$ \\
\hline $\begin{array}{l}\text { I tried to get advice or help from other people about what to } \\
\text { do }\end{array}$ & $\mathrm{O}$ & O & O & $\mathrm{O}$ \\
\hline I worked on learning to live with it & $\mathrm{O}$ & O & $\mathrm{O}$ & $\mathrm{O}$ \\
\hline I thought hard about what steps to take & $\mathrm{O}$ & $\mathrm{O}$ & $\mathrm{O}$ & O \\
\hline I blamed myself for things in my life & $\mathrm{O}$ & O & O & O \\
\hline I meditated & O & O & $\mathrm{O}$ & $\mathrm{O}$ \\
\hline I made fun of my situation & $\mathrm{O}$ & $\mathrm{O}$ & O & $\mathrm{O}$ \\
\hline
\end{tabular}




\section{Perceived Stress Scale}

The questions below ask you about your feelings and thoughts during the last month. In each case, you will be asked to indicate by selecting how often you felt or thought a certain way. In the last month..

\begin{tabular}{|c|c|c|c|c|c|}
\hline & Never & $\begin{array}{c}\text { Almost } \\
\text { never }\end{array}$ & Sometimes & $\begin{array}{l}\text { Fairly } \\
\text { often }\end{array}$ & $\begin{array}{l}\text { All the } \\
\text { time }\end{array}$ \\
\hline $\begin{array}{l}\text { How often have you been upset because of } \\
\text { something that happened unexpectedly? }\end{array}$ & O & $\mathrm{O}$ & $\mathrm{O}$ & O & $\mathrm{O}$ \\
\hline $\begin{array}{l}\text { How often have you felt that you were unable to } \\
\text { control the important things in your life? }\end{array}$ & O & O & $\mathrm{O}$ & O & $\mathrm{O}$ \\
\hline How often have you felt nervous and "stressed"? & O & O & O & O & $\mathrm{O}$ \\
\hline $\begin{array}{l}\text { How often have you felt confident about your } \\
\text { ability to handle your personal problems? }\end{array}$ & O & O & O & $\mathrm{O}$ & $\mathrm{O}$ \\
\hline $\begin{array}{c}\text { How often have you felt that things were going } \\
\text { your way? }\end{array}$ & O & $\mathrm{O}$ & O & $\mathrm{O}$ & $\mathrm{O}$ \\
\hline $\begin{array}{l}\text { How often have you found that you could not } \\
\text { cope with all the things that you had to do? }\end{array}$ & O & O & O & $\mathrm{O}$ & O \\
\hline $\begin{array}{l}\text { How often have you been able to control } \\
\text { irritations in your life? }\end{array}$ & O & O & O & $\mathrm{O}$ & $\mathrm{O}$ \\
\hline $\begin{array}{c}\text { How often have you felt that you were on top of } \\
\text { things? }\end{array}$ & O & O & O & O & O \\
\hline $\begin{array}{l}\text { How often have you angered because of things } \\
\text { that were outside of your control? }\end{array}$ & O & O & O & $\mathrm{O}$ & O \\
\hline $\begin{array}{l}\text { How often have you felt difficulties were piling } \\
\text { up so high that you could not overcome them? }\end{array}$ & 0 & O & O & O & O \\
\hline
\end{tabular}




\section{Demographic Questions}

You have completed the primary survey questions. The remainder of the questions are to help us understand more about who you are. All items are optional, but please be as honest as you can - this information helps us understand who responded to this survey. Please leave any question blank that you feel uncomfortable answering.

Select your primary gender identity (check all):

Man

Woman

Nonbinary

Below is a list of terms people have used to describe their identity. Some of these labels may be offensive of not applicable to you. Please rate the extent you identify with each of the terms listed below. ( o - Not at all, 5 - Completely)

\begin{tabular}{|c|c|c|c|c|c|c|}
\hline Masculine & 0 & 1 & 2 & 3 & 4 & 5 \\
\hline Genderqueer & 0 & 0 & 0 & 0 & 0 & 0 \\
Transwoman & 0 & 0 & 0 & 0 & 0 & 0 \\
Transman & 0 & 0 & 0 & 0 & 0 & 0 \\
Agender & 0 & 0 & 0 & 0 & 0 & 0 \\
Androgynous & 0 & 0 & 0 & 0 & 0 & 0 \\
Cisgender & 0 & 0 & 0 & 0 & 0 & 0 \\
Genderfluid & 0 & 0 & 0 & 0 & 0 & 0 \\
FTM & 0 & 0 & 0 & 0 & 0 & 0 \\
Bigender & 0 & 0 & 0 & 0 & 0 & 0 \\
Transsexual & 0 & 0 & 0 & 0 & 0 & 0 \\
MTF & 0 & 0 & 0 & 0 & 0 & 0 \\
Queer & 0 & 0 & 0 & 0 & 0 & 0 \\
Feminine & 0 & 0 & 0 & 0 & 0 & 0 \\
Nonbinary & 0 & 0 & 0 & 0 & 0 & 0 \\
Crossdresser & 0 & 0 & 0 & 0 & 0 & 0 \\
Transgender & 0 & 0 & 0 & 0 & 0 & 0 \\
& 0 & 0 & 0 & 0 & 0 & 0 \\
\hline
\end{tabular}

Please list any additional terms you use to describe your gender. 
What sex were you assigned at birth? (remember all questions are optional)

- Male

- Female

- Other

Please select the term that BEST describes your sexual orientation

- Asexual

- Bisexual

- Gay/Lesbian

- Heterosexual

- Pansexual

- Queer

- Other

OPTIONAL: The sexual orientation categories listed above are not inclusive and may hold different meanings for a person. Please provide additional terms or information about your sexual orientation here.

Select your race/ethnicity (check all that apply):

African American

Asian

Native Hawaiin or Pacific Islander Hispanic or Latinx

White

American Indian or Alaska Native

Black

Other

How old are you?

How much do you weigh? Please answer with your best estimate in lbs.
How tall are you? (response in inches)

What state/ district do you primarily live? ** If outside of US please leave blank and include location in comments.

Select your highest level of education

- Did not complete High school

- High School or GED

- Some college, no degree

- Associates Degree or vocational training

- Bachelors Degree/ 4- year degree

- Graduate degree or professional School

- Other

Employment Status:(Check all that apply)

Full-time

Part-time

Student

Retired

Unemployed, seeking work

Unemployed, not seeking work

Other

What is your total household income?

- Less than 30,000

- 30,000 - 49,999

- 50,000 - 79,999

- $80,000-100,000$

- $100,000+$

Have you ever been homeless?

- Yes, currently

- Yes, within the last year

- Yes, but stable housing for $1+$ years

- No 
Do you have health insurance?

- Yes

- No
Do you have a primary care doctor?

- Yes

- No

Does your primary care doctor know about your sexual orientation?

- Yes

- No

- N/A

Does your primary care doctor know your gender identity and/or gender history?

- Yes

- No

- $\mathrm{N} / \mathrm{A}$

Do you receive routine physical examinations?

- Yes

- No, unable to afford

- No, unable to access competent/ accepting doctor

- No, I do not need routine physical exams

- Other

Survey Complete!

Thank you for completing this survey. Your responses will be used to understand how health lifestyles are related to experiences of discrimination and feelings about your gender and sexual orientation. Please select or write-in an LGBTQ non-profit organization below to receive a one-dollar donation:

- National LGBTQ Task Force

- National Center for Transgender Equality

- The Trevor Project

- Other

Please leave feedback/ thoughts here. (or if you would like a response you can email the research investigator: lorenbauerband@gmail.com) 


\section{APPENDIX D: BIBLIOGRAPHY}

Aaron, D. J., Markovic, N., Danielson, M. E., Honnold, J. A., Janosky, J. E., \& Schmidt, N. J. (2001). Behavioral risk factors for disease and preventive health practices among lesbians. American Journal of Public Health, 91(6), 972.

Agrawal, R., Sharma, S., Bekir, J., Conway, G., Bailey, J., Balen, A. H., \& Prelevic, G. (2004). Prevalence of polycystic ovaries and polycystic ovary syndrome in lesbian women compared with heterosexual women. Fertility and sterility, 82(5), 1352-1357.

Almeida, J., Johnson, R. M., Corliss, H. L., Molnar, B. E., \& Azrael, D. (2009). Emotional distress among LGBT youth: The influence of perceived discrimination based on sexual orientation. Journal of youth and adolescence, 38(7), 1001-1014.

Babbin, S. F., Velicer, W. F., Paiva, A. L., Brick, L. A. D., \& Redding, C. A. (2015). Replicating cluster subtypes for the prevention of adolescent smoking and alcohol use. Addictive behaviors, 40, 57-65.

Bauerband, L. A., \& Galupo, M. P. (2014). The Gender Identity Reflection and Rumination Scale: Development and Psychometric Evaluation. Journal of Counseling E Development, 92, 219-231.

Balsam, K. F., Beadnell, B., \& Molina, Y. (2013). The Daily Heterosexist Experiences Questionnaire: Measuring minority stress among lesbian, gay, bisexual, and transgender adults. Measurement and Evaluation in Counseling and Development, 46(1), 3-25.

Balsam, K. F., Beadnell, B., \& Riggs, K. R. (2012). Understanding Sexual Orientation Health Disparities in Smoking: A Population-Based Analysis. American Journal of Orthopsychiatry, 82(4), 482-493 
Bilodeau, B. L., \& Renn, K. A. (2005). Analysis of LGBT identity development models and implications for practice. New Directions for Student Services, 2005(111), 2539.

Bilyk, H. T., Wellington, C., \& Kapica, C. (2013). Cultures with unique nutrition concerns: Lesbian, gay, bisexual, transgender. The FASEB Journal, 27(1 Supplement), 625-9.

Bockting, W. O., Miner, M. H., Swinburne Romine, R. E., Hamilton, A., \& Coleman, E. (2013). Stigma, mental health, and resilience in an online sample of the US transgender population. American journal of public health, 103(5), 943-951.

Boehmer, U., Bowen, D. J., \& Bauer, G. R. (2007). Overweight and obesity in sexualminority women: evidence from population-based data. American Journal of Public Health, 97(6), 1134-1140.

Booth, M. L., Ainsworth, B. E., Pratt, M., Ekelund, U., Yngve, A., Sallis, J. F., \& Oja, P. (2003). International physical activity questionnaire: 12-country reliability and validity. Med sci sports Exerc, 195(9131/03), 3508-1381.

Bostwick, W., \& Hequembourg, A. (2014). 'Just a little hint': bisexual-specific microaggressions and their connection to epistemic injustices. Culture, health $\mathcal{E}$ sexuality, 16(5), 488-503.

Breslow, A. S., Brewster, M. E., Velez, B. L., Wong, S., Geiger, E., \& Soderstrom, B. (2015). Resilience and collective action: Exploring buffers against minority stress for transgender individuals. Psychology of Sexual Orientation and Gender Diversity, 2(3), 253 
Brittain, D. R., Baillargeon, T., McElroy, M., Aaron, D. J., \& Gyurcsik, N. C. (2006). Barriers to moderate physical activity in adult lesbians. Women $\mathcal{E}$ health, 43(1), 75-92.

Browne, M. W. \& Cudeck, R. (1993). Alternative ways of assessing model fit. In K. A. Bollen \& J. S. Long (Eds.), Testing structural equation models (pp. 136-162). Newbury Park, CA: Sage.

Budge, S. L., Adelson, J. L., \& Howard, K. A. (2013). Anxiety and depression in transgender individuals: the roles of transition status, loss, social support, and coping. Journal of consulting and clinical psychology, 81(3), 545.

Bush, K., Kivlahan, D. R., McDonell, M. B., Fihn, S. D., \& Bradley, K. A. (1998). The AUDIT alcohol consumption questions (AUDIT-C): an effective brief screening test for problem drinking. Archives of internal medicine, 158(16), 1789-1795.

Cary, M. A., Brittain, D. R., Dinger, M. K., Ford, M. L., Cain, M., \& Sharp, T. A. (2016). Barriers to Physical Activity Among Gay Men. American journal of men's health, 10(5), 408-417.

Conron, K. J., Scott, G., Stowell, G. S., \& Landers, S. J. (2012). Transgender health in Massachusetts: results from a household probability sample of adults. American journal of public health, 102(1), 118-122.

Coulter, R. W., Blosnich, J. R., Bukowski, L. A., Herrick, A. L., Siconolfi, D. E., \& Stall, R. D. (2015). Differences in alcohol use and alcohol-related problems between transgender-and nontransgender-identified young adults. Drug and alcohol dependence, 154, 251-259. 
Eliason, M. J., Ingraham, N., Fogel, S. C., McElroy, J. A., Lorvick, J., Mauery, D. R., \& Haynes, S. (2015). A systematic review of the literature on weight in sexual minority women. Women's Health Issues, 25, 162-175.

Eliason, M. J., McElroy, J. A., Garbers, S., Radix, A., \& Barker, L. T. (2016). Comparing women with and without disabilities in five-site "Healthy Weight" interventions for lesbian/bisexual women over 40. Disability and Health Journal.

Fallin, A., Goodin, A., Lee, Y. O., \& Bennett, K. (2015). Smoking characteristics among lesbian, gay, and bisexual adults. Preventive medicine, 74, 123-130.

Fassinger, R. E., \& Arseneau, J. R. (2007). " I'd Rather Get Wet Than Be Under That Umbrella": Differentiating the Experiences and Identities of Lesbian, Gay, Bisexual, and Transgender People.

Fredriksen-Goldsen, K. I., Kim, H. J., Barkan, S. E., Muraco, A., \& Hoy-Ellis, C. P. (2013). Health disparities among lesbian, gay, and bisexual older adults: results from a population-based study. American journal of public health, 103(10), 1802-1809.

Galupo, M. P., \& Bauerband, L. A. (2016). Sexual Orientation Reflection and Rumination Scale: Development and psychometric evaluation. Stigma and Health, 1, 44-58.

Galupo, M. P., Bauerband, L. A., Gonzalez, K. A., Hagen, D. B., Hether, S. D., \& Krum, T. E. (2014). Transgender friendship experiences: Benefits and barriers of friendships across gender identity and sexual orientation. Feminism $\mathcal{E}$ Psychology, 24(2), 193-215.

Gamarel, K. E., Reisner, S. L., Laurenceau, J. P., Nemoto, T., \& Operario, D. (2014). Gender minority stress, mental health, and relationship quality: A dyadic 
investigation of transgender women and their cisgender male partners. Journal of Family Psychology, 28(4), 437.

Gates, G. J. (2011). How many people are lesbian, gay, bisexual and transgender?. Retrieved on February 1, 2017 from Williams Institute Website: https://williamsinstitute.law.ucla.edu/wp-content/uploads/Gates-How-ManyPeople-LGBT-Apr-2011.pdf

Gates, G. (2014). LGBT People Are Disproportionately Food Insecure. UCLA: The Williams Institute. Retrieved from: http://escholarship.org/uc/item/4wt4102n

Grant, J. M., Mottet, L. A., Tanis, J., Herman, J. L., Harrison, J., \& Keisling, M. (2010). National transgender discrimination survey report on health and health care. Washington, DC: National Center for Transgender Equality and the National Gay and Lesbian Task Force.

Green, K. E., \& Feinstein, B. A. (2012). Substance use in lesbian, gay, and bisexual populations: An update on empirical research and implications for treatment. Psychology of Addictive Behaviors, 26(2), 265.

Gregorich, S. E. (2006). Do self-report instruments allow meaningful comparisons across diverse population groups? Testing measurement invariance using the confirmatory factor analysis framework. Medical care, 44(11 Suppl 3), S78-S94.

Henry, J. D., \& Crawford, J. R. (2005). The short-form version of the Depression Anxiety Stress Scales (DASS-21): Construct validity and normative data in a large non-clinical sample. British journal of clinical psychology, 44(2), 227-239.

Hu, L., \& Bentler, P. M. (1999). Cutoff criteria for fit indexes in covariance structure analysis: Conventional criteria versus new alternatives. Structural Equation Modeling, 6, 1-55. 
Institute of Medicine (US) Committee on Lesbian, Gay, Bisexual, and Transgender Health Issues and Research Gaps and Opportunities. The Health of Lesbian, Gay, Bisexual, and Transgender People: Building a Foundation for Better Understanding. Washington (DC): National Academies Press (US); 2011.

James, S. E., Herman, J. L., Rankin, S., Keisling, M., Mottet, L., \& Anafi, M. (2016). The Report of the 2015 U.S. Transgender Survey. Washington, DC: National Center for Transgender Equality.

Kaminski, P. L., Chapman, B. P., Haynes, S. D., \& Own, L. (2005). Body image, eating behaviors, and attitudes toward exercise among gay and straight men. Eating behaviors, 6(3), 179-187.

Kim, G., Sellbom, M., \& Ford, K.-L. (2014). Race/ethnicity and measurement equivalence of the Everyday Discrimination Scale. Psychological Assessment, 26(3), 892-900.

Kline, R. B. (2011). Principles and practice of structural equation modeling ( $3^{\text {rd }}$ ed.) New York: The Guilford Press, NY.

Laska, M. N., VanKim, N. A., Erickson, D. J., Lust, K., Eisenberg, M. E., \& Rosser, B. S. (2015). Disparities in weight and weight behaviors by sexual orientation in college students. American journal of public health, 105(1), 111-121.

Lathrop, R. G., \& Williams, J. E. (1989). The shape of the inverse scree test for cluster analysis. Educational and Psychological Measurement, 49(4), 827-834.

Lick, D. J., Durso, L. E., \& Johnson, K. L. (2013). Minority stress and physical health among sexual minorities. Perspectives on Psychological Science, 8(5), 521-548. 
Livingston, N. A., Oost, K. M., Heck, N. C., \& Cochran, B. N. (2015). The role of personality in predicting drug and alcohol use among sexual minorities. Psychology of Addictive Behaviors, 29(2), 414.

Mason, T. B., \& Lewis, R. J. (2015). Minority Stress, Depression, Relationship Quality, and Alcohol Use: Associations with Overweight and Obesity Among Partnered Young Adult Lesbians. LGBT health, 2(4), 333-340.

Meredith, W. (1993). Measurement invariance, factor analysis, and factorial invariance. Pschometrika, 58, 521-543.

Meyer, I. H. (2003). Prejudice, social stress, and mental health in lesbian, gay, and bisexual populations: conceptual issues and research evidence. Psychological bulletin, 129, 674-697.

Muthén, L. K. \& Muthén B. O. (2012). Mplus User’s Guide. Seventh Edition. Los Angeles, CA.

Outland, P. L. (2016). Developing the LGBT Minority Stress Measure (Doctoral dissertation, Colorado State University. Libraries).

Reisner, S. L., White, J. M., Bradford, J. B., \& Mimiaga, M. J. (2014). Transgender health disparities: comparing full cohort and nested matched-pair study designs in a community health center. LGBT health, 1(3), 177-184.

Riggle, E. D., \& Mohr, J. J. (2015). A proposed multi factor measure of positive identity for transgender identified individuals. Psychology of Sexual Orientation and Gender Diversity, 2(1), 78-85.

Riggle, E. D., Rostosky, S. S., McCants, L. E., \& Pascale-Hague, D. (2011). The positive aspects of a transgender self-identification. Psychology $\mathcal{E}$ Sexuality, 2, 147-158. 
Rosario, M., Corliss, H. L., Everett, B. G., Reisner, S. L., Austin, S. B., Buchting, F. O., \& Birkett, M. (2014). Sexual orientation disparities in cancer-related risk behaviors of tobacco, alcohol, sexual behaviors, and diet and physical activity: pooled Youth Risk Behavior Surveys. American journal of public health, 104(2), 245-254.

Ross, M. W., \& Rosser, B. R. (1996). Measurement and correlates of internalized homophobia: A factor analytic study. Journal of clinical psychology, 52(1), 15-21.

Satorra, A., \& Bentler, P.M. (2010). Ensuring positiveness of the scaled difference chisquare test statistic. Psychometrika, 75, 243-248.

Saunders, J. B., Aasland, O. G., Babor, T. F., De la Fuente, J. R., \& Grant, M. (1993). Development of the alcohol use disorders identification test (AUDIT): WHO collaborative project on early detection of persons with harmful alcohol consumption-II. Addiction, 88(6), 791-804.

Smalley, K. B., Warren, J. C., \& Barefoot, K. N. (2016). Differences in health risk behaviors across understudied LGBT subgroups. Health Psychology, 35, 103-114.

Smith, M. S., \& Gray, S. W. (2009). The courage to challenge: A new measure of hardiness in LGBT adults. Journal of Gay E Lesbian Social Services, 21(1), 73-89.

Steinmetz, K. (2016). How many Americans are gay?. Time Magazine, http://time.com/lgbt-stats/

Stone, A. L. (2009). More than adding a T: American lesbian and gay activists' attitudes towards transgender inclusion. Sexualities, 12, 334-354.

Testa, R. J., Habarth, J., Peta, J., Balsam, K., \& Bockting, W. (2015). Development of the Gender Minority Stress and Resilience Measure. Psychology of Sexual Orientation and Gender Diversity, 2(1), 65. 
Thompson, F. E., Subar, A. F., Smith, A. F., Midthune, D., Radimer, K. L., Kahle, L. L., \& Kipnis, V. (2002). Fruit and vegetable assessment: performance of 2 new short instruments and a food frequency questionnaire. Journal of the American Dietetic Association, 102(12), 1764-1772.

VanKim, N. A., Austin, S. B., Jun, H. J., Hu, F. B., \& Corliss, H. L. (2016). Dietary Patterns during Adulthood among Lesbian, Bisexual, and Heterosexual Women in the Nurses' Health Study II. Journal of the Academy of Nutrition and

\section{Dietetics.}

VanKim, N. A., Erickson, D. J., Eisenberg, M. E., Lust, K., Rosser, B. R., \& Laska, M. N. (2014). Weight-related disparities for transgender college students. Health behavior and policy review, $1(2), 161-171$.

Ward Jr, J. H. (1963). Hierarchical grouping to optimize an objective function. Journal of the American statistical association, 58(301), 236-244. 